Check for updates

Cite this: Mater. Chem. Front. 2020, 4, 2517

Received 7th May 2020

Accepted 21st June 2020

DOI: 10.1039/d0qm00303d

rsc.li/frontiers-materials

\title{
Recent advances of hollow-structured sulfur cathodes for lithium-sulfur batteries
}

\author{
Xia Huang, ${ }^{a}$ Tengfei Qiu, ${ }^{a}$ Xinghao Zhang, ${ }^{\text {b }}$ Lei Wang, ${ }^{c}$ Bin Luo (D) *ab and \\ Lianzhou Wang (D) *a
}

\begin{abstract}
Lithium-sulfur batteries (LSBs) have attracted increasing interest due to their high theoretical energy density and low-cost sulfur. Challenges are still faced in the development of sulfur cathodes, due to the insulating properties of sulfur and lithium sulfide, diffusion of soluble polysulfides and slow redox kinetics of electrochemical conversion reactions. Hollow-structured materials with features such as high specific surface area, tunable pore structure, and controllable morphology and composition have shown great potential to be applied in high performance sulfur cathodes for LSBs. To promote further breakthroughs in this amazing field, this review highlights on the recent advances of hollow-structured sulfur cathodes, with an emphasis on polar inorganic/organic materials that exhibit strong interactions with polysulfides, thus suppressing the unfavourable shuttle effect, and/or efficient catalytic activity towards sulfur conversion reactions, thus improving the redox kinetics. Material design principles, experimental methods and the subsequent effects on electrochemical performance are discussed. The remaining challenges and perspectives associated with sulfur cathode design and battery evaluation are also presented.
\end{abstract}

\section{Introduction}

Lithium-ion batteries (LIBs) have powered the revolution of our modern society, becoming more and more indispensable, from portable to large-scale electronic devices such as mobile phones and vehicles. ${ }^{1}$ After three decades of intensive research, the energy density of LIBs is approaching their physical limit (500-600 $\mathrm{W} \mathrm{h} \mathrm{kg}^{-1}$ ) based on intercalation/deintercalation reactions of Li ions. ${ }^{2,3}$ Besides, the high cost of LIBs hampers the popularity of electric vehicles. ${ }^{4}$ The ever-growing demands for batteries with higher energy density and lower cost have triggered the (re)exploration of alternative electrochemistry, such as lithium-air, ${ }^{5}$ metal-sulfur, ${ }^{6}$ and metal-ion (Na, $\mathrm{K}, \mathrm{Mg}$, $\mathrm{Ca}, \mathrm{Al}$ ) batteries. ${ }^{7}$ Among these electrochemical energy storage systems, lithium-sulfur batteries (LSBs) composed of a lithium anode and a sulfur cathode, which deliver a high theoretical energy density of $2600 \mathrm{~W} \mathrm{~h} \mathrm{~kg}{ }^{-1}$ and are of low cost owing to the earth abundant and eco-friendly sulfur, have been regarded

\footnotetext{
${ }^{a}$ Nanomaterials Centre, School of Chemical Engineering and Australian Institute for Bioengineering and Nanotechnology, The University of Queensland, St Lucia, QLD 4072, Australia.E-mail: b.luo1@uq.edu.au, l.wang@uq.edu.au

${ }^{b}$ State Key Laboratory Base of Eco-chemical Engineering, College of Chemical Engineering, Qingdao University of Science and Technology, Qingdao, 266042, P. R. China

${ }^{c}$ State Key Laboratory Base of Eco-chemical Engineering, College of Chemistry and Molecular Engineering, Qingdao University of Science and Technology, Qingdao, 266042, P. R. China
}

as one of the most promising candidates. ${ }^{8}$ Hence, it is not surprising that the study of LSBs is dated back to the 1960s. ${ }^{9}$ Nevertheless, in early studies, challenges including low sulfur utilization caused by the intrinsic insulating nature of sulfur and its reduction products (lithium sulfides), and short cycling life owing to the highly soluble lithium polysulfide intermediates (LiPSs), hindered the in-depth research on LSBs. The interest in LSBs was soon shadowed under the effulgence of more reliable LIBs. There remained sporadic research efforts focusing on identifying the redox couples in LSBs operated in different electrolyte systems (solvents and salts). ${ }^{10,11}$

In recent years, with the rapid development of materials science and nanotechnology, the research on LSBs has made much progress. ${ }^{12,13}$ In 2009, Nazar's group applied a highly ordered mesoporous carbon nanostructure (CMC-3) as the sulfur host for the first time, which dramatically improved the capacity from less than $500 \mathrm{~mA} \mathrm{~h} \mathrm{~g}{ }^{-1}$ to $1320 \mathrm{~mA} \mathrm{~h} \mathrm{~g}{ }^{-1}$ with an impressive sulfur utilization of $80 \% .{ }^{14}$ Since then, the electrical conductivity and the LiPS trapping ability have become criteria for the design of sulfur host materials. The LSB community has focused on carbonaceous materials featuring high conductivity and high specific area (SSA), providing an efficient conductive framework and physical confinement to LiPSs. ${ }^{15}$ Later, it was realized that to achieve long-term cycling performance of $>200$ cycles, the weak interaction between the non-polar carbon and polar LiPSs was not enough. ${ }^{16}$ Then, it was found that various metal oxides/sulfides/nitrides and metal-organic-frameworks 
(MOFs) could form strong chemical bond with LiPSs, which greatly enhanced the long-term cycling stability (up to 1000 cycles). ${ }^{17,18}$ Thereupon, the strong chemical interaction with LiPSs became an essential requirement for sulfur hosting materials. ${ }^{19-21}$ More recently, electrocatalysis in LSBs, which has been proved to be able to facilitate the conversion kinetics of sulfur species and reduce the redox overpotential and thus increase the sulfur utilization and prolong the battery cycling life, is becoming a new focus for sulfur host design. ${ }^{22-24}$

Along with an understanding of the chemistry of sulfur hosting materials, studying the morphology and microstructure of these materials also plays a significant role in LSB research. ${ }^{25}$ A wide spectrum of sulfur hosts with a variety of morphologies, including porous/hollow nano-spheres, nanowires/nanotubes, nanosheets/nanoplates and hierarchical structures, have been developed. ${ }^{26,27}$ Hollow-structured nanomaterials stand out as there are plenty of void spaces for accommodating sulfur or lithium sulfide, buffering the huge volume expansion of sulfur during the charge process and physically confining LiPSs. ${ }^{28-30}$ In its first phase, the development of various carbon hollow structures using different hard- and soft-templating methods has provided tremendous opportunities for sulfur cathode design, due to their high specific surface area, tuneable porosity, and controllable morphology. ${ }^{15}$ Many kinds of hollow carbon-based sulfur cathodes have been demonstrated with improved sulfur utilization and cycling stability. ${ }^{31-36}$ Although hollow carbon structures can provide physical confinement to sulfur in the pore channels, the weak interaction between the nonpolar carbon and polar LiPSs cannot effectively immobilize LiPSs in a long run. Subsequently, other strategies, such as doping with heteroatoms (e.g., $\mathrm{N}$ or $\mathrm{S}$ ) or decorating with inorganic polar species, have thus been developed as efficient methods to enhance the chemisorption between LiPSs and the carbon host. ${ }^{19,36-38}$ Recent studies on hollow carbon structures in LSBs have been summarised in another review paper. ${ }^{39}$

Hollow-structured materials with high conductivity, strong LiPS adsorption capability and efficient electrocatalytic activity are supposed to boost the electrochemical performance of LSBs. In this review, we summarize the recent progress and the foremost findings on hollow structured sulfur cathodes. In particular, we focus on hollow structures containing polar inorganic/organic materials, emphasizing the synthesis methods, and the relationship between material microstructures and electrochemical performance of LSBs. In an attempt to provide guidance towards the rational design of practical sulfur cathodes, challenges and perspectives for future development of LSBs are provided.

\section{An overview of LSBs and hollow-structured sulfur cathodes}

\subsection{The redox chemistries and challenges of LSBs}

A typical LSB consists of a lithium anode, sulfur cathode, polypropylene separator, and ether-based electrolyte. The typical galvanostatic discharge/charge profile and cyclic voltammogram are shown in Fig. 1a and b, respectively. During the discharge
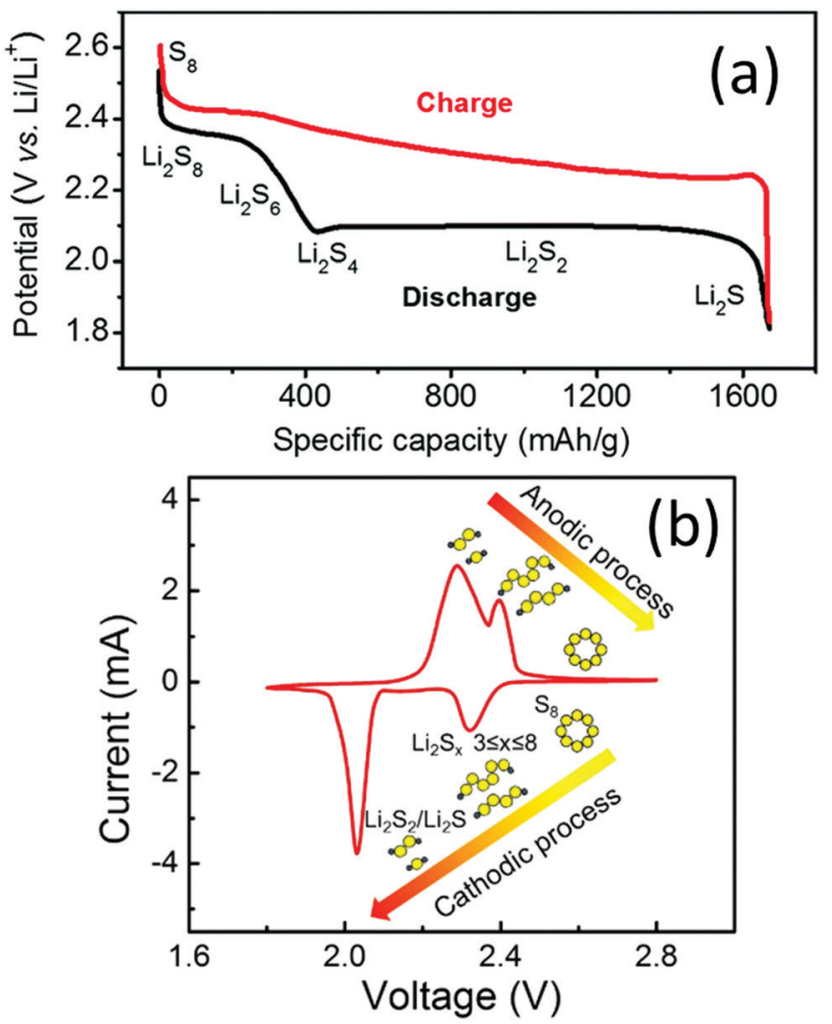

Fig. 1 (a) Typical two-plateau discharge/charge curves of LSBs in etherbased electrolytes. Reproduced with permission. ${ }^{12}$ Copyright 2016, the Royal Society of Chemistry. (b) CV profile of LSBs in ether-based electrolytes. Reproduced with permission. ${ }^{42}$ Copyright 2017 Elsevier.

process, the solid $S_{8}$ undergoes stepwise reduction reactions towards $\mathrm{Li}_{2} \mathrm{~S}$ with a series of soluble polysulfide intermediates. ${ }^{40}$ In detail, $\mathrm{S}_{8}$ is initially reduced to $\mathrm{Li}_{2} \mathrm{~S}_{8}$, and the solid-liquid process generates the first plateau at a potential of $2.2-2.3 \mathrm{~V} v s$. $\mathrm{Li}^{+} / \mathrm{Li}$ (Fig. 1a). $\mathrm{Li}_{2} \mathrm{~S}_{8}$ is then reduced to shorter-chain LiPSs, such as $\mathrm{Li}_{2} \mathrm{~S}_{6}$ and $\mathrm{Li}_{2} \mathrm{~S}_{4}$, and the liquid-liquid transformation generates a slope in the discharge curve (Fig. 1a). The theoretical capacity of these two processes is $419 \mathrm{~mA} \mathrm{~h} \mathrm{~g}{ }^{-1}, 41$ corresponding to the first cathodic peak at around $2.2-2.4 \mathrm{~V} v s$. $\mathrm{Li}^{+} / \mathrm{Li}$ in the CV curves (Fig. 1b). The short-chain LiPSs can be either directly reduced to solid $\mathrm{Li}_{2} \mathrm{~S}$ or follow stepwise reduction from $\mathrm{Li}_{2} \mathrm{~S}_{2}$ to $\mathrm{Li}_{2} \mathrm{~S}$, generating the long-plateau at a potential of 1.9-2.1 V vs. $\mathrm{Li}^{+} / \mathrm{Li}$. These processes correspond to the second cathodic peak at around $2.0 \mathrm{~V} v s$. $\mathrm{Li}^{+} / \mathrm{Li}$ in the $\mathrm{CV}$ curves (Fig. 1b). The low-potential steps contribute three quarters of the overall theoretical capacity $\left(1256 \mathrm{~mA} \mathrm{~h} \mathrm{~g}^{-1}\right) .{ }^{41}$ During the charge process, lithium sulfides are reversibly oxidised back to sulfur.

Despite the high theoretical energy density, there are several critical issues hindering the functioning of LSBs. For the sulfur cathodes, firstly, the insulating nature (both ionically and electronically) of the solid sulfur species $\left(\mathrm{S}_{8}, \mathrm{Li}_{2} \mathrm{~S}_{2}\right.$ and $\left.\mathrm{Li}_{2} \mathrm{~S}\right)$ blocks the charge/ion transfer in the active species. Adding conductive additives is one possible way to make batteries work. However, the quantity of additives has to be strictly controlled, as any excess amount of conductive additives is detrimental to 
the overall energy density. Moreover, the accumulation of sulfur on the electrode surface during repeated charge and discharge cycles increases the cell polarization and leads to higher possibility of device failure caused by the blocking of $\mathrm{Li}^{+}$or $\mathrm{e}^{-}$pathways. ${ }^{43}$ Secondly, the soluble LiPSs shuttle between two electrodes and chemically react with lithium, causing active material loss, lithium corrosion, and electrolyte consumption. For Li anodes, inhomogeneous lithium deposition and lithium dendrite growth lead to repeated breaking and formation of the solid-electrolyte interface (SEI), which consumes lithium and the electrolyte. ${ }^{44}$ Moreover, lithium dendrites may cause short-circuit, leading to safety issues. ${ }^{45}$ For the electrolyte, the widely used ether-based electrolytes consist of flammable solvents and oxidative $\mathrm{LiNO}_{3}$, raising safety concerns for practical application. ${ }^{46}$

\subsection{Hollow-structured sulfur cathodes}

The design of hollow structured sulfur cathodes is a primary way for improving the performance of LSBs. Generally, there are two approaches to prepare hollow structured sulfur composites. One is infiltrating sulfur into the prefabricated hollow nanomaterials via a melt-diffusion or a dissolving-evaporation process $;{ }^{14,47}$ the other is encapsulating the prefabricated sulfur nanoparticles by in situ growing materials on the surface of sulfur. Benefiting from the significant progress of the design and synthesis of hollow structures, the first method is convenient, low cost and widely applicable to a wide spectrum of hollow-structured materials. The melt-diffusion approach usually involves a heat treatment process of the mixture of hosts and sulfur in a sealed vial at around $155{ }^{\circ} \mathrm{C}$, when sulfur exhibits low viscosity and can easily infiltrate into or disperse onto the host matrix. ${ }^{48}$ Sometimes, an additional heat treatment step at around $300{ }^{\circ} \mathrm{C}$ is applied to remove the sulfur remaining on the outer surface of the host. The dissolving approach is realised by dissolving sulfur in carbon disulfide $\left(\mathrm{CS}_{2}\right)$ or other solvents with high sulfur solubility, followed by either immersing the host into the sulfur-containing solution or directly dropping a specific amount of solution onto the hosts. ${ }^{47} \mathrm{CS}_{2}$ can be easily removed via evaporation at room temperature under stirring. Although sulfur can infiltrate into the hollow structure by the dissolving approach, it is difficult to avoid sulfur aggregation. Moreover, sulfur species can spread out from the host. ${ }^{49}$ To better control the sulfur dispersion, sulfur nanoparticles offer an option. There are two methods widely used to prepare nanosized sulfur particles. One is the acid catalysed precipitation of sodium thiosulphate (eqn (1)). Dilute $\mathrm{HCl}$ or $\mathrm{H}_{2} \mathrm{SO}_{4}$ is predominantly used as the acid catalyst, and the surfactants are added to control the size of sulfur particles. ${ }^{50}$ Another one is a microemulsion technique, using sodium polysulfide and $\mathrm{HCl}$ as the reactants (eqn (2)). ${ }^{51}$

$$
\begin{aligned}
& \mathrm{Na}_{2} \mathrm{~S}_{2} \mathrm{O}_{3}+2 \mathrm{HCl} \rightarrow 2 \mathrm{NaCl}+\mathrm{SO}_{2} \uparrow+\mathrm{S} \downarrow+\mathrm{H}_{2} \mathrm{O} \\
& \mathrm{Na}_{2} \mathrm{~S}_{x}+2 \mathrm{HCl} \rightarrow 2 \mathrm{NaCl}+(x-2) \mathrm{S} \downarrow+2 \mathrm{H}_{2} \mathrm{~S} \uparrow
\end{aligned}
$$

Hollow-structured sulfur cathodes summarized in this review are divided into two categories: inorganic hollow-structured sulfur cathodes, which apply hollow metal compounds or metal compound decorated hollow carbons as sulfur host materials, and organic hollow-structured sulfur cathodes, which utilize conductive polymers and organic frameworks.

\section{Inorganic hollow-structured sulfur cathodes}

Compared to nonpolar carbon, inorganic materials with polar surfaces have a better ability to anchor polysulfides. It's worth mentioning that many materials that chemically interact with LiPSs simultaneously possess electrocatalytic activity. ${ }^{24,52}$ A wide range of inorganic hollow structures, such as metal oxides, metal sulfides, metal nitrides, metal hydroxides, metal phosphides, and their hybrids with hollow carbons, have been investigated as sulfur-hosting materials.

\subsection{Metal oxides}

Metal oxides with different morphologies have been widely studied and used as sulfur hosts, or cathode mediators in LSBs. ${ }^{53}$ Metal oxides contain a strong polar surface owing to the oxygen anion $\left(\mathrm{O}^{2-}\right)$, and thus they typically exhibit strong chemical interactions with LiPSs. ${ }^{21}$ The low-cost and easy fabrication of metal oxides greatly promoted their application in LSBs. ${ }^{54}$ The major drawback of metal oxides is their poor conductivity, which seriously affects the rate performance of LSBs. To improve their conductivity, metal oxides have been incorporated into different hollow carbon structures, such as carbon hollow nanofibers, nanoboxes, and nanospheres. Furthermore, developing other phases (such as Magnéli phase), or creating oxygen vacancies is another approach to increase the intrinsic conductivity of metal oxides. In this part, $\mathrm{MnO}_{2}$ and $\mathrm{TiO}_{2}$, which are among the most widely studied metal oxides in LSBs are used as examples to demonstrate the rational design of highly efficient hollow-structured metal oxide sulfur hosts.

3.1.1 $\mathrm{MnO}_{2} \cdot \mathrm{MnO}_{2}$ is widely known as the electrode material for $\mathrm{Zn}-\mathrm{MnO}_{2}$ batteries. Nazar's group initially demonstrated that $\mathrm{MnO}_{2}$ acted as an efficient polysulfide mediator to immobilize LiPSs via reacting with LiPSs, forming surface-bound intermediates of thiosulfate (Fig. 2f). ${ }^{53}$ In their work, $\mathrm{MnO}_{2}$ nanosheets were fabricated through the reaction of graphene oxide and $\mathrm{KMnO}_{4}$. The melt-diffusion process was applied to incorporate sulfur into the $\mathrm{MnO}_{2}$ host, generating $75 \mathrm{~S} / \mathrm{MnO}_{2}$ nanosheet composites (Fig. 2a, sulfur content $75 \mathrm{wt} \%$ ). The superior polysulfide entrapment ability of $\mathrm{MnO}_{2}$ nanosheets was confirmed by an in situ visual electrochemical measurement of $75 \mathrm{~S} / \mathrm{MnO}_{2}$ and $75 \mathrm{~S} / \mathrm{KB}$ (using Ketjenblack carbon as the host). The electrolyte of $75 \mathrm{~S} / \mathrm{MnO}_{2}$ remained light yellow at the end of the discharge-charge process (after $12 \mathrm{~h}$ ), which was in sharp contrast to that of 75S/KB (Fig. 2d). Taking advantage of the hollow structure, the authors further constructed a sulfur-core $\mathrm{MnO}_{2}$ shell architecture by in situ growing of $\mathrm{MnO}_{2}$ nanosheets onto the sulfur particles (Fig. 2b) by a simple redox reaction between sulfur and potassium permanganate (Fig. 2e). ${ }^{55}$ To buffer the volume expansion of sulfur electrode, the yolk-shelled $\mathrm{S}-\mathrm{MnO}_{2}$ structure (Fig. 2c) was created by 

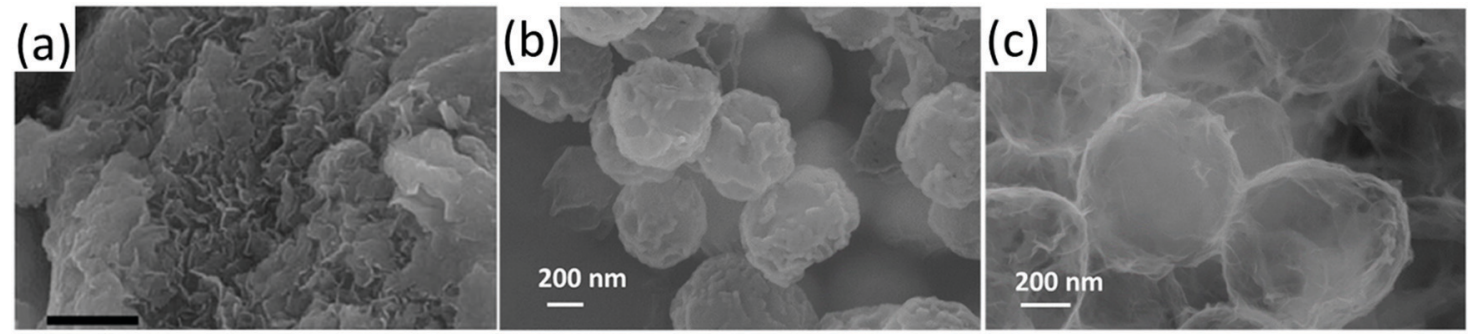

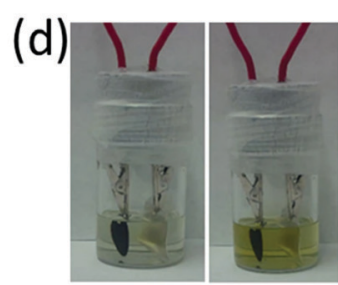

$\mathrm{Oh}$
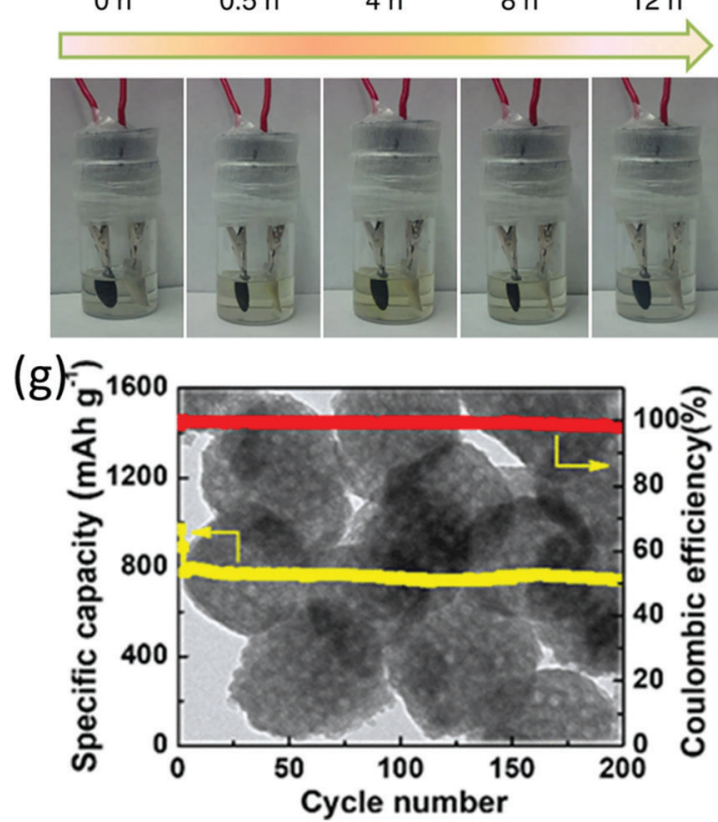
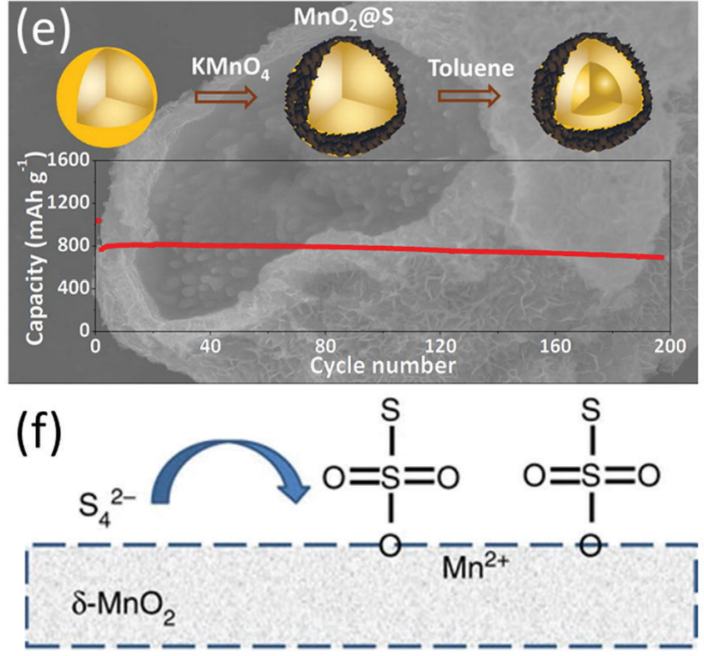

(h)

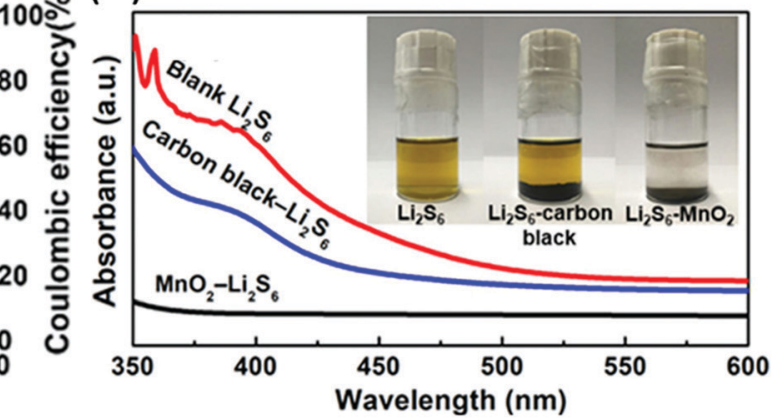

Fig. 2 SEM images of (a) $75 \mathrm{~S} / \mathrm{MnO}_{2}$ nanosheet composite (scale bars, $50 \mathrm{~nm}$ ), (b) spherical sulfur nanoparticles, and (c) rinsed (by toluene) NS-core/ $\mathrm{MnO}_{2}$ with a sulfur content of $80 \mathrm{wt} \%$, (d) visual in situ electrochemical measurement at $\mathrm{C} / 20,75 \mathrm{~S} / \mathrm{KB}$ (up) and $75 \mathrm{~S} / \mathrm{MnO} 2$ (down), (e) schematic illustration of the preparation process, SEM image and cycling performance of the core-shell S- $\mathrm{MnO}_{2}$ composite, (f) schematic for the interactionreaction mechanism of $\mathrm{MnO}_{2}$ and LiPSs with the formation of surface-bound intermediates of thiosulfate. (a, $d$ and f) Reproduced with permission. ${ }^{53}$ Copyright 2015 Springer Nature. (b, c and e) Reproduced with permission. ${ }^{55}$ Copyright 2016 American Chemical Society. (g) SEM image and cycling performance of the $\mathrm{S}$-mesoporous $\mathrm{MnO}_{2}$ nanosphere composite, (h) visual polysulfide adsorption test using mesoporous $\mathrm{MnO}_{2}$ nanosphere and carbon black as the adsorbents (after $0.5 \mathrm{~h}$ ) and the corresponding UV-vis spectra of the supernatant. Reproduced with permission. ${ }^{60}$ Copyright 2018 American Chemical Society.

partially dissolving the sulfur core using toluene. The yolk-shell $\mathrm{S}-\mathrm{MnO}_{2}$ composite (sulfur content $82 \mathrm{wt} \%$ ) achieved a high capacity of $950 \mathrm{~mA} \mathrm{~h} \mathrm{~g}^{-1}$ after 300 cycles at $0.5 \mathrm{C}$, which was $88 \%$ of its initial capacity. The capacity of the yolk-shell $\mathrm{S}-\mathrm{MnO}_{2}$ cathode remained at $315 \mathrm{~mA} \mathrm{~h} \mathrm{~g}{ }^{-1}$ after 1700 cycles at $2 \mathrm{C}$, corresponding to a capacity decay rate of $0.039 \%$ per cycle. Since then, $\mathrm{MnO}_{2}$ with different structures have been developed as sulfur host materials. ${ }^{56-58}$ A core-shell composite with $\lambda-\mathrm{MnO}_{2}$ nanorod encapsulated sulfur was prepared, which exhibited a capacity retention of $82 \%$ for 300 cycles at $0.5 \mathrm{C} .{ }^{59}$ The enhanced high-rate performance was attributed to the unique one-dimensional $\lambda-\mathrm{MnO}_{2}$ nanorods, which acted as large tunnels to incorporate
Li ions, preventing the deposition of solid lithium sulfide. It was further revealed that the capacity degradation could be attributed to the phase transformation from $\lambda-\mathrm{MnO}_{2}$ to $\mathrm{Mn}_{3} \mathrm{O}_{4}$.

Besides encapsulating the prefabricated sulfur nanoparticles in $\mathrm{MnO}_{2}$, mesoporous $\mathrm{MnO}_{2}$ nanospheres were fabricated and used as a sulfur host (Fig. 2g). ${ }^{60}$ To prepare $\mathrm{MnO}_{2}$ nanospheres, polyaniline coated $\mathrm{SiO}_{2}$ spheres were firstly prepared (PANI@) $\mathrm{SiO}_{2}$ ). $\mathrm{MnO}_{2}$ was formed on the surface of PANI@SiO ${ }_{2}$ via the reaction between $\mathrm{KMnO}_{4}$ and PANI. The mesoporous $\mathrm{MnO}_{2}$ nanospheres were finally obtained after purification by annealing and the removal of $\mathrm{SiO}_{2}$ using $\mathrm{NaOH}$ solution. $\mathrm{MnO}_{2}$ nanospheres did not have obvious morphology change after the melt-diffusion 
process, suggesting their robust structure. The strong interaction of the mesoporous $\mathrm{MnO}_{2}$ nanospheres and LiPSs was confirmed by the visual LiPS adsorption test using $\mathrm{MnO}_{2}$ as the adsorbent and UV-vis measurements (Fig. 2h). Benefiting from the strong LiPSs entrapment from both chemical interaction and physical confinement, the $\mathrm{MnO}_{2}$-based sulfur electrode delivered an initial capacity of $1349.3 \mathrm{~mA} \mathrm{~h} \mathrm{~g}^{-1}$ and exhibited a capacity decay rate of $0.073 \%$ per cycle for 500 cycles at $1 \mathrm{C}$.

Despite the impressive polysulfide entrapment of $\mathrm{MnO}_{2}$, its poor conductivity remains a concern. In this regard, $\mathrm{MnO}_{2}$ has been integrated with different hollow carbon structures. For example, carbon hollow nanofibers filled with $\mathrm{MnO}_{2}$ nanosheets $\left(\mathrm{MnO}_{2} @ \mathrm{HCF}\right.$, Fig. 3b) were prepared using $\mathrm{MnO}_{2}$ nanowires as hard templates. ${ }^{61}$ As shown in Fig. $3 \mathrm{a}, \mathrm{MnO}_{2}$ nanowires were firstly coated with $\mathrm{SiO}_{2}$ and resorcinol formaldehyde (RF) resin $\left(\mathrm{MnO}_{2} @\right.$ $\left.\mathrm{SiO}_{2} @ \mathrm{RF}\right)$, followed by annealing and removal of the $\mathrm{SiO}_{2}$ interlayer to achieve $\mathrm{MnO}_{2} @ \mathrm{HCF}$. At a sulfur content of $71 \mathrm{wt} \%$ and a sulfur loading of $3.5 \mathrm{mg} \mathrm{\textrm {cm } ^ { - 2 } \text { , the } \mathrm { MnO } _ { 2 } @ H C F - b a s e d ~ s u l f u r}$ electrode delivered a capacity of $662 \mathrm{~mA} \mathrm{~h} \mathrm{~g}^{-1}$ after 300 cycles at $0.5 \mathrm{C}$, corresponding to an areal capacity of $2.3 \mathrm{~mA} \mathrm{~h} \mathrm{~cm} \mathrm{~cm}^{-2}$. The hollow carbon nanofibers enabled a fast electron and ion transfer, while the polysulfide diffusion was suppressed by the strong chemical bonding of $\mathrm{MnO}_{2}$ and physical confinement of the hollow structure. Based on a similar methodology, $\mathrm{MnO}_{2}$ @carbon hollow nanoboxes were prepared using $\mathrm{MnCO}_{3}$ nanocubes as the template and precursor (Fig. 3c and d). ${ }^{62}$ In these situations, Mn-based species were used as both template and precursor, leading to the formation of hybrids with $\mathrm{MnO}_{2}$ filled inside the

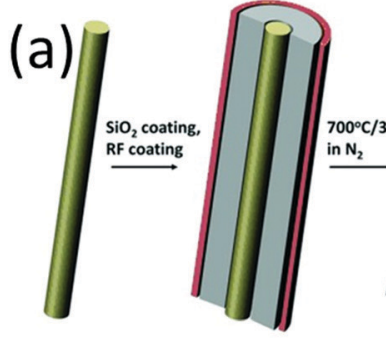

$\mathrm{MnO}_{2} \mathrm{NWs} \quad \mathrm{MnO}_{2} @ \mathrm{SiO}_{2} @ \mathrm{RF}$

(c)
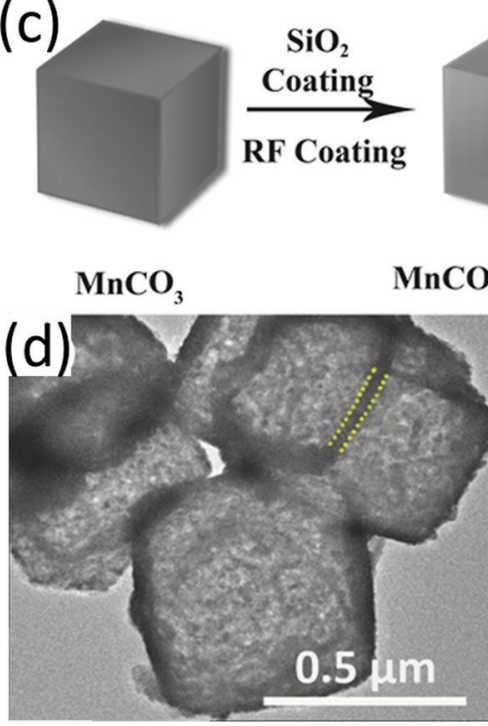

(g)

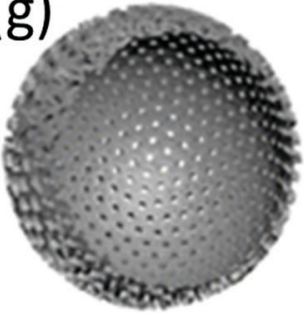

\section{Sloading}

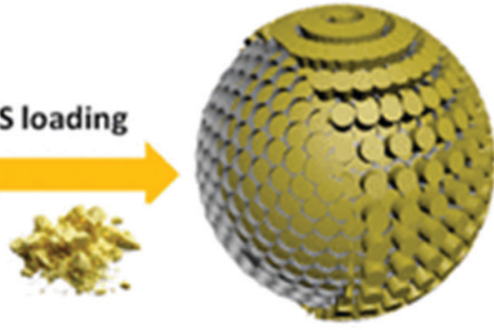

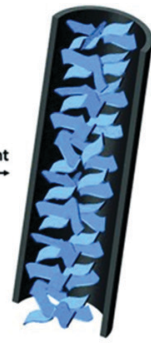

$\mathrm{MnO}_{2} @ \mathrm{HCF}$

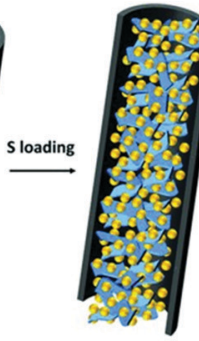

$\mathrm{MnO}_{2} @ \mathrm{HCF} / \mathrm{S}$
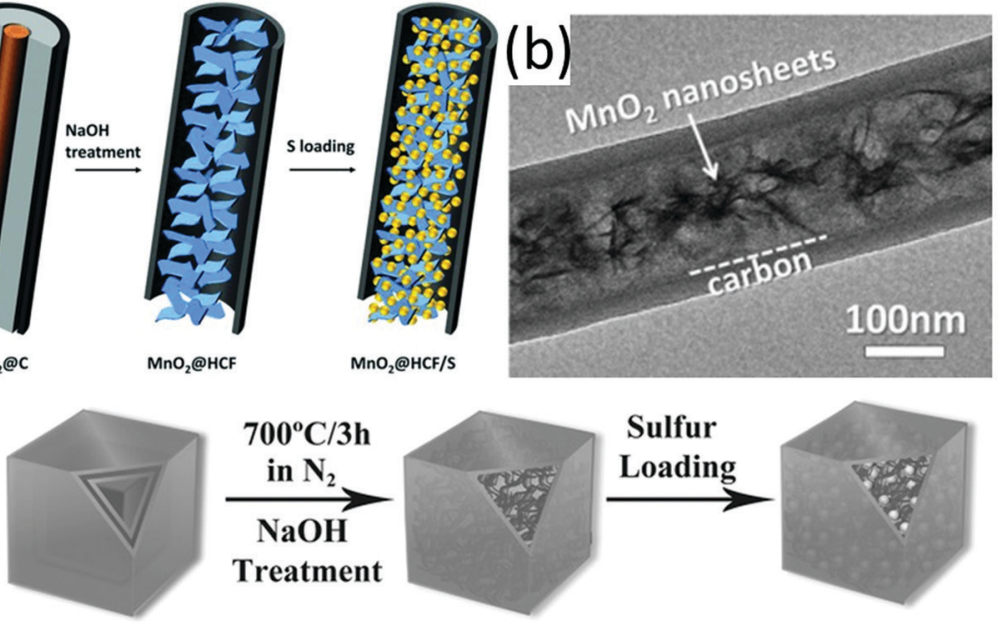

$\mathrm{MnO}_{2} @ \mathrm{HCB}$

$\mathrm{MnO}_{2} @ \mathrm{HCB} / \mathrm{S}$
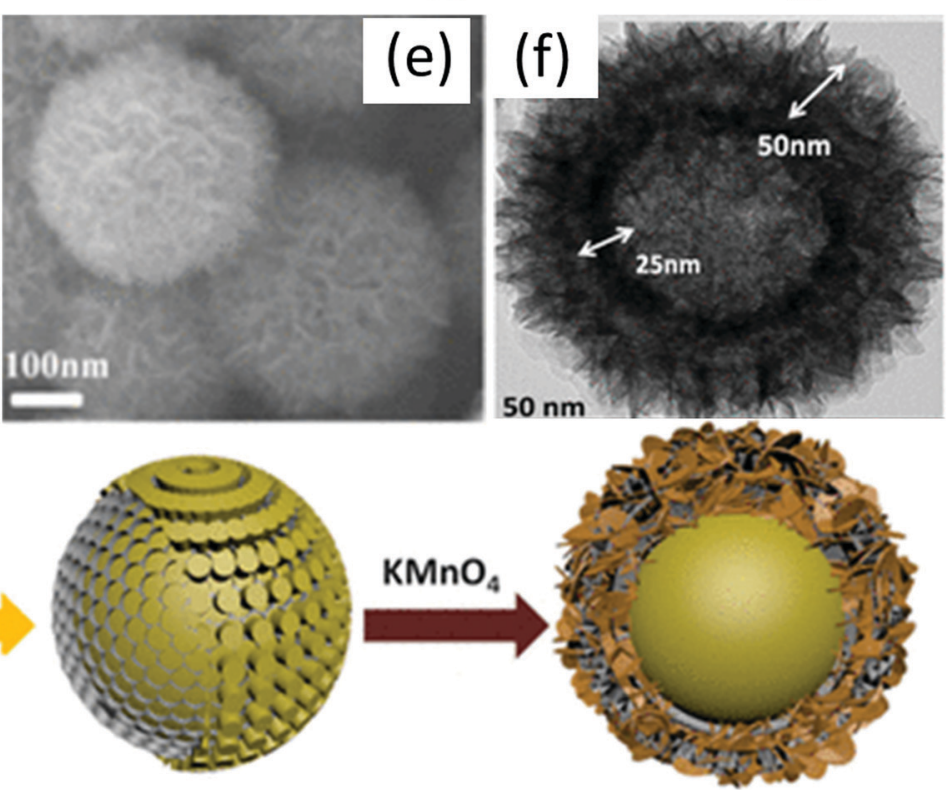

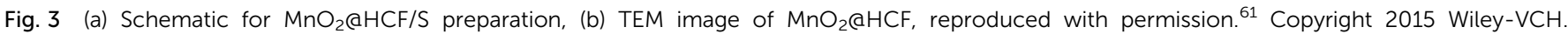

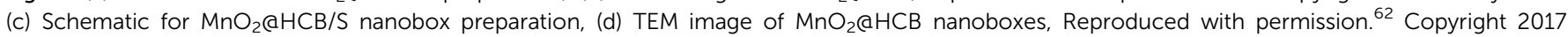

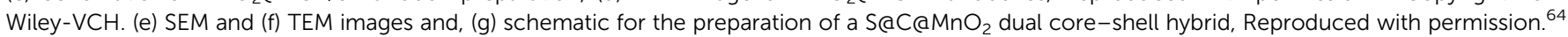
Copyright 2017 American Chemical Society. 
hollow structure. In another study, $\mathrm{MnO}_{2}$ nanosheets were in situ grown on carbon fibres via the reaction of $\mathrm{KMnO}_{4}$ solution and carbon (eqn (3)), forming coaxial $\mathrm{C} / \mathrm{MnO}_{2}$ hollow nanofibers. ${ }^{63}$ The coaxial $\mathrm{C} / \mathrm{MnO}_{2}$ hollow nanofiber-based sulfur cathode exhibited a low capacity decay rate of $0.044 \%$ and $0.051 \%$ per cycle over 1000 cycles at $1 \mathrm{C}$ and 2C, respectively. A dual sulfur@carbon@ $\mathrm{MnO}_{2}$ core-shell structure (Fig. $3 \mathrm{e}-\mathrm{g}$ ) has been designed and synthesized by the same group, delivering an impressive rateperformance of $465 \mathrm{~mA} \mathrm{~h} \mathrm{~g}{ }^{-1}$ at $4 \mathrm{C}$, and a low capacity decay rate of $0.052 \%$ per cycle for 1000 cycles at $3 \mathrm{C} .{ }^{64}$

$$
3 \mathrm{C}+4 \mathrm{MnO}_{4}{ }^{-}+\mathrm{H}_{2} \mathrm{O} \rightarrow 4 \mathrm{MnO}_{2}+2 \mathrm{HCO}_{3}{ }^{-}+\mathrm{CO}_{3}{ }^{2-}
$$

Besides the versatile carbon matrixes, conductive polymers are another choice to improve the conductivity of sulfur- $\mathrm{MnO}_{2}$ composites. For example, a hybrid hollow structure composed of $\mathrm{MnO}_{2}$ nanosheet coating layer and sulfur@poly(3,4-ethylenedioxythiophene) nanospheres $\left(\mathrm{MnO}_{2} @\right.$ sulfur@PEDOT) was fabricated. ${ }^{65}$ The hybrid structure with a superior electrolyte wettability delivered a capacity of $827 \mathrm{~mA} \mathrm{~h} \mathrm{~g}^{-1}$ at $0.2 \mathrm{C}$ after 200 cycles, which was superior to that of sulfur@PEDOT (551 $\left.\mathrm{mA} \mathrm{h} \mathrm{g}^{-1}\right)$. Last but not the least, it was reported that the chemical interaction of $\mathrm{MnO}_{2}$ with LiPSs can be enhanced via creating oxygen vacancies. ${ }^{66}$ The oxygen vacancies generated by annealing $\mathrm{MnO}_{2}$ hollow spheres in a reducing atmosphere $\left(\mathrm{H}_{2} / \mathrm{N}_{2}: 8 / 92\right.$ at volume) not only provided more surface-active sites for LiPS adsorption and solid lithium sulfide precipitation, but also facilitated the transformation of LiPSs to thiosulfate and polythionate intermediates. LSBs using $\mathrm{MnO}_{2}$ with oxygen vacancies as the sulfur host delivered a capacity of $551 \mathrm{~mA} \mathrm{~h} \mathrm{~g}^{-1}$ after 400 cycles at $2 \mathrm{C}$, which was better than that of $410 \mathrm{~mA} \mathrm{~h} \mathrm{~g}^{-1}$ using pristine $\mathrm{MnO}_{2}$ as the sulfur host.

3.1.2 $\mathrm{TiO}_{2} \cdot \mathrm{TiO}_{2}$ is another metal oxide which has long been used as a cathode additive or sulfur host material for LSBs owing to its strong interaction with LiPS and its nature abundance and nontoxicity. $\mathrm{TiO}_{2}$ with different phases has been investigated both experimentally and theoretically. ${ }^{67,68}$ With an emphasis to create enough space to buffer the huge volume expansion of sulfur during lithiation, a sulfur- $\mathrm{TiO}_{2}$ yolk-shell has been initially proposed by Cui and co-workers (Fig. 4a and b). ${ }^{69}$ Monodispersed sulfur nanoparticles with a diameter of around $800 \mathrm{~nm}$ were firstly prepared via the reaction of sodium thiosulfate and hydrochloric acid. A $\mathrm{TiO}_{2}$ layer with a thickness of around $15 \mathrm{~nm}$ was coated on the as-obtained sulfur spheres through a controllable hydrolysis of titanium diisopropoxide bis(acetylacetonate) in a solution of alkaline/aqueous isopropanol.

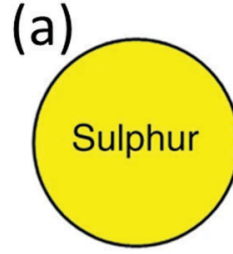

(b)
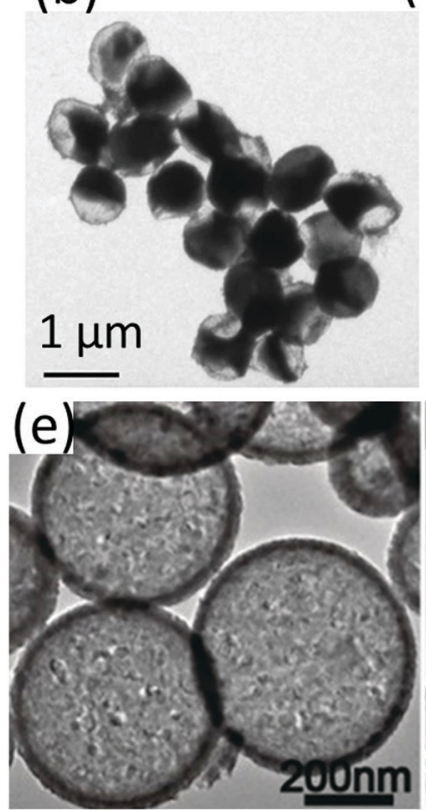

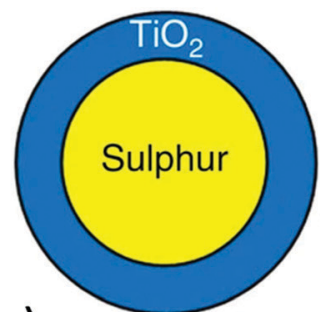

(c)
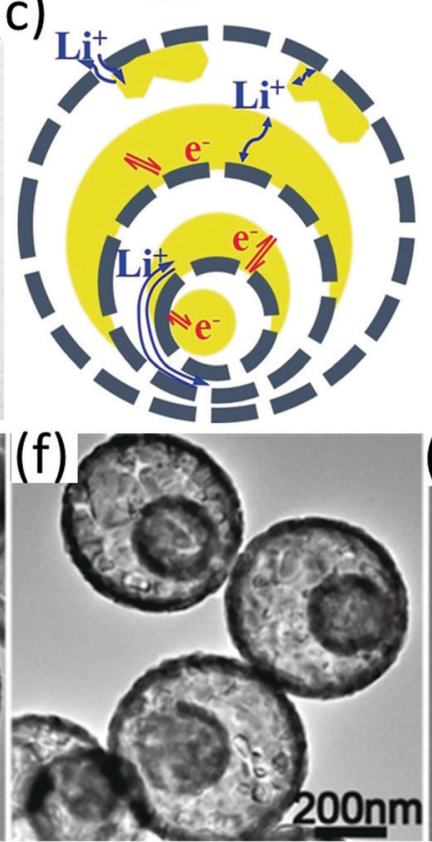

Partial S dissolution
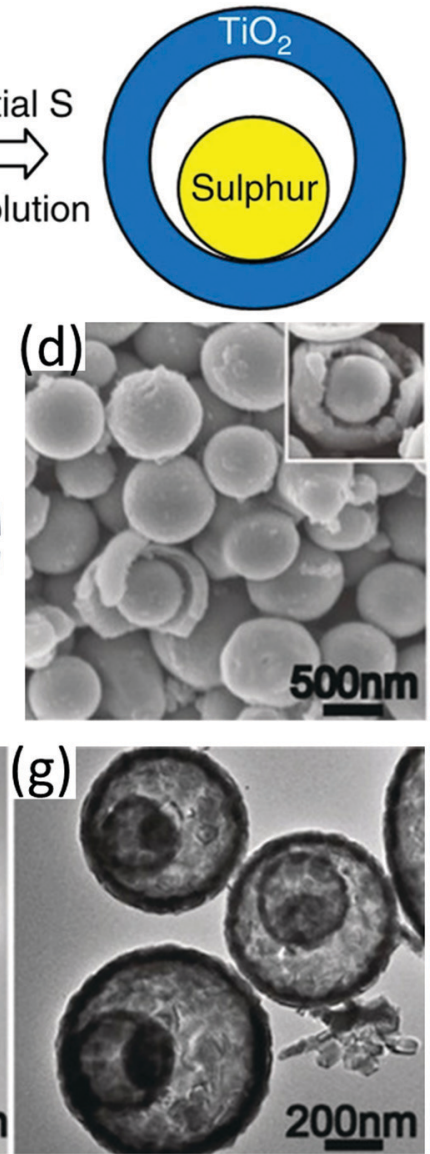

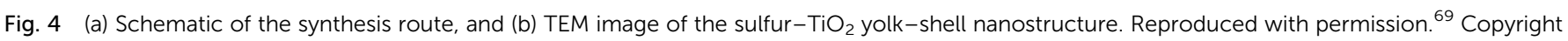

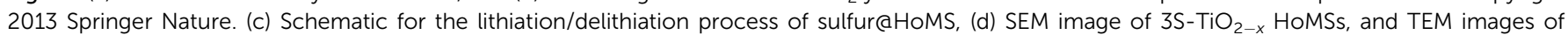
(e) $1 \mathrm{~S}-\mathrm{TiO}_{2-x} \mathrm{HoMSs}$, (f) $2 \mathrm{~S}-\mathrm{TiO}_{2-x} \mathrm{HoMSs}$, and (g) $3 \mathrm{~S}-\mathrm{TiO}_{2-x} \mathrm{HoMSs}_{\text {. Reproduced with permission. }}{ }^{70} \mathrm{Copyright} 2019$ Wiley-VCH. 
The yolk-shell nanoarchitecture was created after partial dissolution of the inner sulfur using toluene. The as-obtained sulfur- $\mathrm{TiO}_{2}$ yolk-shell composite (sulfur content $71 \mathrm{wt} \%$ ) exhibited an initial capacity of $1030 \mathrm{~mA} \mathrm{~h} \mathrm{~g}^{-1}$ at $0.5 \mathrm{C}$ with a capacity retention of $81 \%$ and $67 \%$ after 500 and 1000 cycles, respectively. The yolk-shell structure allowed the volume expansion of sulfur electrode, and the intact $\mathrm{TiO}_{2}$ shell with a small pore size of around $0.3 \mathrm{~nm}$ effectively minimized the diffusion of polysulfide, leading to a superior electrochemical performance to those of bare sulfur and sulfur- $\mathrm{TiO}_{2}$ core-shell counterparts.

More recently, the application of $\mathrm{TiO}_{2}$ microboxes as sulfur host has been reported. ${ }^{71} \mathrm{CaTiO}_{3}$ microcubes, the self-sacrificial templates for the synthesis of $\mathrm{TiO}_{2}$ microboxes, were firstly prepared via a solvothermal process, followed by the generation of $\mathrm{H}_{2} \mathrm{TiO}_{3}$ layer on the surface of $\mathrm{CaTiO}_{3}$ and then $\mathrm{TiO}_{2}$ coated $\mathrm{CaTiO}_{3}$ via $\mathrm{Na}_{2}$ EDTA-assisted ion exchange of $\mathrm{CaTiO}_{3}$ (eqn (4)). ${ }^{72}$ The formation of the hollow structure was driven by the ion exchange between $\mathrm{CaTiO}_{3}$ and $\mathrm{H}^{+}$at a different outward and inward diffusion rate, respectively. ${ }^{73} \mathrm{TiO}_{2}$ microboxes exhibited efficient polysulfide adsorption ability, as revealed by visualized LiPS adsorption and the following UV-vis measurement. ${ }^{71}$ Infiltrating sulfur into the $\mathrm{TiO}_{2}$ microboxes via melt-diffusion generated the $\mathrm{TiO}_{2} / \mathrm{S}$ composite (sulfur content $70 \mathrm{wt} \%$ ), whose capacity was maintained at $600 \mathrm{~mA} \mathrm{~h} \mathrm{~g}^{-1}$ after 500 cycles at $1 \mathrm{C}$. However, obvious voltage humps were observed at the initial charge curves due to the low conductivity of $\mathrm{TiO}_{2} \cdot{ }^{71}$

$$
\mathrm{CaTiO}_{3}+\mathrm{H}_{2} \mathrm{O}+\mathrm{Na}_{2} \mathrm{EDTA} \rightarrow \mathrm{TiO}_{2}+\mathrm{CaEDTA}+2 \mathrm{NaOH}
$$

Developing other phases (such as the Magnéli phase, $\mathrm{Ti}_{n} \mathrm{O}_{2 n-1}$ ) and creating oxygen vacancies have been widely used to increase the conductivity of metal oxides. ${ }^{74,75}$ In addition, multi-shelled hollow structures have demonstrated attracting properties for a wide range of applications (such as energy storage and conversion), which have gained increasing research interest. ${ }^{76-78}$ For example, multi-shelled hollow $\mathrm{TiO}_{2-x}\left(\mathrm{TiO}_{2-x}\right.$ HoMSs) prepared via a sequential templating approach (STA) has been demonstrated as an efficient sulfur carrier (Fig. $4 \mathrm{c}-\mathrm{g}$ ). ${ }^{70}$ To prepare $\mathrm{TiO}_{2} \mathrm{HoMSs}$, carbonaceous microspheres (CMS) were firstly synthesized via the emulsion polymerization of sucrose through a hydrothermal process, followed by a controlled hydrolysis of $\mathrm{TiCl}_{4}$ in the solution containing the as-obtained CMS solution, and a subsequent calcination step in air. The number of shells can be controlled via tuning the aging conditions and annealing process. The surface hydrogenated $\mathrm{TiO}_{2-x}$ HoMSs were prepared via annealing the as-obtained $\mathrm{TiO}_{2}$ HoMSs in an $\mathrm{Ar} / \mathrm{H}_{2}$ (1:9) atmosphere, generating oxygen vacancies and $\mathrm{Ti}^{3+}$ ions. Owing to oxygen vacancies and $\mathrm{Ti}^{3+}$ ions, $\mathrm{TiO}_{2-x}$ HoMSs not only provided multiple spatial confinement and chemical interactions with LiPSs, but also enhanced the electron mobility and electrolyte penetration. The electrochemical properties of $\mathrm{TiO}_{2-x}$ HoMSs with one, two and three shells (1S-TiO ${ }_{2-x}$ HoMSs, $2 \mathrm{~S}-\mathrm{TiO}_{2-x}$ HoMSs, and $3 \mathrm{~S}-\mathrm{TiO}_{2-x}$ HoMSs, respectively) were investigated, among which the triple-shelled one presented the best performance with an initial capacity of $903 \mathrm{~mA} \mathrm{~h} \mathrm{~g}$ at $0.5 \mathrm{C}$ and a superior capacity retention of $79 \%$ for 1000 .
Lou and co-workers designed a hybrid hollow structure composed of highly conductive TiO and carbon shells (TiO@ C-HSs). ${ }^{79}$ TiO presented almost an order of magnitude higher electrical conductivity than the Magnéli phase $\left(\mathrm{Ti}_{n} \mathrm{O}_{2 n-1}\right)$. The preparation process is shown in Fig. $5 \mathrm{a}-\mathrm{d}$. $\mathrm{TiO}_{2}$ and polydopamine were sequentially coated on the polystyrene surface, generating PS@TiO ${ }_{2}$ and $\mathrm{PS} @ \mathrm{TiO}_{2} @ \mathrm{PDA}$, respectively. TiO@ C-HSs were obtained after annealing PS@TiO ${ }_{2} @ P D A$ in $\mathrm{N}_{2} / \mathrm{H}_{2}$ (95/5) flow, during which $\mathrm{TiO}_{2}$ was reduced to conductive TiO, PS was decomposed and a carbon layer derived from PDA was formed on the surface. It was worth noting that without PDA, the PS@TiO 2 core-shell structure would totally collapse after the annealing process, suggesting that PDA played an essential role in the formation of the robust shells. Benefiting from the superior conductivity of the TiO@C shells, the TiO@C-HS based sulfur electrode delivered a capacity of $750 \mathrm{~mA} \mathrm{~h} \mathrm{~g} \mathrm{~g}^{-1}$ and $630 \mathrm{~mA} \mathrm{~h} \mathrm{~g}{ }^{-1}$ after 500 cycles at $0.2 \mathrm{C}$ and $0.5 \mathrm{C}$, respectively. The performance was superior to that of using $\mathrm{TiO}_{2-x}$ @ C-nanoparticles, $\mathrm{TiO}_{2}$-nanoparticles and $\mathrm{C}$-HS as the sulfur hosts. However, a higher content carbon additive of $20 \mathrm{wt} \%$ (vs. $10 \mathrm{wt} \%$ ) was essential to build a conductive network when the sulfur loading was increased to $4.0 \mathrm{mg} \mathrm{cm}^{-2}$. Learning from LIBs, to construct an efficient electrode, micrometre-scale particles need a smaller amount of binder and conductive additives than nanoparticles. In this regard, the authors further designed a hierarchical sulfur electrode composed of highly packed TiO hollow nanospheres and a carbon sheath, which simultaneously mitigated the issues of aggregated polysulfide dissolution and an inefficient conductive network in a thick sulfur electrode (GC-TiO@CHF, Fig. 5e-h). ${ }^{80}$ The grape-like electrode was prepared via electrospinning $\mathrm{SiO}_{2} @ \mathrm{TiO}_{2}$ into polyacrylonitrile (PAN), followed by annealing and etching steps. Using GC-TiO@ $\mathrm{CHF}$ as the sulfur host, the microscale electrode exhibited a superior cycling stability for more than 400 cycles at a high

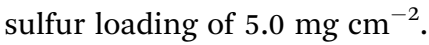

3.1.3 Other metal oxides. Besides $\mathrm{TiO}_{2}$ and $\mathrm{MnO}_{2}$ based hollow structures, a wide range of hollow-structured metal oxides or their compounds have been designed and used as sulfur hosts, from single-shelled hollow structures, such as hollow $\mathrm{MoO}_{2}$ spheres, ${ }^{81}$ hollow $\mathrm{NiCo}_{2} \mathrm{O}_{4}$ nanofibers, ${ }^{82}$ jujube pit like $\mathrm{Fe}_{3} \mathrm{O}_{4^{-}}$ carbon composites, ${ }^{83} \mathrm{CeO}_{2}$-carbon nanospheres, ${ }^{82}$ and $\mathrm{V}_{2} \mathrm{O}_{3}$ spheres, ${ }^{84}$ to various double-shelled hollow structures, such as $\mathrm{SnO}_{2}$ @C nanospheres, ${ }^{85}$ defect-rich $\mathrm{Co}_{3} \mathrm{O}_{4-x}$ microspheres, ${ }^{86}$ and NiO-NiCo ${ }_{2} \mathrm{O}_{4}$-carbon heterostructures, ${ }^{87}$ and finally to multishelled hybrids, such as Fe-doped $\mathrm{Co}_{3} \mathrm{O}_{4}$ hollow microspheres ${ }^{88}$ and V-decorated $\mathrm{V}_{2} \mathrm{O}_{5}$ microspheres $\left(\mathrm{V} / \mathrm{V}_{2} \mathrm{O}_{5}\right) .{ }^{89}$ Integrating metal oxides with highly conductive hollow carbons and polymers and creating defects or oxygen vacancies in these metal oxides are the general and applicable approaches to make better hollowstructured metal oxide sulfur hosts for high-performance LSBs.

\subsection{Metal sulfides}

Different from most of the metal oxides, which are semiconductors, metal sulfides typically consist of a wide range of semimetal or metallic phases. ${ }^{90}$ Furthermore, many metal sulfides exhibit strong LiPS interactions and efficient electrocatalysis for 


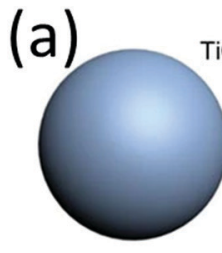

PS

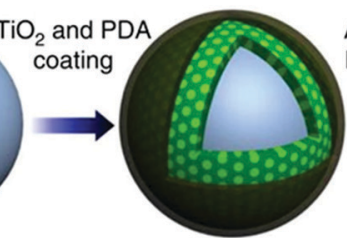

$\mathrm{PS} @ \mathrm{TiO}_{2} @ \mathrm{PDA}$

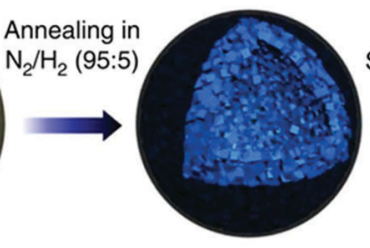

TiO@C-HS

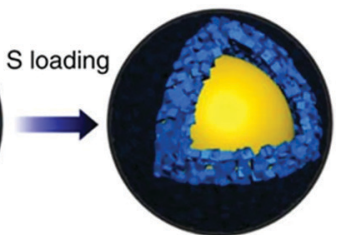

TiO@C-HS/S
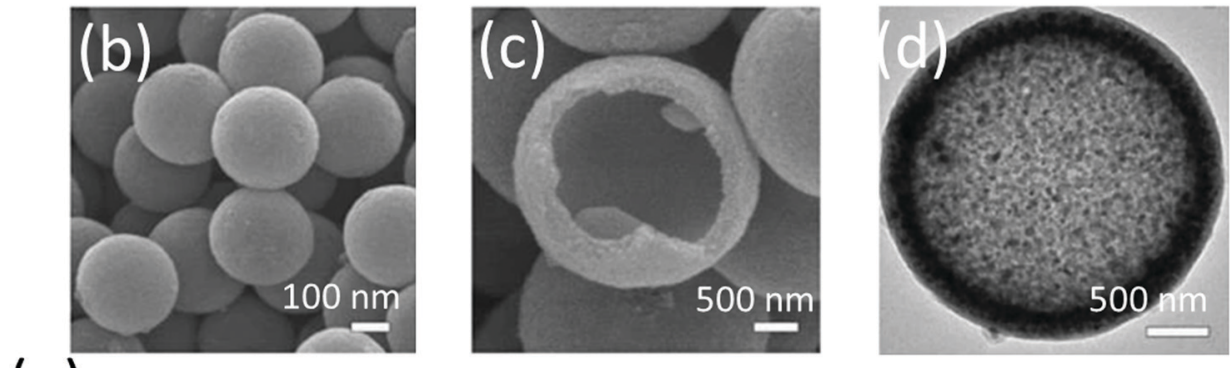

(e)
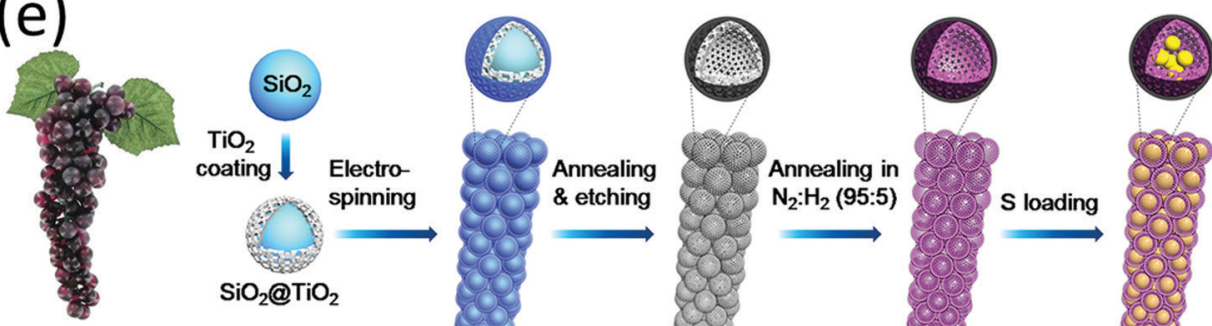

Grape cluster

$\mathrm{SiO}_{2} @ \mathrm{TiO}_{2}$
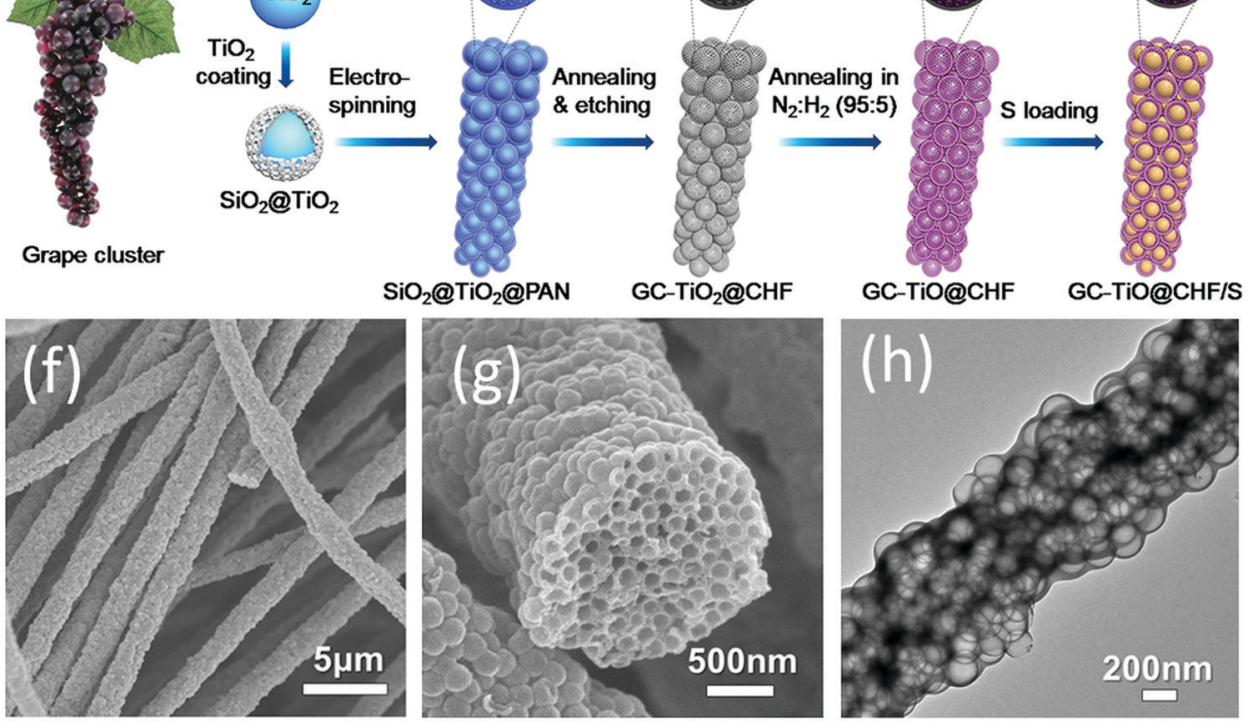

Fig. 5 (a) Schematic for TiO@C-HS/S fabrication, (b and c) SEM, and (d) TEM images of TiO@C-HS. Reproduced with permission. ${ }^{79}$ Copyright 2016 Springer Nature. (e) Schematic for GC-TiO@CHF/S fabrication, (f and g) SEM, and (h) TEM images of GC-TiO@CHF. Reproduced with permission. ${ }^{80}$ Copyright 2017 Elsevier.

the sulfur conversion reactions. Despite these desirable merits for being a sulfur host for LSBs, the list of metal sulfides used as sulfur hosts is obviously shorter than that of metal oxides. ${ }^{54,90}$ Among these hollow-structured metal sulfides, although not much, cobalt sulfides of different phases, such as $\mathrm{CoS}_{2}, \mathrm{Co}_{3} \mathrm{~S}_{4}$, and $\mathrm{Co}_{8} \mathrm{~S}_{9}$, have gained particular attention. This is not only because of their good conductivity and superior electrocatalysis, but also benefited from the well-developed fabrication process using Co-based MOF/ZIF as the templates for the rational design of hollow structures. In this part, representative cobalt sulfide-based hollow sulfur hosts are summarized, with a focus on material design, preparation procedure and the electrochemical properties of the corresponding LSBs.

3.2.1 $\mathrm{CoS}_{2}$. $\mathrm{CoS}_{2}$, a stable and metallic mineral, exhibits efficient electrocatalysis for hydrogen evolution reaction and oxygen reduction. ${ }^{91,92}$ Zhang and co-workers integrated microsized $\mathrm{CoS}_{2}$ with graphene as a sulfur host for LSBs. ${ }^{93}$ The $\mathrm{CoS}_{2}-$ electrolyte interface served as polysulfide adsorption and activation sites, which promoted the redox reactions of polysulfide and the energy efficiency of LSBs. However, the nonporous bulk $\mathrm{CoS}_{2}$ particles unavoidably limited the exposed active sites to fully fulfil the properties of LiPS adsorption and redox acceleration. To make a better use of $\mathrm{CoS}_{2}$, a brain-coral-like mesoporous hollow nitrogen-doped graphitic carbon structure decorated with the in situ grown $\mathrm{CoS}_{2}$ nanoparticles ( $\left.\mathrm{CoS}_{2} @ N G C N s\right)$ was rationally designed and prepared through a four-step process (Fig. 6a). ${ }^{94}$ The hollow ZIF-67 spheres were firstly prepared using a roomtemperature solution process (with $\mathrm{CH}_{3} \mathrm{OH}$ and $\mathrm{SO}_{4}{ }^{2-}$ ions). Secondly, the spherical Co@NGCNs was generated by a pyrolysis process of ZIF- 67 under $\mathrm{Ar} / \mathrm{H}_{2}$ (95: 5 by volume) at $650{ }^{\circ} \mathrm{C}$. Thirdly, 
the Co/CoS ${ }_{2} @ N G C N s$ was obtained by thermal sulfidation of the Co@NGCNs by sulfur at $300{ }^{\circ} \mathrm{C}$. $\mathrm{CoS}_{2} @ N G C N s$ was finally obtained after chemically etching out the Co of $\mathrm{Co} / \mathrm{CoS}_{2} @ \mathrm{NGCNs}$ using $\mathrm{HCl}$ solution, when mesopores with an average size of around $9 \mathrm{~nm}$ were created on the carbon shell. The stepwise morphology evolution and the formation mechanisms of the unique structure are demonstrated in Fig. $6 \mathrm{a}$ and b, respectively. The unique nanostructure exhibited multiple advantages when used as a sulfur host, including (a) the mesoporous surface acted as the conductive pathways and storeroom for sulfur species, allowing enhanced sulfur utilization and high sulfur loading, (b) the void space in the centre could accommodate sulfur, buffer the volume expansion and provide physical confinement to the polysulfide, and (c) the polar $\mathrm{CoS}_{2}$ nanoparticles and nitrogendoped carbon matrix could chemically immobilize polysulfide. $\mathrm{CoS}_{2} @ N G C N s$ presented the strongest LiPS adsorption ability

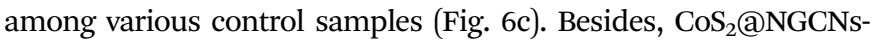
based LSBs achieved a higher sulfur utilization and lower polarization (Fig. 6d), and a positive shift in the reduction peaks and a negative shift of the oxidation peaks (Fig. 6e), suggesting (a)

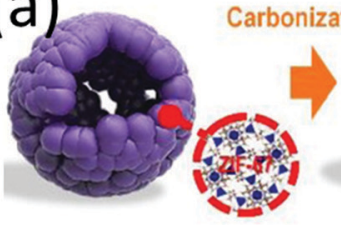

Hollow ZIF-67

$\square$

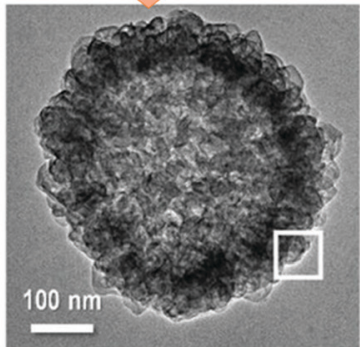

(b)

(b) coagulation

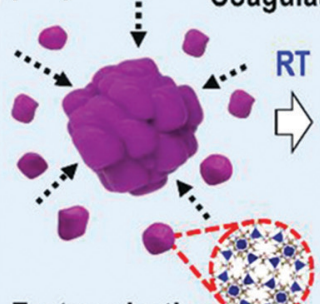

Fast nucleation by $\mathrm{MeOH}$

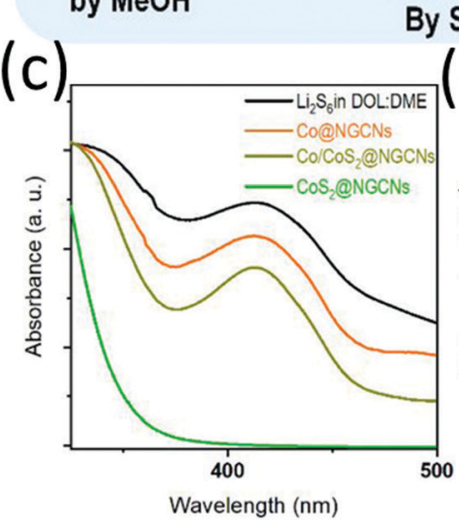

Co@NGCNs

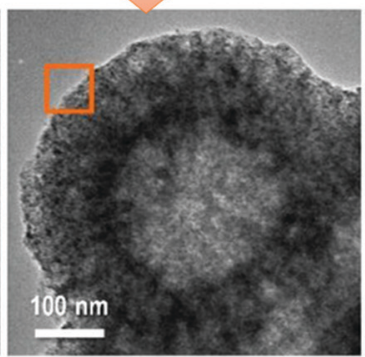

Mixing

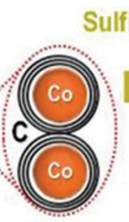

Sulfidation

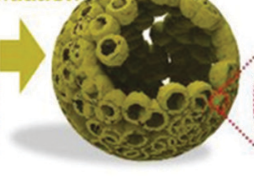

Co/CoS $S_{2} @ \mathrm{NGCNs}$

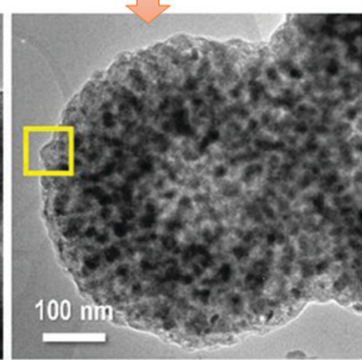

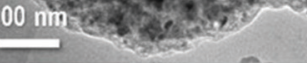

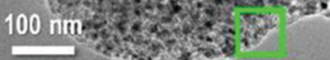

Annealing
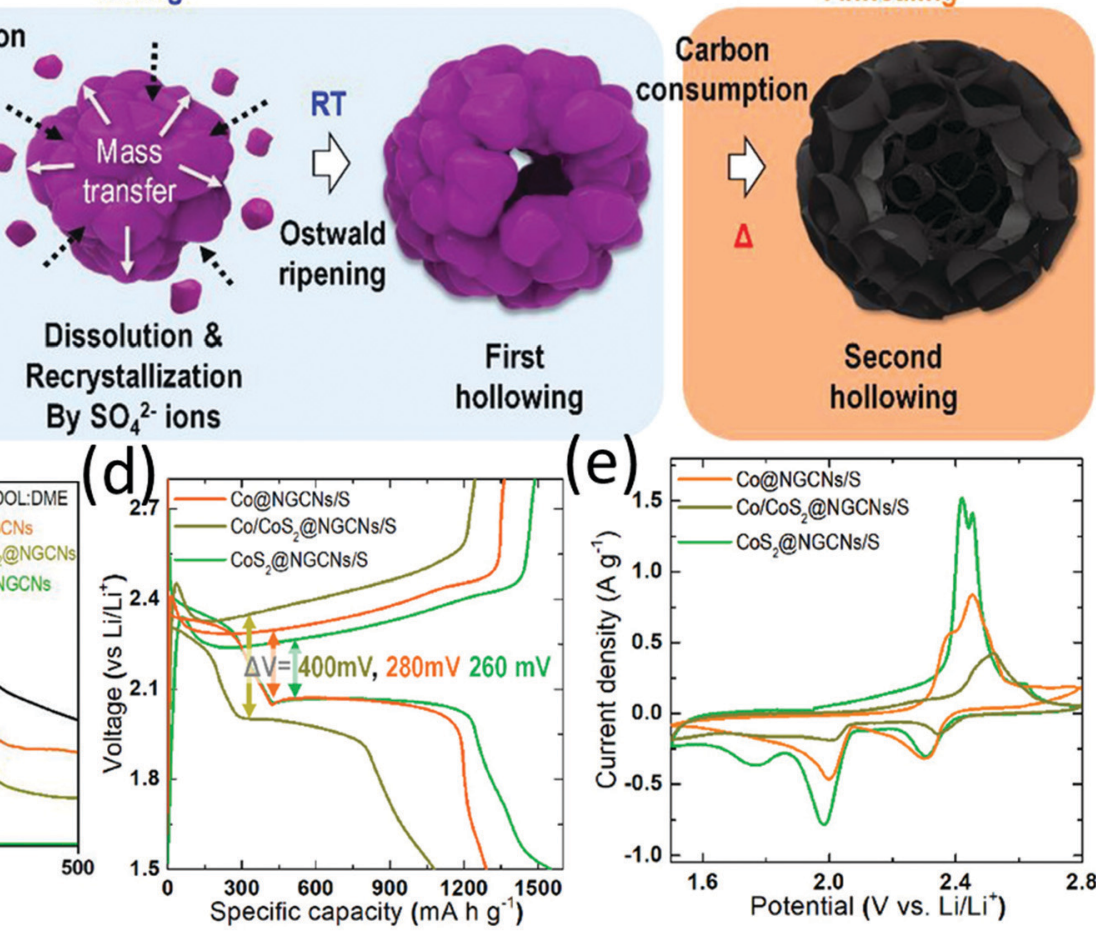

(e)

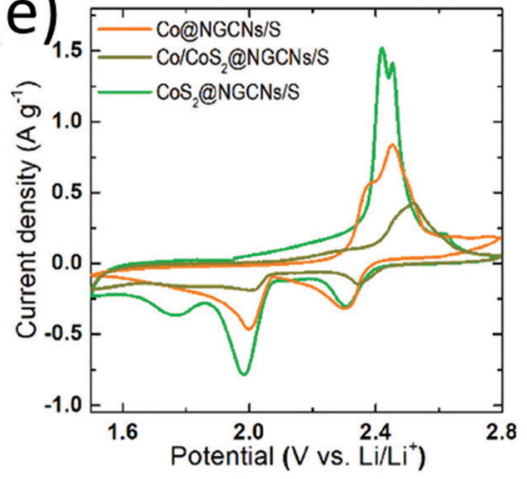

Fig. 6 (a) Schematic for the four-step fabrication of $\mathrm{CoS}_{2}$ aNGCNs, and TEM images of the corresponding intermediates, (b) proposed formation mechanisms of $\mathrm{CoS}_{2} @ N G C N s$, (c) UV-vis spectrum of the original $\mathrm{Li}_{2} \mathrm{~S}_{6}$, and the supernatant solutions after adsorption test using different adsorbents for

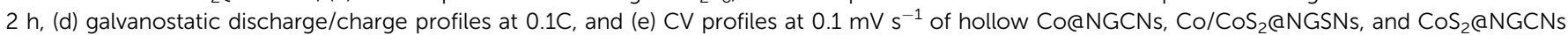
based LSBs. Reproduced with permission. ${ }^{94}$ Copyright 2019 Wiley-VCH. 
the promoted redox kinetics of sulfur conversion. With a sulfur content of $75 \mathrm{wt} \%$, the $\mathrm{CoS}_{2} @ \mathrm{NGCNs}$ based sulfur electrode delivered a capacity of $900.3 \mathrm{~mA} \mathrm{~h} \mathrm{~g}{ }^{-1}$ after 100 cycles at $0.1 \mathrm{C}$ and $519 \mathrm{~mA} \mathrm{~h} \mathrm{~g}^{-1}$ after 300 cycles at $1 \mathrm{C}$.

3.2.2 $\mathrm{Co}_{3} \mathrm{~S}_{4} \cdot \mathrm{Co}_{3} \mathrm{~S}_{4}$ presents a high conductivity of $330 \mathrm{~S} \mathrm{~cm}^{-1}$ at room temperature ${ }^{95}$ and has been applied as sulfur hosts with various material integration and structure designs. $\mathrm{Co}_{3} \mathrm{~S}_{4}$ polyhedra prepared using ZIF-67 as a self-sacrificing template ${ }^{96}$ were integrated with activated carbon nanofibers (ACNF) and sulfur via vacuum filtration, forming a compact film electrode. ${ }^{97}$ The compact sulfur electrode delivered high areal capacities of $5.25 \mathrm{~mA} \mathrm{~h} \mathrm{~cm}{ }^{-2}\left(701 \mathrm{~mA} \mathrm{~h} \mathrm{~g}^{-1}\right)$ and $7.47 \mathrm{~mA} \mathrm{~h} \mathrm{~cm} \mathrm{~cm}^{-2}$ $\left(550 \mathrm{~mA} \mathrm{~h} \mathrm{~g}^{-1}\right)$ after 100 cycles at $0.5 \mathrm{C}$ when the sulfur loading was $7.5 \mathrm{mg} \mathrm{cm}^{-2}$ and $13.5 \mathrm{mg} \mathrm{cm}^{-2}$, respectively. The superior performance was attributed to the highly-conductive hollow $\mathrm{Co}_{3} \mathrm{~S}_{4}$ polyhedra which not only chemically trapped polysulfide and allowed quick electron transport, but also provided sufficient void space for LiPS storage.

The catalytic effect of $\mathrm{Co}_{3} \mathrm{~S}_{4}$ for the sulfur conversion reactions in LSBs was initially investigated by Zhang and co-workers, ${ }^{98}$ inspired by the earlier reports that $\mathrm{Co}_{3} \mathrm{~S}_{4}$ demonstrated 2-3 times higher electrocatalytic activity for oxygen reduction reactions than $\mathrm{CoS}_{2} \cdot{ }^{99}$ In Zhang's work, $\mathrm{Co}_{3} \mathrm{~S}_{4}$ nanotubes were firstly synthesized by a two-step hydrothermal process. Specifically, the first hydrothermal process $\left(\mathrm{CoCl}_{2} \cdot 6 \mathrm{H}_{2} \mathrm{O}+\mathrm{CO}\left(\mathrm{NH}_{2}\right)_{2}\right)$ generated the nanoneedle $\mathrm{Co}\left(\mathrm{CO}_{3}\right)_{0.35} \mathrm{Cl}_{0.20}(\mathrm{OH})_{1.10}$ with a diameter of around 80-90 nm, and the nano-needle $\mathrm{Co}\left(\mathrm{CO}_{3}\right)_{0.35} \mathrm{Cl}_{0.20}(\mathrm{OH})_{1.10}$ transformed into $\mathrm{Co}_{3} \mathrm{~S}_{4}$ nanotubes due to the Kirkendall effect during the hydrothermal sulfuration process. $\mathrm{Co}_{3} \mathrm{~S}_{4} @ \mathrm{~S}$ was obtained by a melt-diffusion process. The $\mathrm{Co}_{3} \mathrm{~S}_{4} @ S$ cathode delivered an initial capacity of $517 \mathrm{~mA} \mathrm{~h} \mathrm{~g}^{-1}$ at $5 \mathrm{C}$ with $305 \mathrm{~mA} \mathrm{~h} \mathrm{~g}^{-1}$ left after 1000 cycles, corresponding to a capacity retention of $59 \%$ and a capacity decay rate of $0.041 \%$ per cycle. The $\mathrm{Li}_{2} \mathrm{~S}_{4}$ adsorption test revealed the strong interaction between $\mathrm{Co}_{3} \mathrm{~S}_{4}$ and LiPSs, and the CV results using symmetrical cells demonstrated the superior catalysis of $\mathrm{Co}_{3} \mathrm{~S}_{4}$ on the conversion of $\mathrm{Li}_{2} \mathrm{~S}_{6}$.

A hybrid nanocomposite of carbon nanotube intercalated hollow $\mathrm{Co}_{3} \mathrm{~S}_{4}$ nanoboxes (CNT/Co $3 \mathrm{~S}_{4}$-NBs Fig. 7c) was prepared via a self-template method, which presented as an efficient sulfur host. ${ }^{100}$ The composite of sulfur and $\mathrm{CNT} / \mathrm{Co}_{3} \mathrm{~S}_{4}-\mathrm{NBS}$ (S@CNT/ $/ \mathrm{Co}_{3} \mathrm{~S}_{4}-\mathrm{NBs}$, Fig. 7b and d) was prepared as shown in Fig. 7a. Specifically, ZIF-67 nanocubes were firstly in situ nucleated onto a -COOH-functionalized CNT network (CNTs/ ZIF-67), followed by solvothermal sulfuration and a subsequent carbonization process. The difference in diffusion rates of sulfur species and cobalt (Kirkendall effect) was the driving force for the formation of hollow $\mathrm{Co}_{3} \mathrm{~S}_{4}$-NBs. Combining the three-dimensional CNT conductive network with the conductive, polar hollow $\mathrm{Co}_{3} \mathrm{~S}_{4}$ nanoboxes, the hybrid exhibited superior charge transfer ability, and synergistic chemical immobilization and physical confinement of LiPSs. Owing to these properties, the $\mathrm{S} @ \mathrm{CNT} / \mathrm{Co}_{3} \mathrm{~S}_{4}-\mathrm{NBs}$ cathode with a sulfur loading of $3.5 \mathrm{mg} \mathrm{cm}$ delivered an initial areal capacity of $3.32 \mathrm{~mA} \mathrm{~h} \mathrm{~cm}{ }^{-2}\left(1012 \mathrm{~mA} \mathrm{~h} \mathrm{~g}^{-1}\right)$ at $0.2 \mathrm{C}$, and $2.87 \mathrm{~mA} \mathrm{~h} \mathrm{~cm}{ }^{-2}\left(820 \mathrm{~mA} \mathrm{~h} \mathrm{~g}^{-1}\right)$ was maintained after 150 cycles. To uncover the mechanism of the superior performance, coin cells with different sulfur cathodes (S@CNT/Co $\mathrm{S}_{4}-\mathrm{NBs,}$
S@CNT, S@Co $\mathrm{S}_{4}$-NBs) were disassembled after 30 cycles $(0.2 \mathrm{C})$ at the discharged state, and the cathodes were soaked in the electrolyte solvent for $4 \mathrm{~h}$ (Fig. 7e). The transparent colour of the $\mathrm{S} @ \mathrm{CNT} / \mathrm{Co}_{3} \mathrm{~S}_{4}-\mathrm{NBs}$ containing solution and the corresponding UV-vis absorption spectra confirmed that the shuttle effect was efficiently suppressed by $\mathrm{CNT} / \mathrm{Co}_{3} \mathrm{~S}_{4}$-NBs.

More recently, a hierarchical carbon nanostructure composed of highly-dispersed $\mathrm{Co}_{3} \mathrm{~S}_{4}$ nanoparticles, ZIF-67 and CNT sponge (CNTs/ $\mathrm{Co}_{3} \mathrm{~S}_{4} @ N C$, Fig. 7f and $\mathrm{h}$ ) was developed as a sulfur host. ${ }^{101}$ The S@CNTs/Co $\mathrm{Co}_{3} @ N C$ (Fig. 7g) cathode exhibited impressive high-rate performance with $720 \mathrm{~mA} \mathrm{~h} \mathrm{~g}^{-1}$ retained after 1000 cycles at 5C (85\% capacity retention) and a low voltage polarization (refer to the distance of the charge and discharge plateaus at half capacity). The impressive high-rate performance was attributed to the excellent catalytic capability of CNTs/ $\mathrm{Co}_{3} \mathrm{~S}_{4} @ \mathrm{NC}$. As revealed by the CV curves of the symmetric cells, sharp peaks with narrow separation was obtained using CNTs/ $\mathrm{Co}_{3} \mathrm{~S}_{4} @ \mathrm{NC}$ as the electrodes (Fig. 7i), compared to the much broader peaks with widened separation observed in the case of using CNTs/Co@NC and CNTs (Fig. 7j).

3.2.3 $\mathrm{Co}_{8} \mathrm{~S}_{9}$. Metallic $\mathrm{Co}_{8} \mathrm{~S}_{9}$ with a high conductivity of $290 \mathrm{~S} \mathrm{~cm}^{-1}$ at room temperature ${ }^{102}$ is among the most widely studied metal sulfides in LSBs. Nazar et al. have demonstrated the dual-interaction of polysulfide with graphene-like $\mathrm{Co}_{8} \mathrm{~S}_{9}$ nanosheets $\left(\mathrm{S}_{2}{ }^{2-}-\mathrm{Co}^{\delta+}\right.$ and $\left.\mathrm{Li}^{+}-\mathrm{S}^{\delta-}\right)$ through both theoretical calculation and spectroscopic studies. ${ }^{103}$ It is known that the polar-polar interaction between the host and polysulfide is generally based on monolayered chemical adsorption. ${ }^{104}$ Despite the strong chemical interaction and large exposed adsorption sites of the polar host materials, it might be difficult to trap all LiPSs in a long run relying on two-dimensional nanosheets. ${ }^{28}$ In this regard, a highly-conductive honeycomb-like spherical structure assembled from hollow $\mathrm{Co}_{9} \mathrm{~S}_{8}$ tubes was designed as a sulfur host. The well-aligned hollow tubes allow a fast ion transfer and provide a buffer room for the volume expansion of the sulfur electrode during the lithiation process, and the polar $\mathrm{Co}_{9} \mathrm{~S}_{8}$ effectively bonds the polysulfide for long-term cycling. ${ }^{105}$ The two-step fabrication process is shown in Fig. 8a. The first step is the preparation of the urchin-like precursor with a diameter of around $10 \mu \mathrm{m}$ (Fig. 8b), which was constructed from $\mathrm{Co}\left(\mathrm{CO}_{3}\right)_{0.5} \mathrm{OH} \cdot 0.11 \mathrm{H}_{2} \mathrm{O}$ nanotubes with a diameter of about $100 \mathrm{~nm}$ (Fig. 8c and d). The solid nanorods transformed into hollow nanotubes due to the anion exchange. The honeycomb-like $\mathrm{Co}_{9} \mathrm{~S}_{8}$ was obtained after the reaction between $\mathrm{Na}_{2} \mathrm{~S}$ and the as-prepared precursor under a hydrothermal process. The $\mathrm{S} @ \mathrm{Co}_{9} \mathrm{~S}_{8}$ composite with sulfur infiltrated into the hollow $\mathrm{Co}_{9} \mathrm{~S}_{8}$ tubes (Fig. 8e) was obtained through the melt-diffusion process. Compared to the pure sulfur electrode, the $\mathrm{S} @ \mathrm{Co}_{9} \mathrm{~S}_{8}$ cathode exhibited a higher capacity, a lower voltage polarization and sharper redox peaks of the CV curves. In a long-term cycling process, the $\mathrm{S} @ \mathrm{Co}_{9} \mathrm{~S}_{8}$ cathode delivered a capacity of $756.6 \mathrm{~mA} \mathrm{~h} \mathrm{~g}^{-1}$ after 600 cycles at $1 \mathrm{C}$, corresponding to a capacity degradation rate of $0.026 \%$ per cycle. Based on a similar sulfur host design methodology, $\mathrm{Co}_{9} \mathrm{~S}_{8} / \mathrm{C}$ nanopolyhedra were prepared via sulfurization of ZIF-67 nanopolyhedra using thioacetamide (TAA), followed by an annealing process at $350{ }^{\circ} \mathrm{C}$ in a $\mathrm{N}_{2}$ atmosphere. ${ }^{106}$ Large internal cavities were created due to the 

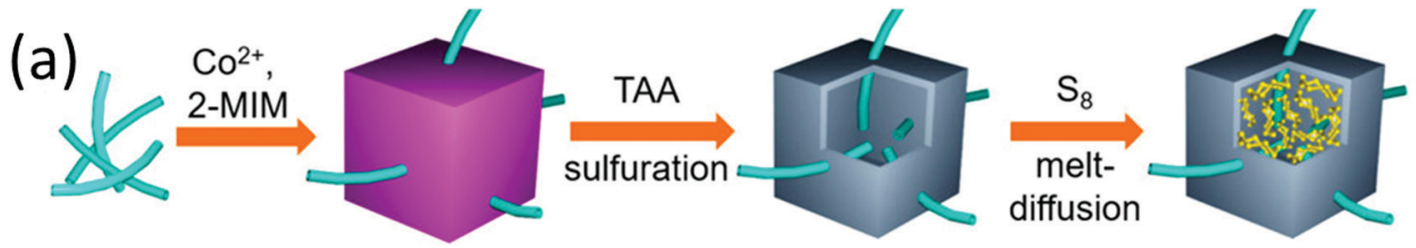

CNTs

CNTs/ZIF-67

$\mathrm{CNTs} / \mathrm{Co}_{3} \mathrm{~S}_{4}-\mathrm{NBs}$

$\mathrm{S} @ \mathrm{CNTs} / \mathrm{Co}_{3} \mathrm{~S}_{4}-\mathrm{NBs}$
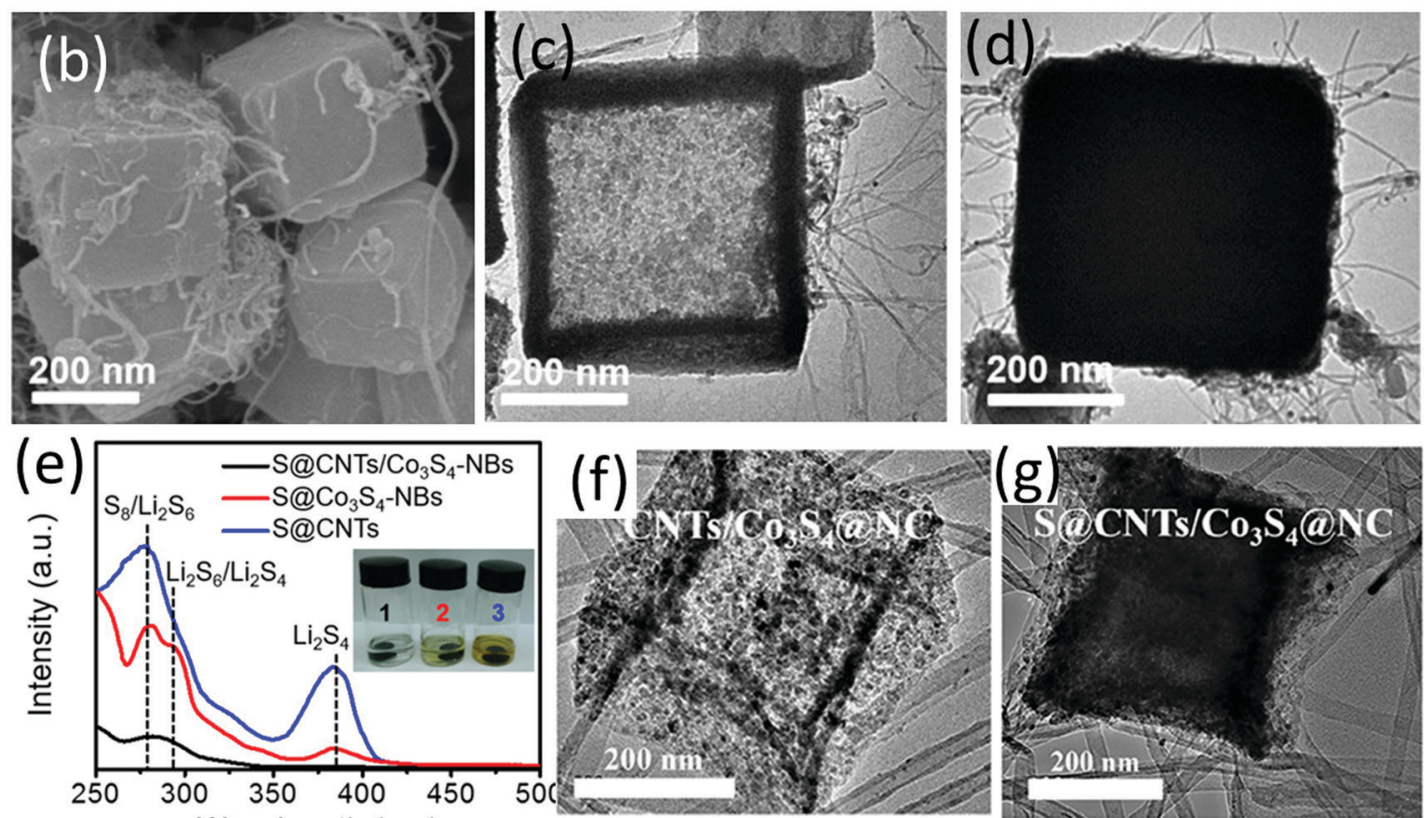

Wavelength $(\mathrm{nm})$
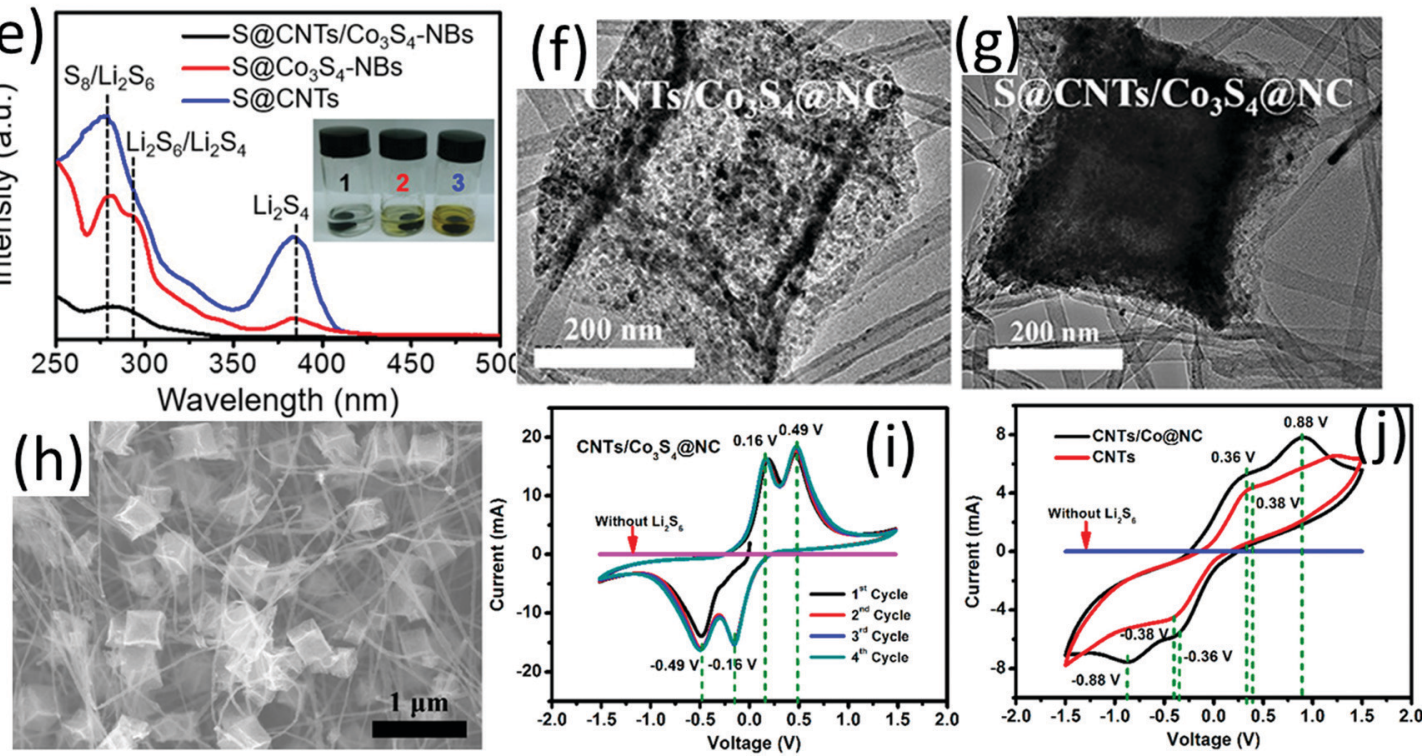

Fig. 7 (a) Schematic for SaCNTs/Co $\mathrm{S}_{4}-\mathrm{NBs}$ preparation, (b) SEM image of SaCNTs/Co $3 \mathrm{~S}_{4}-\mathrm{NBs}$, TEM images of (c) CNTs/Co $3 \mathrm{~S}_{4}-\mathrm{NBs}$, and (d) S@CNTs/ $\mathrm{Co}_{3} \mathrm{~S}_{4}-\mathrm{NBs}$, (e) UV-vis absorption spectra of the electrolyte solvent (DOL/DME) with the soaked cycled cathode: (1) S@CNTs/Co $\mathrm{S}_{4}-\mathrm{NBs}$, (2) SaCo $\mathrm{S}_{4}$ NBs and (3) SaCNTs. The inset photograph compares the colour of the solutions containing the corresponding cathodes. Reproduced with permission. ${ }^{100}$ Copyright 2017 American Chemical Society. TEM images of (f) CNTs/Co $\mathrm{C}_{4} @ \mathrm{aNC}$ and (g) SaCNTs/Co $3 \mathrm{~S}_{4}$ (aNC, (h) SEM image of CNTs/ $\mathrm{Co}_{3} \mathrm{~S}_{4} @ \mathrm{QNC}$, and $\mathrm{CV}$ curves of the symmetric cells with and without $\mathrm{Li}_{2} \mathrm{~S}_{6}$ at $10 \mathrm{mV} \mathrm{s}{ }^{-1}$ using (i) CNTs/Co $\mathrm{S}_{4} @ \mathrm{QNC}$, (j) CNTs/Co@NC and CNTs as the electrodes. Reproduced with permission. ${ }^{101}$ Copyright 2019 American Chemical Society.

different ion diffusion rates of sulfur ions in TAA and cobalt ions in ZIF-67. Benefitting from the large void space and the polar $\mathrm{Co}_{9} \mathrm{~S}_{8} / \mathrm{C}$ shell that provided both spatial and chemical confinement of polysulfide, the $\mathrm{Co}_{9} \mathrm{~S}_{8} / \mathrm{C}$ based sulfur electrode presented a capacity of $560 \mathrm{~mA} \mathrm{~h} \mathrm{~g}^{-1}$ after 1000 cycles at 2C, corresponding to a low capacity rate of $0.041 \%$ per cycle.

More recently, a double-shelled hollow polyhedron composed of a core of cobalt nanoparticles encapsulated in nitrogen-doped carbon, an inner $\mathrm{Co}_{9} \mathrm{~S}_{8}$ shell, and an outer nitrogen-doped porous carbon layer (Co/NC@ $\mathrm{Co}_{9} \mathrm{~S}_{8} / \mathrm{NPC}$, Fig. 8f and g) was developed as a sulfur host. ${ }^{107}$ Compared to $\mathrm{Co} / \mathrm{NC} @ \mathrm{Co}_{9} \mathrm{~S}_{8}$ and the hollow $\mathrm{Co}_{9} \mathrm{~S}_{8} / \mathrm{NPC}$, the $\mathrm{Co} / \mathrm{NC} @ \mathrm{Co}_{9} \mathrm{~S}_{8} / \mathrm{NPC}$ presented an enhanced chemisorption ability to LiPSs and catalytic activity to sulfur conversion reactions. The author systematically investigated the formation process of the $\mathrm{Co} / \mathrm{NC} @ \mathrm{Co}_{9} \mathrm{~S}_{8} / \mathrm{NPC}$. The imidazoliumbased ionic polymer (ImIP)-encapsulated ZIF-67 (ZIF-67@ImIP), used as the core-shell precursor, was firstly prepared, followed by refluxing the precursor in thioacetamide (TAA) solution, during which the inner CoS shell was generated based on the reaction of TAA and ZIF-67, generating the yolk-double-shelled ZIF-67@CoS/ImIP. The final product was obtained after annealing the intermediate in a $\mathrm{N}_{2}$ atmosphere at $600{ }^{\circ} \mathrm{C}$, during which the amorphous $\mathrm{CoS}$ converted to $\mathrm{Co}_{9} \mathrm{~S}_{8}$, the $\mathrm{ZIF}-67$ converted to $\mathrm{Co} / \mathrm{NC}$ nanodots, and ImIP converted to porous nitrogen-doped carbon 

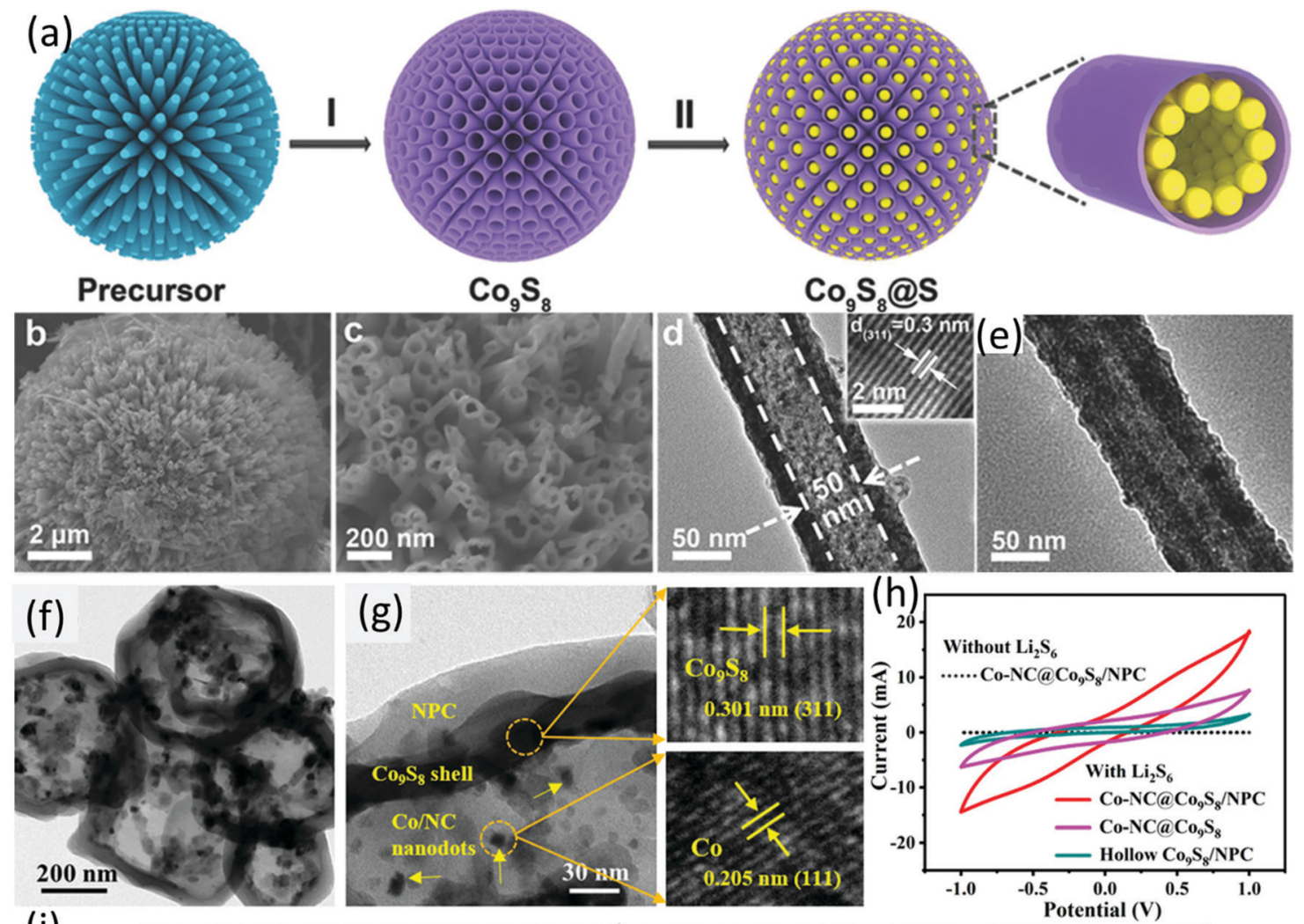

(i)

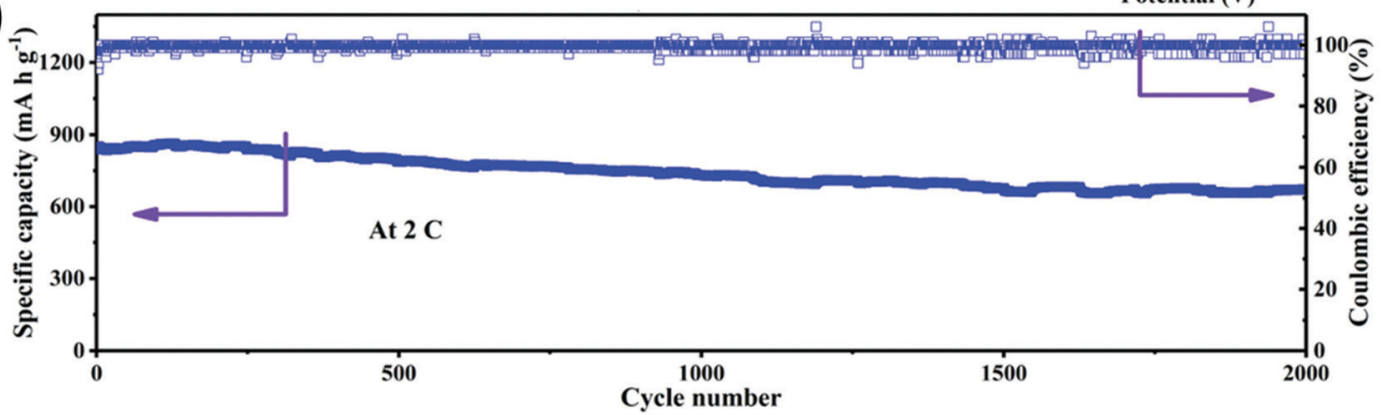

Fig. 8 (a) Schematic for $\mathrm{S}_{a C_{9}} \mathrm{~S}_{8}$ preparation, (b and c) SEM images, (d) TEM image of honeycomb-like Cog $\mathrm{S}_{8}$, and (e) TEM image of SaCo, $\mathrm{S}_{8}$. Reproduced with permission. ${ }^{105}$ Copyright 2018 Wiley-VCH. (f) TEM and (g) HRTEM images of Co-NC@Cog $\mathrm{S}_{8} / \mathrm{NPC}$, and (h) CV profiles of the symmetric cells using different hosts as electrodes, (i) long-term cycling performance of Co-NC@Cog $\mathrm{S}_{8} / \mathrm{NPC}-\mathrm{S}$ at a sulfur loading of $1.8 \mathrm{mg} \mathrm{cm}^{-2}$. Reproduced with permission. ${ }^{107}$ Copyright 2020 Wiley-VCH.

simultaneously. To verify the catalytic effect of the hosts, symmetrical cells composed of identical electrode (the hosts) and $\mathrm{Li}_{2} \mathrm{~S}_{6}$ catholyte were assembled. CV measurements using the symmetrical cell presented the redox current trend of Co-NC@ $\mathrm{Co}_{9} \mathrm{~S}_{8} / \mathrm{NPC}>$ Co-NC@ $\mathrm{Co}_{9} \mathrm{~S}_{8}>\mathrm{Co}_{9} \mathrm{~S}_{8} @ N P C$, suggesting the superior catalytic activity of NC@Co $\mathrm{S}_{8} / \mathrm{NPC}$ (Fig. 8h). Benefiting from the elaborate double-shelled structure and the intrinsic material chemistry, the sulfur electrode using $\mathrm{Co} / \mathrm{NC@} \mathrm{Co}_{9} \mathrm{~S}_{8} / \mathrm{NPC}$ as the sulfur host (Co/NC@ $\mathrm{Co}_{9} \mathrm{~S}_{8} / \mathrm{NPC}-\mathrm{S}$ ) maintained a superior capacity of $670 \mathrm{~mA} \mathrm{~h} \mathrm{~g}^{-2}$ after 2000 cycles at $2 \mathrm{C}$, corresponding to a low capacity decay rate of 0.011 each cycle (Fig. 8i). Moreover, both of the sulfur cathode and lithium anode remained intact without yellow-coloured LiPSs on their surface, suggesting that the shuttle effect was effectively suppressed. Even without $\mathrm{LiNO}_{3}$ in the electrolyte, the $\mathrm{Co} / \mathrm{NC} @ \mathrm{Co}_{9} \mathrm{~S}_{8} / \mathrm{NPC}-\mathrm{S}$ electrode exhibited a low capacity decay rate of $0.032 \%$ for 500 cycles at $2 \mathrm{C}$. At a high sulfur loading of $4.5 \mathrm{mg} \mathrm{cm}^{-2}, \mathrm{Co} / \mathrm{NC} @ \mathrm{Co}_{9} \mathrm{~S}_{8} / \mathrm{NPC}-\mathrm{S}$ delivered an initial capacity of $946 \mathrm{~mA} \mathrm{~h} \mathrm{~g}^{-1}$, which was maintained at $806 \mathrm{~mA} \mathrm{~h} \mathrm{~g}^{-1}$ after 500 cycles at $0.5 \mathrm{C}$.

3.2.4 Other metal sulfides. Besides the above-mentioned cobalt sulfides which were prepared using ZIF-67 as the template, there are other hollow-structured metal sulfides applied as sulfur hosts using $\mathrm{SiO}_{2}$ spheres as the hard templates. For example, NiSnanoparticle decorated spherical hollow carbon was prepared with $\mathrm{SiO}_{2}$ spheres as the template. ${ }^{108} \mathrm{SiO}_{2}$ spheres $(450 \mathrm{~nm})$ were firstly prepared, then $\mathrm{SiO}_{2} @ N i-$ silicate@RF spheres (530 nm) were generated by adding nickel nitrate solution and resorcinol formaldehyde resin (RF). After annealing the as-obtained product in a $\mathrm{N}_{2}$ atmosphere, $\mathrm{SiO}_{2} @ \mathrm{Ni@C} \mathrm{spheres} \mathrm{were} \mathrm{obtained.} \mathrm{NiS@}$ C-HSs were generated via the reaction between $\mathrm{SiO}_{2} @ \mathrm{Ni} @ \mathrm{C}$ and 
$\mathrm{Na}_{2} \mathrm{~S}$, when $\mathrm{Ni}$ was converted to $\mathrm{NiS}$ nanoparticles and $\mathrm{SiO}_{2}$ was etched away by $\mathrm{OH}^{-}$generated from the hydrolysis of $\mathrm{S}^{2-}$ ions. LSBs with NiS@C-HSs as the sulfur host delivered a capacity of $695 \mathrm{~mA} \mathrm{~h} \mathrm{~g}{ }^{-1}$ after 300 cycles at $0.5 \mathrm{C}$, corresponding to a low capacity degradation rate of $0.013 \%$ per cycle. A hollow carbon structure with sulfur-deficient $\mathrm{MoS}_{2}$ nanosheets anchored on the inner side ( $\left.\mathrm{MoS}_{2-x} / \mathrm{HMC}\right)$ was achieved, where $\mathrm{SiO}_{2}$ spheres were used as the templates for the preparation of HMC. ${ }^{109} \mathrm{MoS}_{2}$ nanosheets were grown on the $\mathrm{HMC}\left(\mathrm{MoS}_{2} / \mathrm{HMC}\right)$ via a hydrothermal process. The sulfur-deficient $\mathrm{MoS}_{2-x}$ was generated by further annealing the as-obtained $\mathrm{MoS}_{2} / \mathrm{HMC}$ in $\mathrm{H}_{2} / \mathrm{Ar}$ (5/95) flow. LSBs using $\mathrm{MoS}_{2-x} / \mathrm{HMC}$ as a sulfur host delivered a capacity of $754 \mathrm{~mA} \mathrm{~h} \mathrm{~g}^{-1}$ after 100 cycles at $0.2 \mathrm{C}$, corresponding to a capacity retention of $70 \%$, which was higher than those of $\mathrm{MoS}_{2} / \mathrm{HMC}$ (58.5\%) and HMC (51.1\%). The enhanced performance was attributed to sulfur vacancies which promoted the chemical interaction of $\mathrm{MoS}_{2}$ and polysulfide. Besides creating sulfur vacancies, taking advantage of metallic $1 \mathrm{~T}-\mathrm{MoS}_{2}$ is another approach to enhance the performance of $\mathrm{MoS}_{2}$ as a sulfur host. A porous graphene/ $\mathrm{MoS}_{2}$ hybrid with $\mathrm{N}$-doped graphene wrapped $1 \mathrm{~T}-\mathrm{MoS}_{2}$ nanotube was synthesized as a sulfur host. ${ }^{110}$ The nanotube was constructed from vertically oriented few-layered $\mathrm{MoS}_{2}$, which self-assembled through a spray-drying approach. Benefiting from the strong LiPS adsorption and efficient catalytic activity of $1 \mathrm{~T}-\mathrm{MoS}_{2}$ and the graphene conductive network, the S-graphene/ $\mathrm{MoS}_{2}$ cathode exhibited a high capacity of $1214 \mathrm{~mA} \mathrm{~h} \mathrm{~g}{ }^{-1}$ after 200 cycles at $0.2 \mathrm{C}$.

It is noticed that most of the metal sulfides used in LSBs are mono-metal sulfides. Inspired by the outstanding electrochemical properties of $\mathrm{NiCo}_{2} \mathrm{~S}_{4}$ for oxygen reduction and hydrogen evolution reactions ${ }^{111,112}$ and other energy storage systems, ${ }^{113,114}$ Xia and co-workers initially designed $\mathrm{NiCo}_{2} \mathrm{~S}_{4}$ yolk-shell hollow spheres as the sulfur host. ${ }^{115}$ The $\mathrm{NiCo}_{2} \mathrm{~S}_{4}$ yolk-shell hollow spheres were synthesized via sulfurization of NiCo-glycerate spheres using thioacetamide (TAA) under a hydrothermal process. The $\mathrm{S} / \mathrm{NiCo}_{2} \mathrm{~S}_{4}$ electrode presented a low capacity rate of $0.074 \%$ per cycle for 500 cycles at $0.5 \mathrm{C}$. Compared to $\mathrm{Ni}_{3} \mathrm{~S}_{4}$ and $\mathrm{Co}_{3} \mathrm{~S}_{4}$ with a similar morphology, $\mathrm{NiCo}_{2} \mathrm{~S}_{4}$ yolk-shell hollow spheres exhibited a high current density in the CV curves measured by symmetrical cells, demonstrating the most efficient catalytic activity to sulfur conversion reactions.

Compared to the abundant hollow metal oxides family, fewer hollow metal sulfides have been developed for sulfur hosts, while significant progress has been made in using metal sulfides for other energy storage systems and energy conversion. ${ }^{116,117}$ The impressive electrochemical performance of the hollow metal sulfide-based LSBs encourages more research efforts on the design and investigation of hollow metal sulfides for LSBs.

\subsection{Metal nitrides}

Metal nitrides typically present a better conductivity than their metal oxide counterparts, which is highly desirable when used as sulfur hosts. ${ }^{118}$ Many metal oxides can be readily transformed into relevant metal nitrides through an ammonization process, with the morphology of the metal oxide well inherited by metal nitrides, and vice versa. ${ }^{119}$ Most of the hollow metal nitride sulfur hosts are obtained via annealing the corresponding metal oxides in a $\mathrm{NH}_{3}$ atmosphere at high temperature.

3.3.1 TiN. The conductivity of TiN (from $4 \times 10^{3}$ to $5.5 \times$ $10^{5} \mathrm{~S} \mathrm{~cm}^{-1}$ ) is comparable to those of metals, which is highly desirable for a sulfur host. ${ }^{119,120}$ Goodenough et al. have initially investigated the electrochemical properties of LSBs using mesoporous TiN as the sulfur host, revealing strong chemical interactions between TiN and LiPSs. ${ }^{121}$ Later, the chemical interaction and catalytic mechanisms of TiN have been confirmed by several other groups. ${ }^{122,123}$ TiN of different morphologies can be readily synthesized by annealing $\mathrm{TiO}_{2}$ with desirable morphologies. ${ }^{124,125}$ For example, a hollow TiN nanosphere was synthesized by annealing a hollow $\mathrm{TiO}_{2}$ nanosphere in ammonia gas, and the S-TiN cathode with a high sulfur loading of $3.6 \mathrm{mg} \mathrm{cm}{ }^{-2}$ exhibited a capacity of $710 \mathrm{~mA} \mathrm{~h} \mathrm{~g}^{-1}$ after 100 cycles at $0.2 \mathrm{C}$. $^{126}$ The enhanced electrochemical performance was attributed to the highly conductive TiN shells, which provided strong chemical interactions with polysulfide, and the void space in the hollow spheres, which buffered the volume expansion of the sulfur electrode during the discharge process. Due to enhanced conductivity and efficient electrocatalysis of TiN, these $\mathrm{TiO}_{2}$-derived $\mathrm{TiN}$ hollow structures when used as sulfur hosts typically allowed superior electrochemical performance to that using the original $\mathrm{TiO}_{2} \cdot{ }^{127,128}$ Hollow porous $\mathrm{TiN}$ tubes were prepared via ammonizing the pre-synthesized hollow $\mathrm{TiO}_{2}$ tubes, and the TiN-sulfur composite (TiN/S) was obtained through the melt-diffusion process. ${ }^{129}$ Owing to the high metallic conductivity of TiN and its high affinity for LiPSs, the TiN/S cathode delivered a capacity of $890 \mathrm{~mA} \mathrm{~h} \mathrm{~g}^{-1}$ after 100 cycles at $0.5 \mathrm{C}$ and $740 \mathrm{~mA} \mathrm{~h} \mathrm{~g}^{-1}$ after 450 cycles at $1 \mathrm{C}$.

3.3.2 VN. Li and co-workers have demonstrated the strong LiPS anchoring effect and fast LiPS conversion enabled by using VN/Graphene composites as the current collector for LSBs. ${ }^{130}$ To prepare a sulfur host that meets the requirements of high conductivity, sufficient void space for sulfur accommodation, volume buffering and LiPS confinement, strong chemical interactions with LiPSs, and efficient electrocatalytic activity for sulfur conversion, porous-shell VN nanobubbles were designed and synthesized through an organometallic conversion and a subsequent thermal nitridation process (Fig. 9a). ${ }^{131}$ Specifically, $\mathrm{V}_{2} \mathrm{O}_{5}$ nanobubbles $\left(\mathrm{V}_{2} \mathrm{O}_{5}\right.$-NBs) were firstly prepared with carbon nanospheres as the sacrificial templates. VN-NBs (Fig. 9b) were then obtained after a heat treatment of the $\mathrm{V}_{2} \mathrm{O}_{5}$-NBs in $\mathrm{NH}_{3} / \mathrm{Ar}$ flow. The infiltration of sulfur into the VN-NBs (S@VN-NBs, Fig. 9c) was achieved via a melt-diffusion process. The S@VNNBs cathode with a sulfur loading of $1.2 \mathrm{mg} \mathrm{cm}^{-2}$ maintained a capacity of 837 and $704 \mathrm{~mA} \mathrm{~h} \mathrm{~g}^{-1}$ after 1000 cycles at 1 and 2C, corresponding to a capacity decay rate of $0.024 \%$ and $0.027 \%$, respectively. When the sulfur loading was increased to 3.3, 5.4 and $6.8 \mathrm{mg} \mathrm{cm}^{-2}$, the S@VN-NBs cathode delivered a capacity of 951, 799, and $563 \mathrm{~mA} \mathrm{~h} \mathrm{~g}^{-1}$ after 200 cycles at $0.5 \mathrm{C}$, respectively. The areal capacity of S@VN-NBs with $5.4 \mathrm{mg} \mathrm{cm}^{-2}$ was among the best reported at that time, suggesting that the rational design of ordered nanostructures was an efficient approach to achieve high-performance LSBs. With a similar material design methodology for a superior sulfur host, a hybrid structure of 


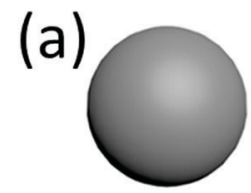

Carbon nanospheres
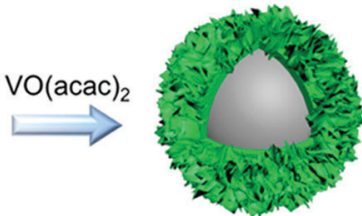

heating $\overrightarrow{\text { air, } 300^{\circ} \mathrm{C}}$ V-precursor/carbon
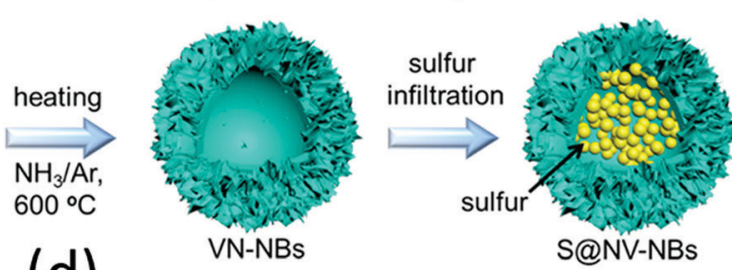

(d)

S@NV-NBs
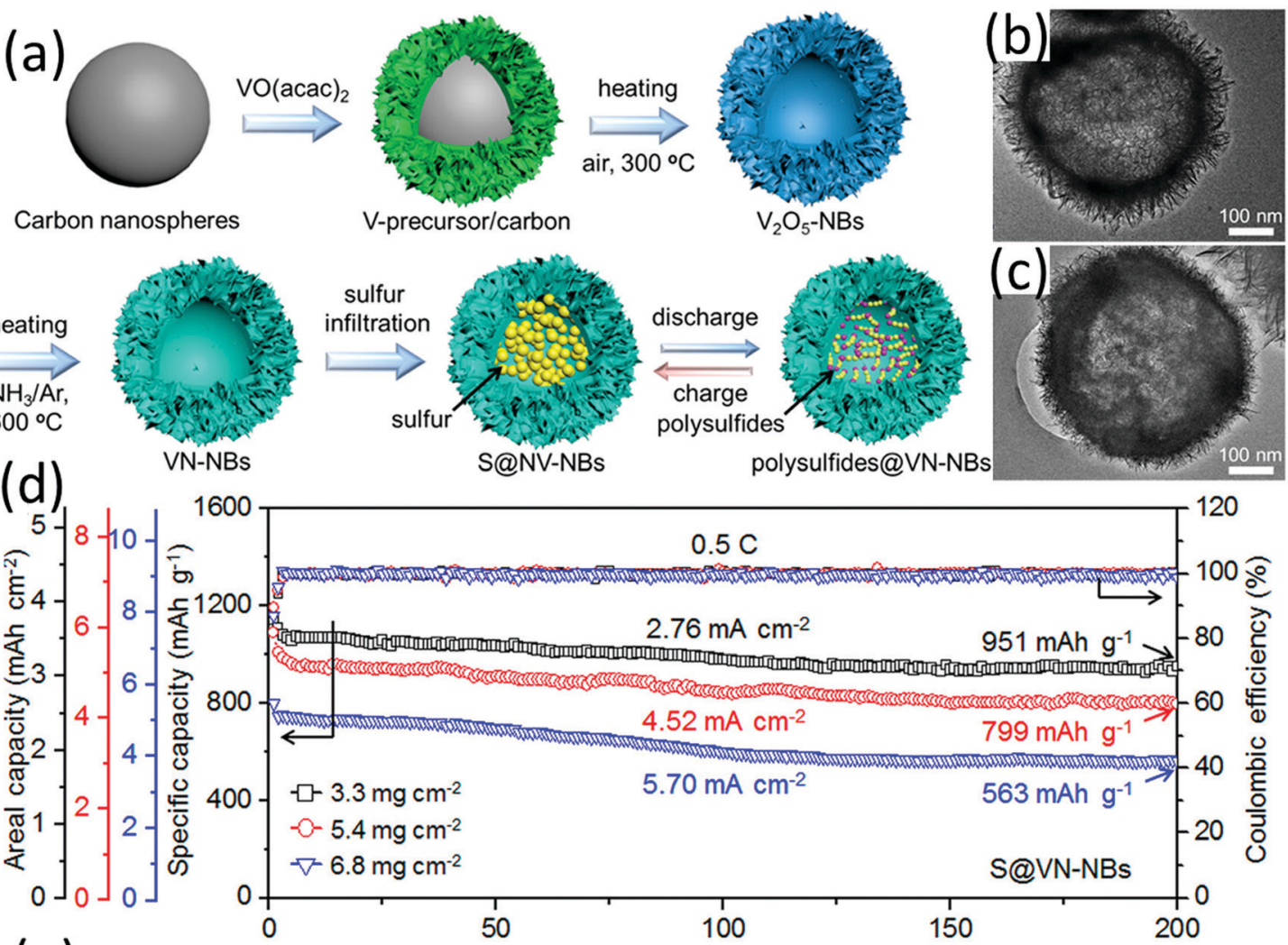

(e)

Cycle number

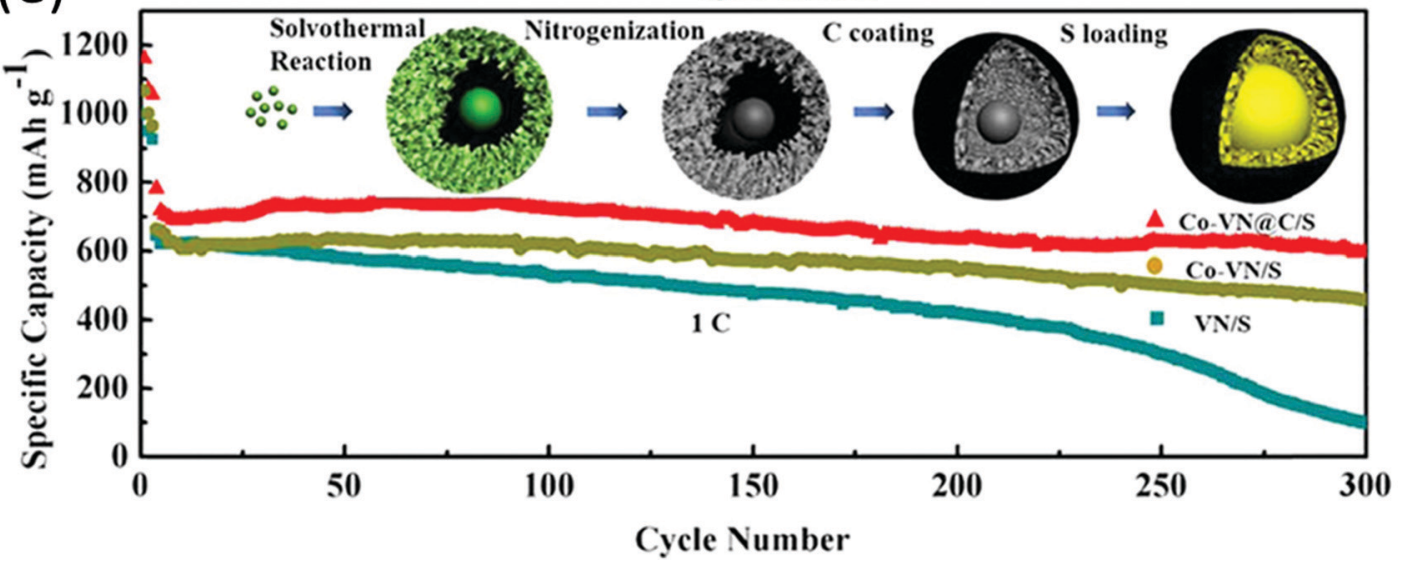

Fig. 9 (a) Schematic for preparation of VN-NBs and SaVN-NBs and the delithiation/lithiation process, TEM images of (b) VN-NBs and (c) SaVN-NBs, and (d) cycling capabilities of SaVN-NBs cathodes with different sulfur loadings at $0.5 \mathrm{C}$. Reproduced with permission. ${ }^{131}$ Copyright 2017 American Chemical Society. (e) Cycling performance of VN/S, Co-VN/S, and Co-VNaC/S at 1C; inset: schematic illustration for Co-VNaC/S fabrication. Reproduced with permission. ${ }^{132}$ Copyright 2018 American Chemical Society.

cobalt-doped VN yolk-shell nanosphere encapsulated in carbon (Co-VN@C) was designed through a template-free solvothermal process with a subsequent nitridation step (Fig. 9e inset). ${ }^{132}$ Benefiting from the synergistic effect of cobalt, vanadium nitride, and carbon matrix, Co-VN@C/S exhibited a superior rate performance and long-term cycling stability compared to Co-VN@/S and VN/S (Fig. 9e). Even with a high sulfur loading of $4.07 \mathrm{mg} \mathrm{cm}{ }^{-2}$, Co-VN@C/S delivered a high capacity of $830 \mathrm{~mA} \mathrm{~h} \mathrm{~g}^{-1}$ after 100 cycles at $0.2 \mathrm{C}$.

Despite these attractive properties of metal nitrides and the well-known merits of hollow structures, the hollow-structured metal nitrides developed for sulfur hosts are fewer than the hollow-structured metal sulfides. This may be due to the difficulty and high-cost for the synthesis of metal nitride hollow structures. More efforts are desirable for the development of facile, efficient and cost-effective approaches to fabricate hollow-structured metal nitrides.

\subsection{Metal carbides}

Nazar and co-workers are the pioneers who used the delaminated MXene phase (the early-transition-metal carbides or carbonitrides) as sulfur hosts. ${ }^{133}$ Two-dimensional $\mathrm{Ti}_{2} \mathrm{C}$ and $\mathrm{Ti}_{3} \mathrm{C}_{2}$ nanosheets 
were demonstrated as efficient sulfur hosts, which enabled stable cycling performance of LSBs. ${ }^{134}$ Coupling the polar metallic metal carbide with the hollow carbon spheres, a hybrid hollow structure with double-shelled carbon with encapsulated $\mathrm{Mo}_{2} \mathrm{C}$ nanoparticles $\left(\mathrm{Mo}_{2} \mathrm{C} / \mathrm{C} @ \mathrm{C}\right)$ was developed as the sulfur host. ${ }^{135}$ The inner carbon shell was mainly used for encapsulation, while the outer carbon layer was for surface modification, thus leading to a better battery performance than that with a single carbon shell $\left(\mathrm{Mo}_{2} \mathrm{C} / \mathrm{C}\right)$ host.
A hybrid hollow structure with $\mathrm{MoSe}_{2}$ and $\mathrm{Mo}_{2} \mathrm{C}$ encapsulated into hollow F-doped carbon fibers (MoSe2@FC@Mo2C, Fig. 10a) was synthesized through electrospinning (ZIF-67 was incorporated into the fibre precursor), followed by carbonization and a subsequent hydrothermal process. ${ }^{136}$ MoSe2@FC@Mo2C allowed stepwise electrocatalysis of different sulfur species with F-doped carbon fibers (FC) accelerating the transformation of $\mathrm{S}_{8}$ and $\mathrm{Li}_{2} \mathrm{~S}_{4}$, while the $\mathrm{MoSe}_{2}$ and $\mathrm{Mo}_{2} \mathrm{C}$ promoted the conversion between $\mathrm{Li}_{2} \mathrm{~S}_{4}$ and $\mathrm{Li}_{2} \mathrm{~S}$. Benefitting from these advantages, the
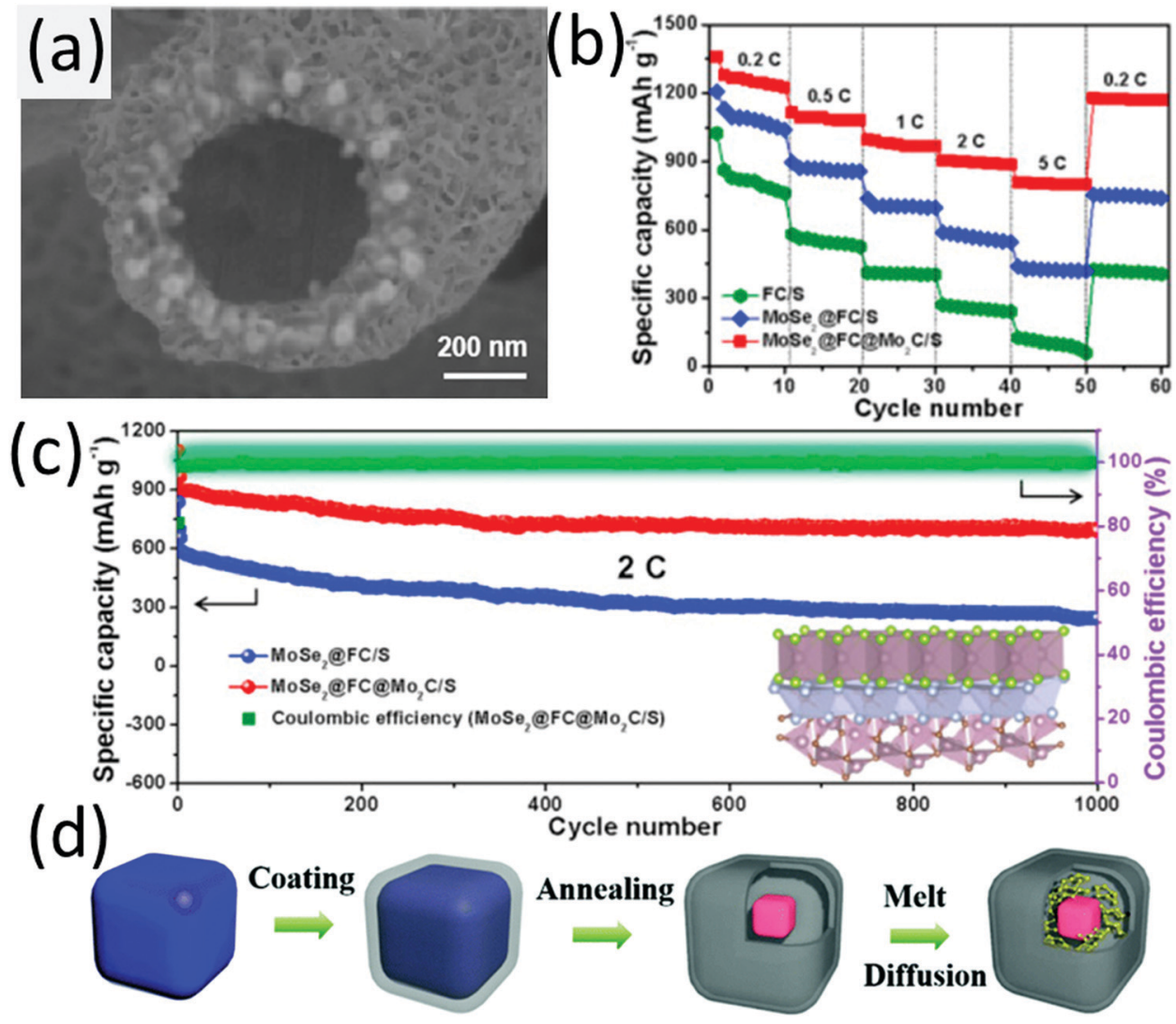

PB

PB@PDA

$\mathrm{Fe}_{3} \mathrm{C} @ \mathrm{~N}-\mathrm{C}$

$\mathrm{Fe}_{3} \mathrm{C} @ \mathrm{~N}-\mathrm{C} / \mathrm{S}$
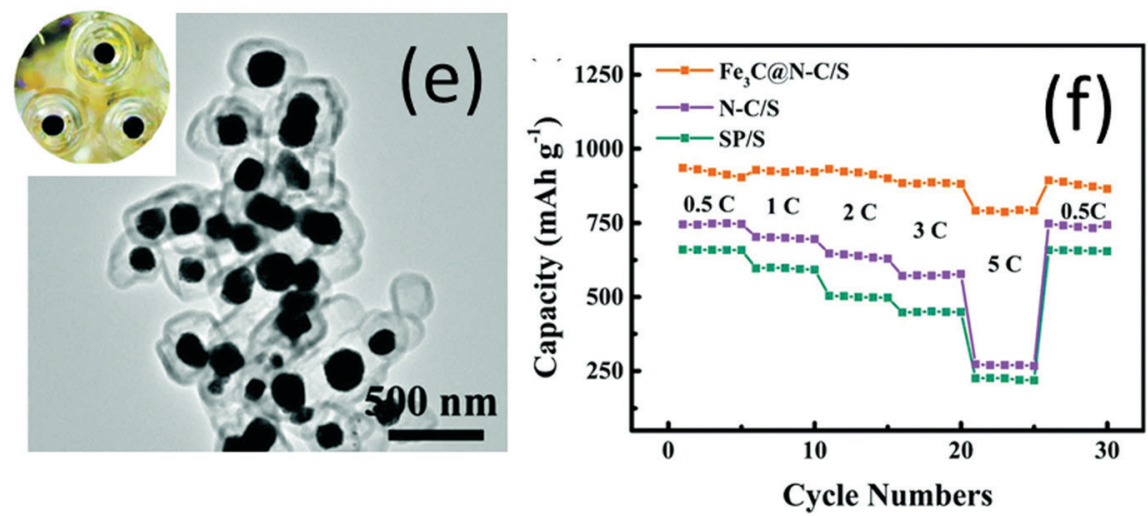

Fig. 10 (a) SEM image of $\mathrm{MoSe}_{2}\left(\mathrm{aFC}_{\mathrm{aMO}} \mathrm{C}\right.$, (b) rate-performances of LSBs using different sulfur hosts, and (c) long-term cycling of the MoSe $\mathrm{QFC}(\mathrm{a}$ $\mathrm{Mo}_{2} \mathrm{C} / \mathrm{S}$ cathode. Reproduced with permission. ${ }^{136}$ Copyright 2020 Elsevier. (d) Schematic for frogspawn-like hollow Fe 3 CaN-C preparation, (e) TEM image of $\mathrm{Fe}_{3} \mathrm{C} @ \mathrm{~N}-\mathrm{C}$; the inset is the photo of frogspawn, (f) rate-performance of $\mathrm{Fe}_{3} \mathrm{C}(\mathrm{NN}-\mathrm{C} / \mathrm{S}$, super P/S, and N-C/S (nitrogen-doped carbon). Reproduced with permission. ${ }^{137}$ Copyright 2019 the Royal Society of Chemistry. 
MoSe2@FC@Mo2C/S cathode exhibited a high capacity of $802 \mathrm{~mA} \mathrm{~h} \mathrm{~g}^{-1}$ at $5 \mathrm{C}$, which was superior to those of $\mathrm{FC} / \mathrm{S}$ and MoSe2@FC/S (Fig. 10b). Under a challenging electrolyte/sulfur ratio of $5 \mathrm{~mL} \mathrm{~g}^{-1}$ and a high sulfur loading of $5.5 \mathrm{mg} \mathrm{cm}^{-2}$, MoSe2@FC@Mo2C/S presented a low capacity decay rate of $0.029 \%$ each cycle for 1000 cycles at 2C (Fig. 10c).

Different from most of the hybrids where metal compounds are generally anchored on either the outer surface or the inner surface of the carbon shells, a frogspawn-like structure composed of a nitrogen-doped carbon shell and a $\mathrm{Fe}_{3} \mathrm{C}$ particle core $\left(\mathrm{Fe}_{3} \mathrm{C} @ \mathrm{~N}-\mathrm{C}\right.$, Fig. 10e) was designed and presented as an efficient sulfur host. ${ }^{137}$ The $\mathrm{Fe}_{3} \mathrm{C} @ \mathrm{~N}-\mathrm{C}$ was obtained by annealing polydopamine (PDA) coated cubic Prussian blue (PB), when the metallike $\mathrm{Fe}_{3} \mathrm{C}$ generated from the $\mathrm{PB}$ precursor was encapsulated in nitrogen-doped carbon shells derived from PDA (Fig. 10d). $\mathrm{Fe}_{3} \mathrm{C}$ cores acted as a centre for polysulfide trapping, while the void space provided sufficient room to buffer the volume expansion of sulfur during discharge. The $\mathrm{Fe}_{3} \mathrm{C} @ \mathrm{~N}-\mathrm{C} / \mathrm{S}$ electrode delivered an impressive high-rate capacity of $792 \mathrm{~mA} \mathrm{~h} \mathrm{~g}^{-1}$ at 5C (Fig. 10f). The electrode maintained a capacity of $586 \mathrm{~mA} \mathrm{~h} \mathrm{~g}^{-1}$ after 400 cycles at $0.5 \mathrm{C}$, corresponding to a low capacity decay rate of $0.08 \%$ per cycle.

The number of hollow-structured metal carbides applied as sulfur hosts are relatively limited, possibly due to the hightemperature annealing process, which is essential for the synthesis of metal carbides but detrimental for the hollow structure. To prepare highly-efficient sulfur hosts, integrating the metallic and polar metal carbides with hollow carbons should be a solution.

\subsection{Metal phosphide}

Wang and co-workers are among the pioneering researchers who applied metal phosphides as sulfur host materials and investigated their chemical interaction with LiPSs and electrocatalysis for sulfur conversion in LSBs. ${ }^{138}$ They initially proposed the surface oxidation-induced polysulfide-binding mechanism which is generally applicable to a wide range of transition metal phosphides. ${ }^{139}$ A sulfur cathode containing CNT supported CoP nanoparticles (CoP-CNT) with a high sulfur loading of $7.0 \mathrm{mg} \mathrm{cm} \mathrm{cm}^{-2}$ maintained a high areal capacity of $5.6 \mathrm{~mA} \mathrm{~h} \mathrm{~cm} \mathrm{~cm}^{-2}$ for 200 cycles. ${ }^{139}$ When MoP-CNT was used as the host material, the sulfur cathode realized a stable areal capacity of $5.0 \mathrm{~mA} \mathrm{~h} \mathrm{~cm} \mathrm{~cm}^{-2}$ under a lean electrolyte condition of $4 \mathrm{~mL}_{\mathrm{E}} \mathrm{g}_{\mathrm{S}}{ }^{-1}$ (electrolyte/ sulfur). ${ }^{140}$ To integrate the advantages of transition metal phosphides (for LiPSs immobilization and conversion) with the hollow structure (to carry sulfur, buffer the volume expansion and confine LiPSs), a $\mathrm{Ni}_{2} \mathrm{P}$ yolk-shell structure $\left(\mathrm{Ni}_{2} \mathrm{P}-\mathrm{YS}\right)$ was prepared via a multistep process (Fig. 11a). Ni-yolk-shell (Ni-YS) was first prepared with a one-pot solvothermal process. The morphology evolution of the Ni-YS along with the solvothermal process $(3,6,9,12 \mathrm{~h})$ is shown in Fig. 11b-e, revealing the stepwise hollowing out of the yolk-shell structure (Fig. 11f). $\mathrm{Ni}_{2} \mathrm{P}-\mathrm{YS}$ composed of a core with a dimeter of $276 \mathrm{~nm}$ and a spherical shell with a dimeter of $855 \mathrm{~nm}$ (Fig. 11g and h) was obtained by annealing Ni-SY (glycerol) in $\mathrm{PH}_{3} / \mathrm{Ar}$ flow. The $\mathrm{Ni}_{2} \mathrm{P}-\mathrm{YS}$ based sulfur cathode delivered an impressive high-rate performance with a capacity of $439 \mathrm{~mA} \mathrm{~h} \mathrm{~g}{ }^{-1}$ at $10 \mathrm{C}$, which was maintained at $394 \mathrm{~mA} \mathrm{~h} \mathrm{~g}^{-1}$ after 1000 cycles at $5 \mathrm{C}$ (Fig. 11i). ${ }^{141}$ It was revealed that the conductive polar $\mathrm{Ni}_{2} \mathrm{P}$ not only facilitated the ion transportation but also improved the polysulfide nucleation. Besides, the yolkshell structure could accommodate sulfur species and provided buffer room for the correlated volume expansion.

A hybrid structure composed of CoP nanoparticles, hollow carbon polyhedra and carbon nanotube (CoP@HPCN) was prepared using ZIF-8 and ZIF-67 as the templates and metal ion sources. After a successive carbonization, oxidization and phosphorization process, $\mathrm{Co} @ \mathrm{HPCN}, \mathrm{Co}_{3} \mathrm{O}_{4} @ \mathrm{HPCN}$, and the final CoP@HPCN were generated, respectively. ${ }^{142}$ The CoP@ HPCN/S cathode with a high sulfur loading of $3.7 \mathrm{mg} \mathrm{cm} \mathrm{cm}^{-2}$ presented a low self-discharge constant of $0.03 \%$ per day for 60 days. This was mainly attributed to the high porosity and cavity of the hollow architecture, which can accommodate sulfur and buffer its volume expansion, and the uniformly dispersed CoP nanoparticles, which not only chemically immobilized LiPSs but also acted as an electrocatalyst to promote the redox kinetics of sulfur species. More recently, $\mathrm{Ru}-\mathrm{Mo}_{4} \mathrm{P}_{3}$ nanoparticle-decorated hollow carbon spheres ( $\mathrm{HCS}-\mathrm{Ru}-\mathrm{Mo}_{4} \mathrm{P}_{3}$ ) were demonstrated as good sulfur hosts, and the corresponding S/HCS$\mathrm{Ru}-\mathrm{Mo}_{4} \mathrm{P}_{3}$ cathode achieved a high capacity of $660 \mathrm{~mA} \mathrm{~h} \mathrm{~g}{ }^{-1}$ at $4 \mathrm{C}$ and a high areal capacity of $5.6 \mathrm{~mA} \mathrm{~h} \mathrm{~cm} \mathrm{~cm}^{-2}$ after 50 cycles at a sulfur loading of $6.6 \mathrm{mg} \mathrm{cm}^{-2} \cdot{ }^{143}$ The performance was among the best of LSBs using transition metal phosphides as the sulfur host materials. It was revealed that $\mathrm{Ru}$ induced the phase transformation from $\mathrm{MoP}$ to $\mathrm{Mo}_{4} \mathrm{P}_{3}$, which possessed higher electrocatalytic activity towards sulfur conversion than $\mathrm{RuP}_{2}$ and MoP. The synergistic effect of $\mathrm{Mo}_{4} \mathrm{P}_{3}$ and $\mathrm{Ru}$ made $\mathrm{Ru}-\mathrm{Mo}_{4} \mathrm{P}_{3}$ highly active sites for LiPS adsorption and conversion. Combining the advantages of the hollow carbon structure as a sulfur carrier, the $\mathrm{S} / \mathrm{HCS}-\mathrm{Ru}-\mathrm{Mo}_{4} \mathrm{P}_{3}$ cathode achieved superior electrochemical properties.

Transition metal phosphides have long been used as efficient catalysts for photoelectrochemical, hydro-processing. ${ }^{144,145}$ The application of transition metal phosphides for LSBs is still in its infancy. More efforts on the preparation and application of novel metal phosphides for LSBs are desirable.

\subsection{Metal hydroxides}

Metal hydroxides, such as $\mathrm{Co}(\mathrm{OH})_{2}$, have been demonstrated as efficient stabilizers for high-performance LSBs, presenting good capability to suppress the shuttle effect of LiPSs. ${ }^{146}$ Huang and co-workers demonstrated that a drastically enhanced performance (with negligible capacity decay for 500 cycles) was achieved by encapsulating a conventional $\mathrm{S}_{8}$-carbon black composite $\left(\mathrm{S}_{8} @ \mathrm{CB}\right)$ in nickel nitrate hydroxide, $\mathrm{Ni}_{3}\left(\mathrm{NO}_{3}\right)_{2}(\mathrm{OH})_{4} \cdot{ }^{147}$ The $\mathrm{Ni}_{3}\left(\mathrm{NO}_{3}\right)_{2}(\mathrm{OH})_{4}$ layer not only served as a physical barrier to trap LiPSs, but also reacted with lithium to generate an ion-conductive, polar/hydrophilic-rich layer for ion transportation and LiPS trapping. These results suggest metal hydroxides are potential sulfur hosts to achieve high-performance LSBs. Layered double hydroxides (LDHs) have long been applied as catalysts for a wide range of areas, such as oxygen evolution reactions ${ }^{148}$ and photodegradation of organic waste. ${ }^{149,150}$ Lou et al. designed various hollow-structure LDHs as sulfur host materials, and investigated the electrochemical properties of S-LDHs composites. 

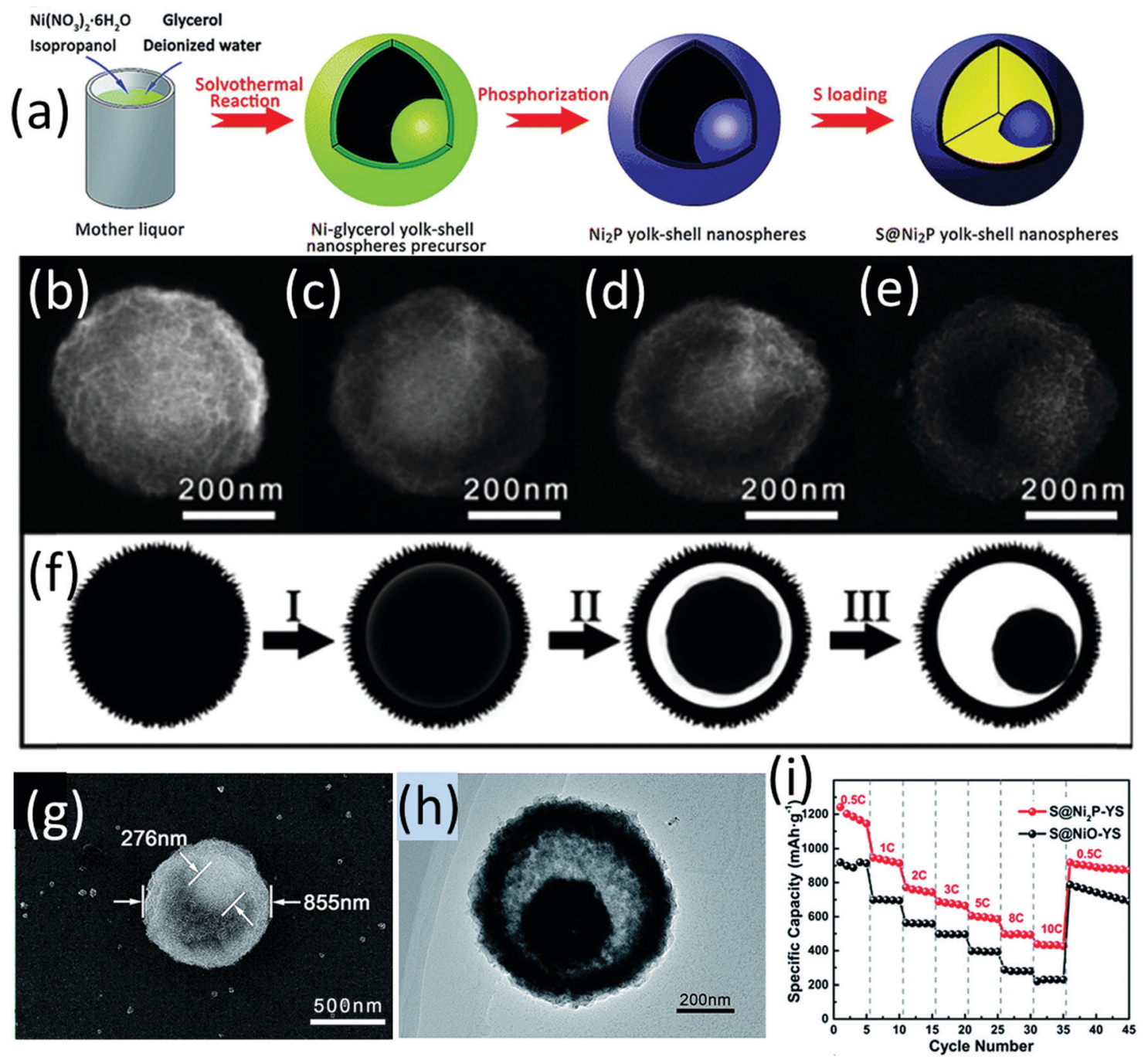

Fig. 11 (a) Schematic for the preparation of hollow yolk-shell $\mathrm{Ni}_{2} \mathrm{P}-\mathrm{YS}$ and $\mathrm{S}\left(\mathrm{NNi}_{2} \mathrm{P}-\mathrm{YS}\right.$ composites, SEM images of Ni-YS precursor/intermediates generated at different stages of the solvothermal process: (b) $3 \mathrm{~h}$, (c) $6 \mathrm{~h}$, (d) $9 \mathrm{~h}$, and (e) $12 \mathrm{~h}$, (f) schematic for the stepwise formation of the Ni-glycerate yolk-shell structure, (g) SEM, and (h) TEM of NiP-YS, (i) rate performance of SaNi ${ }_{2} \mathrm{P}-\mathrm{YS}$ and S@NiO-YS. Reproduced with permission. ${ }^{141} \mathrm{Copyright} 2017$ the Royal Society of Chemistry.

For example, double-shelled nanocages composed of a layered double hydroxide outer shell and a $\mathrm{Co}(\mathrm{OH})_{2}$ inner shell were prepared (CH@LDH), which could not only accommodate a high sulfur content of $75 \mathrm{wt} \%$, but also suppress the diffusion of polysulfide via a self-functionalized surface as chemical adsorption sites, maximizing the advantages of the hollow structure as a sulfur host. ${ }^{151}$ When used as a sulfur host, the CH@LDH-based sulfur electrode with a high sulfur loading of $3.0 \mathrm{mg} \mathrm{cm} \mathrm{cm}^{-2}$ delivered an initial capacity of $747 \mathrm{~mA} \mathrm{~h} \mathrm{~g}^{-1}$ at $0.5 \mathrm{C}$, which was maintained at $491 \mathrm{~mA} \mathrm{~h} \mathrm{~g}^{-1}$ after 100 cycles. The preparation process and TEM images of the corresponding intermediates are shown in Fig. 12a. Specifically, ZIF-67 was firstly synthesized as a sacrificial template, followed by reaction with $\mathrm{Ni}\left(\mathrm{NO}_{3}\right)_{2}$, forming ZIF-67@LDH. After the reaction of ZIF-67@LDH with $\mathrm{Na}_{2} \mathrm{MoO}_{4}$ solution, double-shelled $\mathrm{CH} @ L D H$ was obtained. More recently, authors from the same group further demonstrated that hollow nickel-ion layered double hydroxide polyhedra
(Ni/Fe LDH, Fig. 12b and c) were suitable for a sulfur host. ${ }^{152}$ MIL-88A was used as a template for Ni/Fe LDH. S@Ni/Fe LDH was prepared via the melt-diffusion process, which well inherited the morphology of Ni/Fe LDH except that the void in the core was filled with sulfur (Fig. 12b-e). S@Ni/Fe LDH with a sulfur loading of $2-3 \mathrm{mg} \mathrm{cm} \mathrm{cm}^{-2}$ presented an initial capacity of $844 \mathrm{~mA} \mathrm{~h} \mathrm{~g}^{-1}$ at $1 \mathrm{C}$, which was maintained at $501 \mathrm{~mA} \mathrm{~h} \mathrm{~g}$ after 1000 cycles, corresponding to a decay rate of $0.04 \%$ each cycle.

Besides infiltrating sulfur into a pre-synthesized hollow structure, sulfur can be encapsulated in metal hydroxides, forming core-shell or hollow yolk-shell sulfur composites. A $\alpha-\mathrm{Ni}(\mathrm{OH})_{2}$ nanosheet encapsulated nanosized sulfur ( $\left.\mathrm{S} @ \mathrm{Ni}(\mathrm{OH})_{2}\right)$ composite was prepared via a two-step method (Fig. 12f). ${ }^{153}$ Hollow sulfur nanospheres were firstly synthesized based on the reaction of $\mathrm{Na}_{2} \mathrm{~S}_{2} \mathrm{O}_{3}$, polyvinylpyrrolidone (PVP) and $\mathrm{HCl}$, followed by the growth of $\alpha-\mathrm{Ni}(\mathrm{OH})_{2}$ nanosheets (3.5 nm thick) on the surface of 

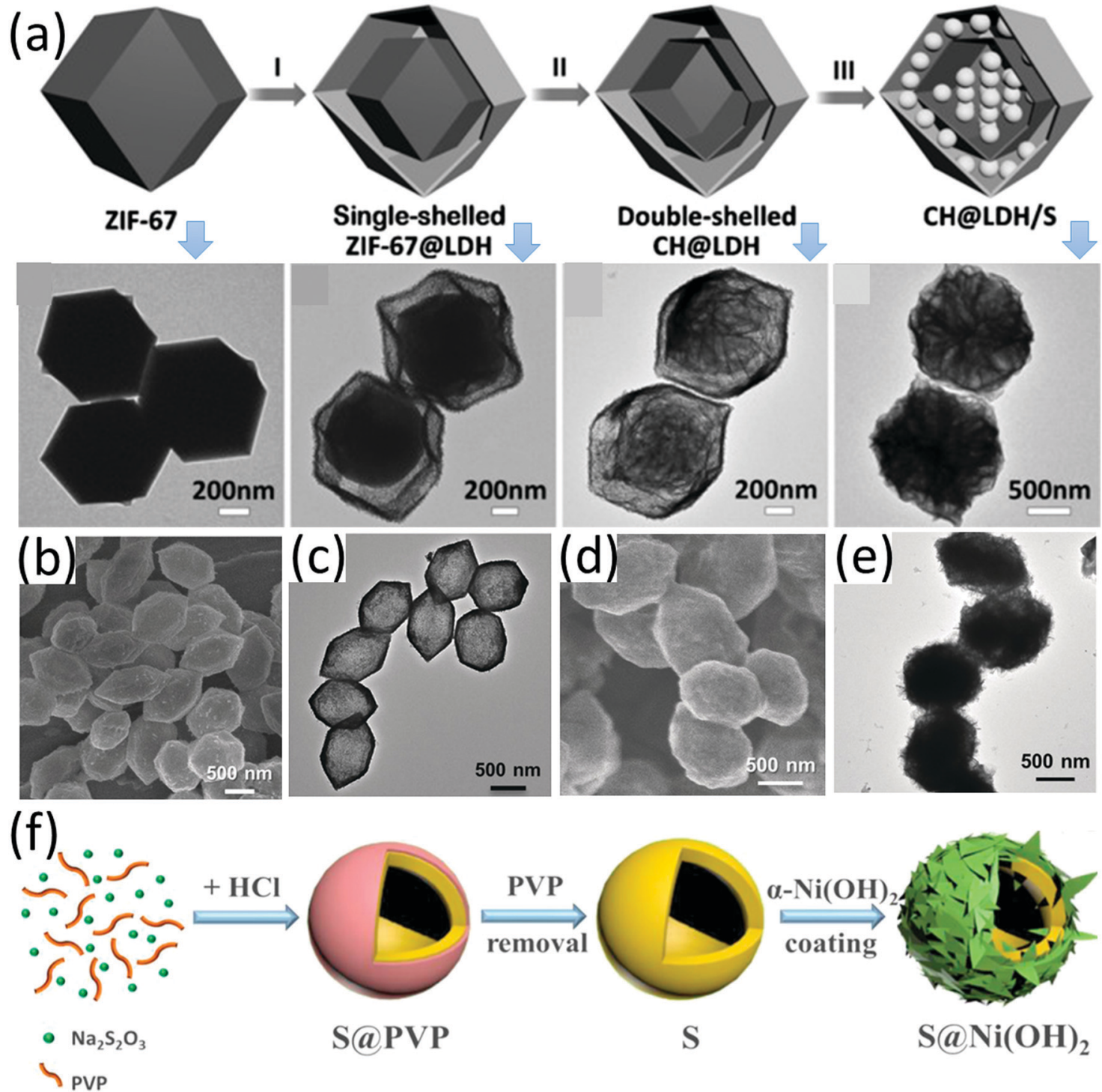

Fig. 12 (a) Schematic for synthesis of $\mathrm{CHQLDH}$ and TEM images of the corresponding intermediates. Reproduced with permission. ${ }^{151}$ Copyright 2016 Wiley-VCH. (b) SEM and (c) TEM images of Ni/Fe LDH, and (d) SEM and (e) TEM images of S(aNi/Fe LDH. Reproduced with permission. ${ }^{152}$ Copyright 2018 , Wiley- $\mathrm{VCH}$. (f) Schematic for the synthesis of double-shelled hollow $\mathrm{S}\left(\mathrm{Ni}(\mathrm{OH})_{2}\right.$ spheres. Reproduced with permission. ${ }^{153} \mathrm{Copyright} 2017 \mathrm{Elsevier}$.

the as-obtained sulfur nanospheres based on the reaction of $\mathrm{C}_{6} \mathrm{H}_{12} \mathrm{~N}_{4}$ and $\mathrm{Ni}\left(\mathrm{NO}_{3}\right)_{2} \cdot 6 \mathrm{H}_{2} \mathrm{O}$. The as-prepared $\mathrm{S} @ \mathrm{Ni}(\mathrm{OH})_{2}$ (sulfur content of $81 \mathrm{wt} \%$ ) exhibited a maximum capacity of $708 \mathrm{~mA} \mathrm{~h} \mathrm{~g}^{-1}$ at $1 \mathrm{C}$ after a few activating cycles, which was maintained at $422 \mathrm{~mA} \mathrm{~h} \mathrm{~g}{ }^{-1}$ after 1000 cycles, corresponding to a capacity decay rate of $0.04 \%$ per cycle and a capacity retention of $58.8 \%$.

\subsection{Metals}

Metal catalysts with high electrical conductivity, such as Pt and Co, were demonstrated with excellent capability to enhance polysulfide anchoring and increase the kinetics of the polysulfide conversion reaction. ${ }^{23}$ To promote the dispersion of metal catalysts and achieve a better sulfur distribution, hybrid hollow structures with metallic nanoparticles decorated on the surface of hollow carbon matrix are desirable. For example, a cobalt nanoparticle-decorated porous nitrogen-doped graphitic carbon polyhedron (Co-N-GC) was prepared by thermal annealing ZIF-67 in a $\mathrm{N}_{2}$ atmosphere. ${ }^{154} \mathrm{Co}-\mathrm{N}-\mathrm{GC}$ well inherited the polyhedron morphology of ZIF-67 with a similar size of $350 \mathrm{~nm}$. Cobalt particles with a calculated size of $22.09 \mathrm{~nm}$ were uniformly dispersed on the carbon surface. The hollow-structured sulfur electrode (sulfur content $70 \mathrm{wt} \%$ ) was obtained via meltdiffusion, which delivered an initial capacity of $1440 \mathrm{~mA} \mathrm{~h} \mathrm{~g}^{-1}$ at $0.2 \mathrm{C}$ which was maintained at $850 \mathrm{~mA} \mathrm{~h} \mathrm{~g}^{-1}$ after 200 cycles, corresponding to a decay rate of $0.023 \%$ per cycle. A nitrogendoped hollow carbon microflower with embedded cobalt nanoparticles (H-Co-NCM) was prepared through carbonizing metanilic acid intercalated cobalt-aluminum layered double hydroxides (CoAl LDHs), followed by an acid etching step when only strongly bonded Co functionalities by nitrogen atoms remained. ${ }^{47} \mathrm{Co} / \mathrm{N}$ heteroatom-doping not only promoted conductivity of the carbon matrix, but also synergistically served as active catalysts and 
adsorption sites. S@H-Co-NCM was prepared by a sulfur dissolving and evaporation process in $\mathrm{CS}_{2}$, followed by a heat treatment at $200{ }^{\circ} \mathrm{C}$ under $\mathrm{N}_{2}$ flow. The S@H-Co-NCM cathode delivered a capacity of $611 \mathrm{~mA} \mathrm{~h} \mathrm{~g}^{-1}$ at $2 \mathrm{C}$, and achieved a capacity decay rate of $0.069 \%$ each cycle over 500 cycles at $0.5 \mathrm{C}$.

Palladium has long been used as a catalyst in different areas, such as alkynylation, ${ }^{155}$ coupling reactions of aryl chlorides, ${ }^{156}$ oxygen reduction and hydrogen oxidation in full cells. ${ }^{157}$ Zuo and co-workers initially investigated the catalysis of palladium on the sulfur conversion reaction in LSBs. ${ }^{158} \mathrm{Pd}-$ Nanocrystalembedded hollow carbon spheres (Pd@HCS, Fig. 13c and d) were designed as the sulfur host, which were prepared through the process as shown in Fig. 13a. Combining the hollow nanostructure with Pd nanocrystals, LiPSs were synergistically trapped by physical confinement and chemical adsorption, achieving rapid redox reactions for sulfur conversion reactions (Fig. 13b). Both $\mathrm{Li}_{2} \mathrm{~S}_{6}$ adsorption test and theoretical calculations confirmed the strong interaction between LiPSs and Pd@HCS. The catalytic ability of Pd NPs was further testified by CV tests using symmetrical coin cells, with much higher redox currents when Pd@HCS was used as the electrode compared to that of using HCS. To further investigate the electrocatalysis of Pd NPs, a $\mathrm{CV}$ test based on semi-liquid cells was conducted. Compared to Pd@HCS, HCS exhibited much broader peaks and larger voltage hysteresis with lower cathodic onset potential and higher anodic onset potential (Fig. 13e). Owing to the advantages of Pd@HCS,
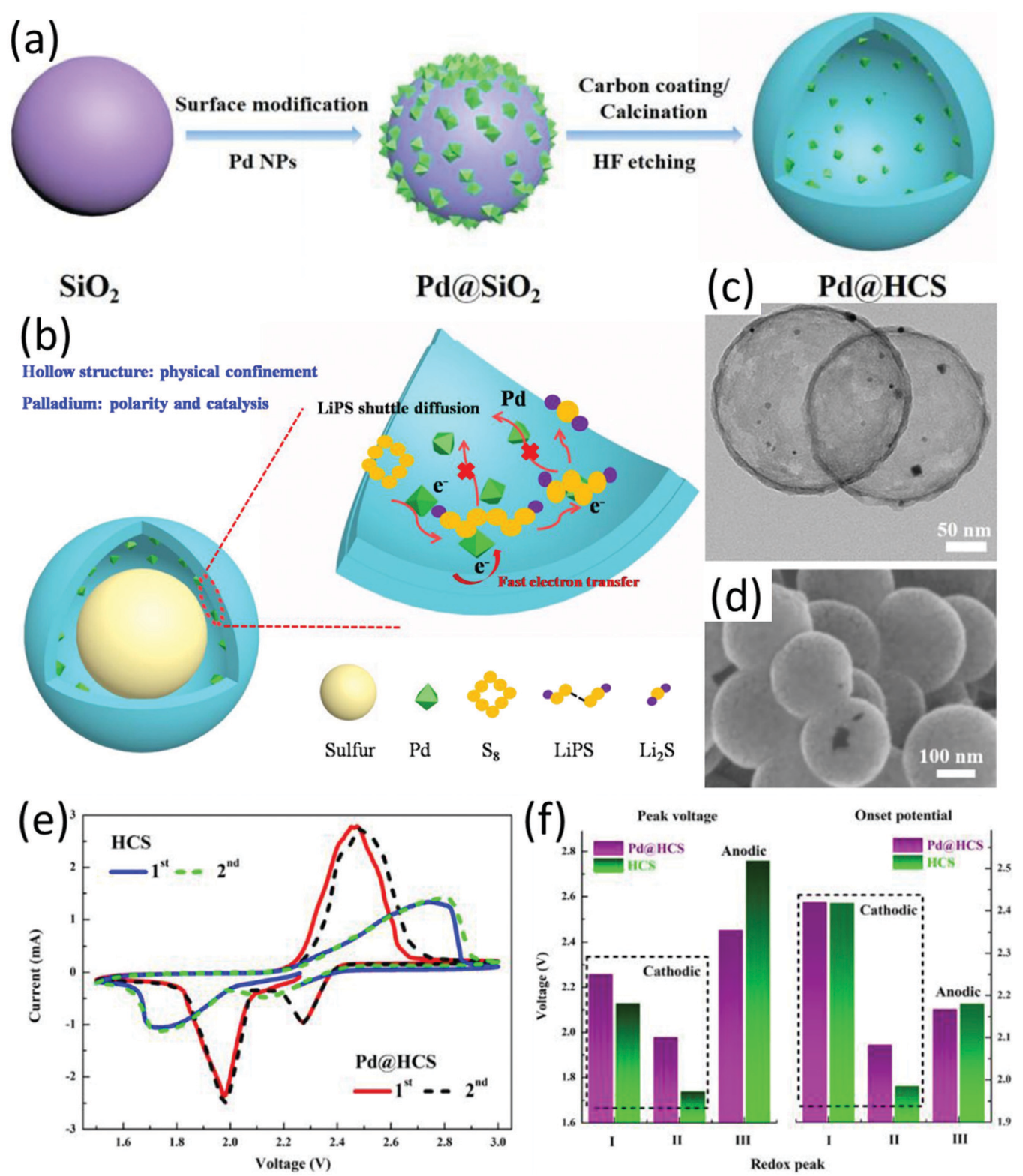

Fig. 13 (a) Schematic for the synthesis of hollow PdaHCS microspheres, (b) schematic of the hollow PdaHCS/S structure and the discharge process, (c) TEM, and (d) SEM images of Pd@HCS, (e) CV curves of the semi-liquid LSBs using $\mathrm{Li}_{2} \mathrm{~S}_{6}$ as the active material, and (f) the corresponding peak voltages and onset potentials of the asymmetrical LSBs. Reproduced with permission. ${ }^{158}$ Copyright 2019 Elsevier. 
the Pd@HCS/S cathode with a high sulfur loading of $5.88 \mathrm{mg} \mathrm{cm}$ delivered an initial capacity of $873 \mathrm{~mA} \mathrm{~h} \mathrm{~g}^{-1}$ at $0.2 \mathrm{C}$, with a capacity retention of $85 \%$ after 100 cycles.

Single-atom catalysts have attracted ever growing interest due to their potential to achieve $100 \%$ atom utilization when used as catalysts. ${ }^{159}$ By annealing Fe-ZIF-8 in an argon atmosphere, Wang et al. prepared an iron single-atom-decorated nitrogen-rich carbon nanocage (FeSA-CN). ${ }^{160}$ Using FeSA-CN as the sulfur host, the FeSA-CN/S cathode with a sulfur content of $68.7 \mathrm{wt} \%$ delivered a high capacity of $605 \mathrm{~mA} \mathrm{~h} \mathrm{~g}^{-1}$ at $4 \mathrm{C}$ and exhibited a capacity retention of $70 \%$ for 500 cycles, corresponding to a capacity decay rate of $0.06 \%$ per cycle. The cycled battery using FeSA-CN as the sulfur host presented a much smoother lithium anode. The enhanced performance was attributed to the synergetic effect of the single-atom iron catalyst and nitrogendoped carbon polyhedron. FeSA greatly facilitated the redox kinetics and thus the shuttle effect of polysulfide was mitigated. Moreover, the nitrogen-doped carbon polyhedron provided good conductivity and physical confinement to the polysulfide.

\subsection{Other inorganic metal compounds}

The conventional transition metal compounds, such as metal oxides/sulfides/nitrides, have attracted huge interest as sulfur host materials. The abundant material chemistries provide sufficient choices for sulfur hosts. Efforts to explore a wider range of materials as the sulfur host materials are desirable to further promote the performance of LSBs. There are some other inorganic hollow-structured materials, such as $\mathrm{LiFePO}_{4}$ microspheres, ${ }^{161}$ Prussian blue nanocubes, ${ }^{162}$ and metal fluoridebased hybrid hollow structures, ${ }^{163}$ reported as sulfur host materials and demonstrated some desirable properties. For example, hollow $\mathrm{LiFePO}_{4}$ microspheres (LFP) were investigated as the sulfur carrier, which suppressed the shuttle effect via chemical adsorption and catalytically promoted the redox kinetics of conversion between long-chain and short-chain polysulfides. ${ }^{161}$ Combining with holey graphene (HG), LFP enabled the corresponding sulfur electrode to exhibit a high capacity of $748 \mathrm{~mA} \mathrm{~h} \mathrm{~g}^{-1}$ at $5 \mathrm{C}$, and it maintained a capacity of $831 \mathrm{~mA} \mathrm{~h} \mathrm{~g}^{-1}$ at $1 \mathrm{C}$ after 500 cycles at a high sulfur loading of $4.3 \mathrm{mg} \mathrm{cm}^{-2}$.

Prussian blue nanocubes $\left(\mathrm{Na}_{2} \mathrm{Fe}\left[\mathrm{Fe}(\mathrm{CN})_{6}\right]\right)$ could trap polysulfide through both spatial confinement and Lewis acid-base interactions. When a conductive poly(3,4-ethylenedioxythiophene) (PEDOT) layer was coated onto $\mathrm{Na}_{2} \mathrm{Fe}\left[\mathrm{Fe}(\mathrm{CN})_{6}\right]$, a high-performance sulfur host (( $\left.\left.\mathrm{Na}_{2} \mathrm{Fe}\left[\mathrm{Fe}(\mathrm{CN})_{6}\right]\right) @ P E D O T\right)$ was obtained. ${ }^{162}$ The corresponding sulfur electrode delivered a high rate performance of $683 \mathrm{~mA} \mathrm{~h} \mathrm{~g}^{-1}$ at $5 \mathrm{C}$, which was maintained at $544 \mathrm{~mA} \mathrm{~h} \mathrm{~g}^{-1}$ after 200 cycles. In another study, a thin $\mathrm{AlF}_{3}$ layer was deposited on a core-shell sulfur-hollow carbon composite (S@HCS), generating

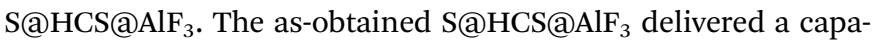
city of $702 \mathrm{~mA} \mathrm{~h} \mathrm{~g}{ }^{-1}$ after 500 cycles at $1 \mathrm{C}$, corresponding to a capacity decay rate of $0.052 \%$ per cycle. ${ }^{163}$ The inner carbon shell not only enhanced the electrode conductivity but also provided a physical barrier to the soluble polysulfide, while the outer $\mathrm{AlF}_{3}$ layer further improved the overall electrode conductivity and immobilized the polysulfide via chemical bonding.

\section{Organic hollow-structured sulfur cathodes}

\subsection{Conductive polymers}

Conductive polymers have been widely used for sulfur cathode design in LSBs, which can not only increase the electrode conductivity but also provide strong chemical adsorption to LiPSs. Hollow polymer-sulfur composites can be constructed by either encapsulating the prefabricated sulfur particle templates with various conductive polymers on the sulfur surface, or infiltrating sulfur into the prefabricated hollow-structured polymers via a melt-diffusion process.

A core-shell sulfur-polypyrrole (S-PPy) composite was prepared by coating a conductive polypyrrole layer on sulfur nanospheres. ${ }^{164}$ The spherical sulfur nanoparticles were prepared by a reaction of sodium thiosulfate and $p$-toluenesulfonic acid (pTSA). With the help of a cationic surfactant, decyltrimethylammonium bromide (DeTAB), polypyrrole could be readily nucleated and then formed a polypyrrole layer with a thickness of around $100 \mathrm{~nm}$ onto sulfur spheres. The capacity of the as-obtained S-PPy composite (sulfur content $65.8 \mathrm{wt} \%$ ) was maintained at around $600 \mathrm{~mA} \mathrm{~h} \mathrm{~g}^{-1}$ at $0.5 \mathrm{C}$ and $400 \mathrm{~mA} \mathrm{~h} \mathrm{~g}^{-1}$ at $2 \mathrm{C}$ after 50 cycles. However, SEM images revealed that sulfur spheres were not uniformly covered by the polymer layer. Another core-shell PPy encapsulated nanosized sulfur sphere (around $150 \mathrm{~nm}$ ) was prepared via a one-pot process (S@PPy, Fig. 14a). ${ }^{165}$ The nanosized sulfur spheres were firstly fabricated by the reaction of $\mathrm{Na}_{2} \mathrm{~S}$, sulfur powder and Triton X-100 solution. Then, $\mathrm{HCl}$ and $\mathrm{FeCl}_{3}$ were added sequentially into the as-formed sulfur solution, followed by washing and immersing the mixture into $\mathrm{H}_{3} \mathrm{PO}_{4}$ solution for $\mathrm{PO}_{4}{ }^{3-}$ doping. The as-prepared S@PPy with a sulfur content of $80 \mathrm{wt} \%$ (Fig. 14c) exhibited an initial discharge capacity of $1142 \mathrm{~mA} \mathrm{~h} \mathrm{~g}^{-1}$ at $0.1 \mathrm{C}$, which was maintained at $805 \mathrm{~mA} \mathrm{~h} \mathrm{~g}^{-1}$ after 50 cycles. Besides encapsulating sulfur with polymers, melt-diffusion has also been applied to prepare polymer-sulfur hollow composites. Hollow polypyrrole nanospheres (PHNS) with wrinkled, ultra-thin shell were firstly prepared through in situ polymerization of pyrrole on the surface of $\mathrm{Fe}_{3} \mathrm{O}_{4}$ nanospheres ( $\mathrm{PPy} @ \mathrm{Fe}_{3} \mathrm{O}_{4}$ ), followed by removal of the $\mathrm{Fe}_{3} \mathrm{O}_{4}$ template using $\mathrm{HCl}$ solution (Fig. 14b). ${ }^{166}$ S@PHNS composites were obtained via a melt-diffusion process. The conductive PHNS shells served as channels which enabled fast ion and electron transport, and promoted the redox reactions. Benefiting from these advantages, S@PHNS delivered a high capacity of $536.5 \mathrm{~mA} \mathrm{~h} \mathrm{~g}^{-1}$ at $5 \mathrm{C}$.

Despite the enhanced electrochemical properties, such as sulfur utilization and rate performance, it is difficult for the core-shell structure to accommodate the huge volume expansion of suflur during the lithiation process, which might lead to unsatisfactory cycling stability. Creating a yolk-shell structure with reserved interior void space is an effective way to buffer the volume change of the conversion-type electrode materials. ${ }^{69}$ Yolk-shell structured sulfur cathodes can be achieved by partially removing the inner sulfur of the core-shell structures via dissolving or thermal evaporation. A yolk-shell polyanilinesulfur composite (S-Pani) was prepared via the process shown in Fig. 14 f. $^{49}$ Instead of partially dissolving sulfur by toluene as 

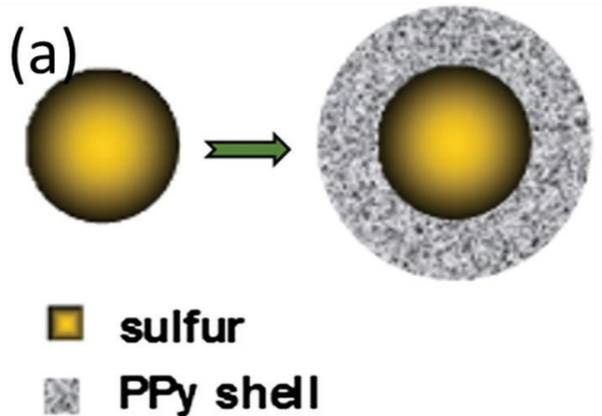
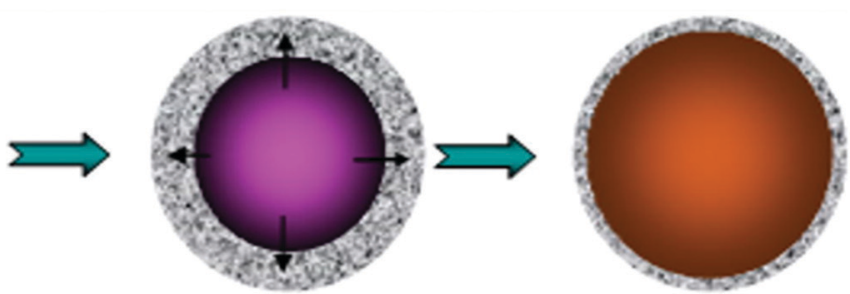

$\square$ polysulfide

\section{$\mathrm{Li}_{2} \mathrm{~S}$}
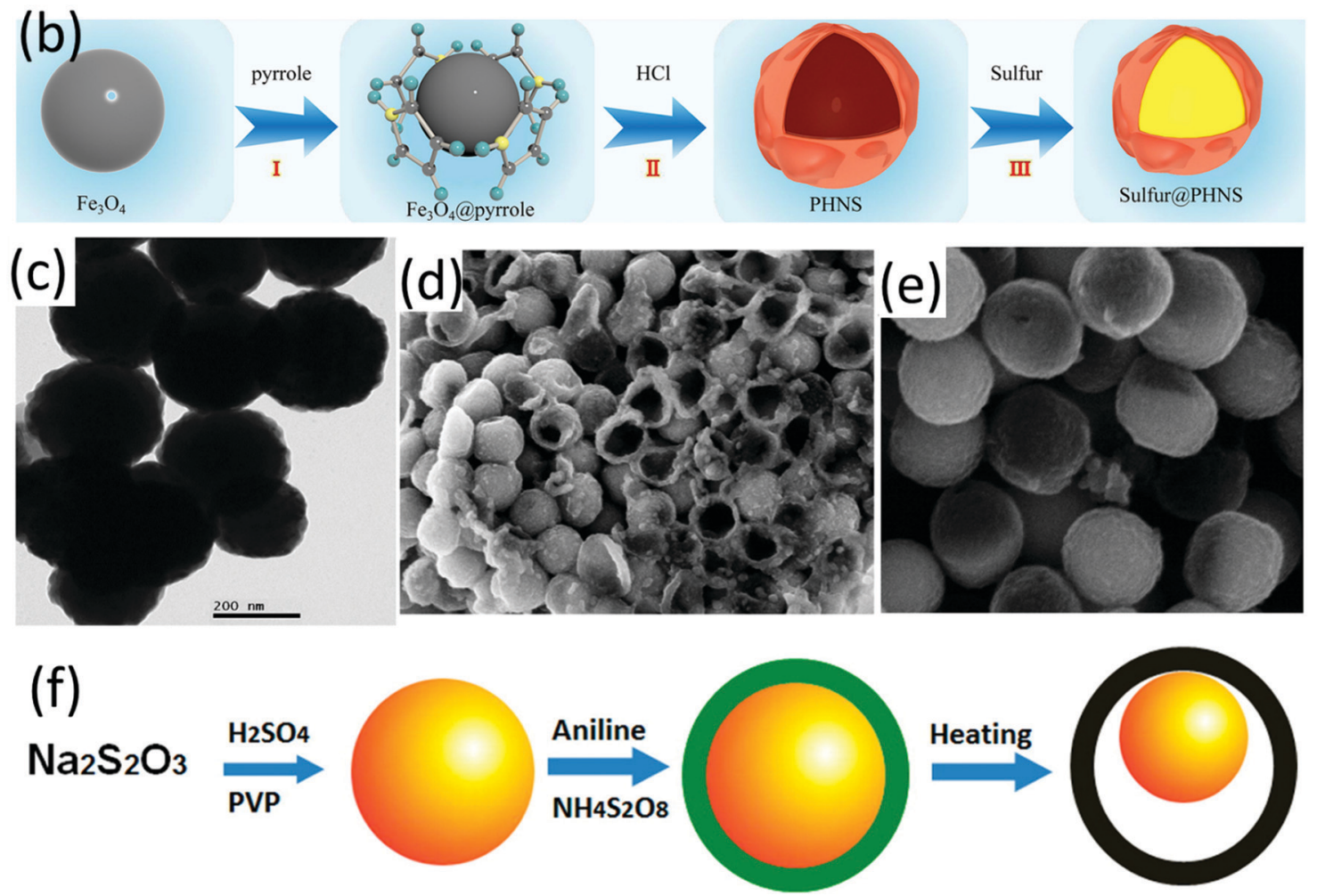

Fig. 14 (a) Schematic for the synthetic process of core-shell structured S@PPy. Reproduced with permission. ${ }^{165}$ Copyright 2016 Elsevier. (b) Schematic for the synthesis of the S@PHNS composite. Reproduced with permission. ${ }^{166}$ Copyright 2018, Elsevier. (c) TEM image of core-shell structured S@PPy. Reproduced with permission. ${ }^{165}$ Copyright 2016 Elsevier. SEM images of (d) core-shell- and (e) yolk-shell-based S-Pani composites after five cycles, (f) schematic for the two-step synthesis process of the core-shell and yolk-shell S-Pani composites. Reproduced with permission. ${ }^{49}$ Copyright 2013 American Chemical Society.

in Cui's work, ${ }^{69}$ the yolk-shell structure was created via a heat treatment. On one hand, it was found that the S-Pani core-shell was destroyed by toluene. On the other hand, the author proposed something that was worth pondering - if sulfur could leach out from the $\mathrm{TiO}_{2}$ shell via dissolving in toluene, polysulfide could leach out from the shell as it dissolved in the electrolyte. The core-shell S-Pani (sulfur content of $82 \mathrm{wt} \%$ ) based LSBs suffered from fast capacity decay with only $280 \mathrm{~mA} \mathrm{~h} \mathrm{~g}{ }^{-1}$ left after 125 cycles. In comparison, the yolk-shell s-Pani (sulfur content of $58 \mathrm{wt} \%$ ) based electrodes exhibited a high capacity of $765 \mathrm{~mA} \mathrm{~h}^{-1}$ after 200 cycles at $0.2 \mathrm{C}$, corresponding to a capacity retention of $69.5 \%$. The SEM images of the cycled sulfur electrode revealed that about half of the core-shell S-Pani particles were either broken or shrunk (Fig. 14d), while the yolk-shell S-Pani particles were well preserved (Fig. 14e). These results suggested that void space in the yolk-shell structure was essential for long-term cycling stability. Despite the overwhelming cycling stability of the yolk-shell S-Pani based LSB over that of core-shell, it is unreasonable to attribute all these achievements to the yolkshell structure, considering different sulfur contents in these two systems ( $82 \mathrm{wt} \%$ vs. $69.5 \mathrm{wt} \%$ ). As is known, sulfur contents can greatly affect the battery performance.

\subsection{Organic-frameworks}

Owing to the high specific area and tuneable pore sizes, porous aromatic frameworks (PAFs) and metal organic frameworks (MOFs) have gained intensive research interest and have been applied in a wide spectrum of areas. ${ }^{167,168}$ However, due to their low conductivity, both PAFs and MOFs are typically considered not suitable for sulfur host materials. Despite the shortfall of 
low conductivity, the confining effect of the porous structure and the strong Lewis acid-base interaction between LiPSs and MOFs endowed them with the potential as efficient sulfur host. ${ }^{169-171}$ Instead of being used as the sacrifice template for the preparation of hollow structures, hollow ZIF-67 was applied as the sulfur carrier, considering the strong Lewis acid-base bonding between $\mathrm{Co}^{2+}$ and $\mathrm{S}^{2-}$. To increase the conductivity, the ZIF-67-S composite was coated with PPy through a water-phase chemical oxidative polymerization process (ZIF-67-S-PPy). ${ }^{172}$ The fabrication is as shown in Fig. 15a. The ZIF-67-S-PPy composite with a sulfur content of $60 \mathrm{wt} \%$ (Fig. 15b and c) achieved the best performance among various control samples, with an initial capacity of $1092.5 \mathrm{~mA} \mathrm{~h} \mathrm{~g}^{-1}$ and $353.6 \mathrm{~mA} \mathrm{~h} \mathrm{~g}^{-1}$ remained after 200 cycles. Although the performance is not as impressive as many other reports, this work provides some guidance for constructing conductive hollow MOF-based composites for sulfur hosts. Considering the rich chemistries of the MOF family, more efforts on applying MOFs as sulfur host materials may bring some new findings. As an emerging family of advanced materials, organic frameworks have gained increasing interest. Using polystyrene (PS) microspheres as sacrificial templates, porphyrin organic framework hollow spheres (POF-HSs) with regulated shell thickness and void size were prepared and used as a sulfur host (Fig. 15f and g). ${ }^{173}$ Owing to polar POF shells and a hollow architecture, POF-HSs exhibited strong LiPS adsorption ability (Fig. 15d). Benefiting from dual chemical adsorption and physical confinement of POF-HSs, the shuttle effect of LSBS was efficiently suppressed, leading to a superior rate performance with a high capacity of $800 \mathrm{~mA} \mathrm{~h} \mathrm{~g}^{-1}$ at 4C (Fig. 15d), and stable cycling performance with $773 \mathrm{~mA} \mathrm{~h} \mathrm{~g}{ }^{-1}$ remained after 200 cycles at $0.5 \mathrm{C}$. The enhanced performance of the POF-HS based LSB suggests that organic framework engineering is an applicable approach for the preparation of efficient sulfur host materials.
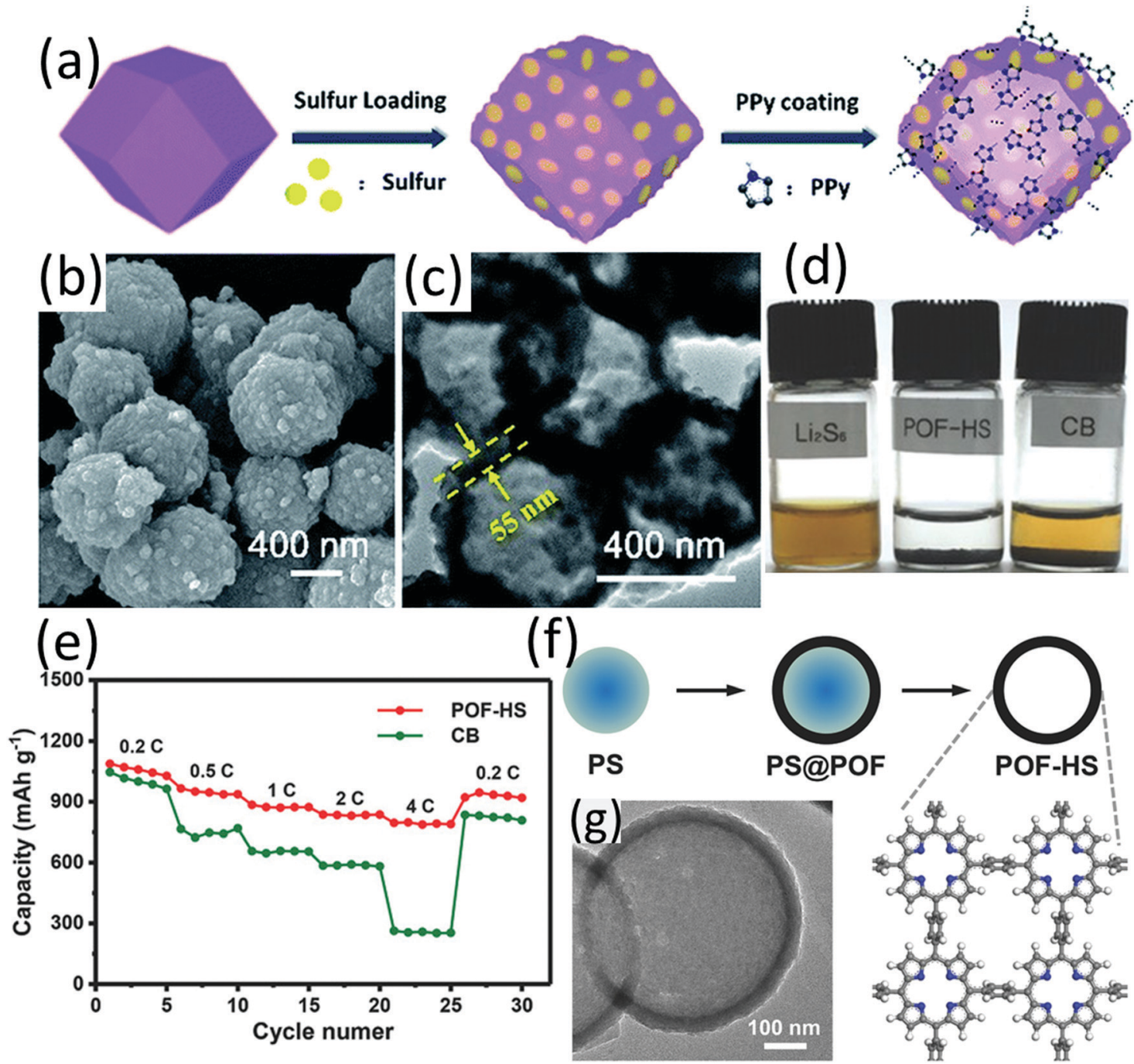

Fig. 15 (a) Schematic for the synthesis of ZIF-67-S-PPy, (b) SEM, and (c) TEM images of ZIF-67-S-PPy. Reproduced with permission. ${ }^{172}$ Copyright 2019 the Royal Society of Chemistry. (d) Visualized adsorption test of polysulfides (after $24 \mathrm{~h}$ ) using POF-HS or CB as the adsorbents, (e) rate performance of POF-HS/S and CB/S cathodes, (f) schematic for the preparation of POF-HSs, (g) TEM image of the hollow spherical POF-HS. Reproduced with permission. ${ }^{173}$ Copyright 2018 Wiley-VCH. 


\section{Summary and perspectives}

The design of sulfur hosts relies on the knowledge of materials chemistry and nanostructure engineering. In brief, from the materials chemistry perspective, good electric conductivity, strong polysulfide interactions and efficient electrocatalytic activity are the key requirements; and from the nanostructure engineering angle, creating suitable porosity and void space to accommodate $\mathrm{S}_{8} / \mathrm{Li}_{2} \mathrm{~S}$, to buffer volume expansion and confine polysulfide, are critical. Because the hollow-structured materials possess a high specific surface area and tunable pore structure, and their morphology and composition are highly controllable, they have shown great potential to undertake the role of sulfur hosts in the cathode of LSBs.

In this review, we have summarised the recent advances in the design of hollow-structured sulfur cathodes for LSBs. In particular, hollow structures containing polar materials including inorganic or organic compounds and their hybrids with hollow carbons are highlighted by analysing their synthesis methods, structures and electrochemical performance in LSBs. Carbon hollow structured materials show high sulfur utilization and cycling performance due to the physical confinement of the pore channels; however, the nonpolar carbon surface is not efficient to immobilize LiPSs for long-term cycling. In contrast, inorganic or organic hollow structures including metal oxides, sulfides, nitrides, carbides, phosphides, hydroxides, conductive polymers and organic frameworks show a better ability to anchor polysulfides due to the strong interaction between polar surfaces and LiPSs, and a higher electrocatalytic activity for the sulfur conversion reactions. Nevertheless, some of these inorganic/organic compounds face the issue of low conductivity or/and the difficulty in fabricating the hollow structure. Hybrid hollow structures integrating carbonaceous conductive frameworks with inorganic/organic polar species have provided a variety of solutions to tackle the above-mentioned issue. A comparison of some representative hollow-structured sulfur cathodes is summarised in Table 1 . At the early stage when carbon materials were predominantly used as sulfur hosts, to improve the performance of LSBs, research effort was mainly focused on optimizing the geometrical structures of the host, such as the porosity, pore size distribution, pore volume, specific surface area, and the ratio between sulfur and the host. ${ }^{28}$ For example, when the pores of carbon materials are small enough to confine small sulfur molecules, the cycling stability of LSBs can be significantly improved owing to the direct solid-solid reaction without generating soluble LiPSs. ${ }^{174-176}$ Once the sulfur content exceeded the pore volume of the host materials, the performance of LSBs degenerated quickly. Xiao et al. reported that

Table 1 Comparison of representative hollow-structured sulfur electrodes

\begin{tabular}{|c|c|c|c|c|c|c|c|}
\hline A & B & $\mathrm{C}$ & $\mathrm{D}$ & $\mathrm{E}$ & $\mathrm{F}$ & G & $\mathrm{H}$ \\
\hline Yolk-shell S-MnO ${ }_{2}$ & Nano-S template & 80 & 64 & 1.5 & $\mathrm{n} / \mathrm{a}$ & $315 / 1700 / 2.0$ & 55 \\
\hline Core-shell $\mathrm{S} / \gamma \mathrm{MnO}_{2}$ & Nano-S template & 61 & 43 & 2 & $\mathrm{n} / \mathrm{a}$ & $374 / 400 / 2.0$ & 59 \\
\hline $\mathrm{MnO}_{2}$ nanospheres ${ }^{a}$ & Melt-diffusion & 71 & 0.50 & 1.2 & 15 & $721 / 500 / 1.0$ & 60 \\
\hline Hollow C nanofibers- $\mathrm{MnO}_{2}$ & Melt-diffusion & 71 & 0.50 & 3.5 & $\mathrm{n} / \mathrm{a}$ & $662 / 300 / 0.5$ & 61 \\
\hline $\mathrm{C} / \mathrm{MnO}_{2}$ hollow nanofibers & Melt-diffusion & 70 & 49 & 2.5 & 24 & $629 / 300 / 1.0$ & 63 \\
\hline Core-shell C@@ $\mathrm{MnO}_{2}$ & Melt-diffusion & 58 & 41 & 3.0 & 19 & $550 / 500 / 1.0$ & 64 \\
\hline Yolk-shell S-TiO ${ }_{2}$ & Nano-S template & 71 & 53 & $0.4-0.6$ & $\mathrm{n} / \mathrm{a}$ & $690 / 1000 / 0.5$ & 69 \\
\hline $\mathrm{TiO}_{2}$ microboxes & Melt-diffusion & 70 & 48 & 1.0 & $\mathrm{n} / \mathrm{a}$ & $626 / 500 / 1.0$ & 71 \\
\hline Multi-shelled hollow $\mathrm{TiO}_{2-x}$ & Melt-diffusion & 56 & 39 & 0.5 & $\mathrm{n} / \mathrm{a}$ & $713 / 1000 / 0.5$ & 70 \\
\hline $\mathrm{TiO}_{2} @$ hollow C sphere & Melt-diffusion & 70 & 56 & 1.5 & $\mathrm{n} / \mathrm{a}$ & $630 / 500 / 0.5$ & 79 \\
\hline TiO-C hollow fiber & Vapor phase infusion & 73 & 58 & 5.0 & $\mathrm{n} / \mathrm{a}$ & $680 / 400 / 0.2$ & 80 \\
\hline Hollow $\mathrm{CoS}_{2} @ N$-doped Carbon & Melt-diffusion & 75 & $\mathrm{n} / \mathrm{a}$ & $\sim 1.3$ & $\mathrm{n} / \mathrm{a}$ & $519 / 300 / 1.0$ & 94 \\
\hline $\mathrm{Co}_{3} \mathrm{~S}_{4}$ nanotubes & Melt-diffusion & 74 & 59 & $\sim 2$ & $40 \mu \mathrm{L}$ per cell & $305 / 1000 / 5.0$ & 98 \\
\hline CNTs threaded hollow $\mathrm{Co}_{3} \mathrm{~S}_{4}$ nanoboxes & $\mathrm{CS}_{2}$ dissolution, melt-diffusion + evaporation & $\begin{array}{l}70 \\
70\end{array}$ & $\begin{array}{l}49 \\
56\end{array}$ & 3.5 & 15 & $820 / 150 / 0.2$ & 100 \\
\hline $\mathrm{CNT} / \mathrm{Co}_{3} \mathrm{~S}_{4} \mathrm{~N}$-doped carbon nanocubes & Melt-diffusion + evaporation & 74 & 74 & 7.4 & 10 & $810 / 1000 / 5.0$ & 101 \\
\hline $\mathrm{Co}_{9} \mathrm{~S}_{8}$ tubules & Melt-diffusion $\mathrm{CS}_{2}$ dissolution & 70 & 52 & $\mathrm{n} / \mathrm{a}$ & $\mathrm{n} / \mathrm{a}$ & $894 / 600 / 1.0$ & 105 \\
\hline $\mathrm{Co}_{9} \mathrm{~S}_{8}$-hollow C-polyhedra & $\mathrm{CS}_{2}$ dissolution + melt diffusion + evaporation & 77 & 32 & 3.0 & $15 \mu \mathrm{L}$ per cell & $680 / 300 / 0.5$ & 178 \\
\hline $\mathrm{Co}-\mathrm{NC} @ \mathrm{Co}_{9} \mathrm{~S}_{8} / \mathrm{NPC}^{b}$ & $\mathrm{CS}_{2}$ dissolution + melt-diffusion + evaporation & 75 & 60 & 4.5 & 10 & $607 / 500 / 1.0$ & 107 \\
\hline NiS-hollow carbon spheres & Melt-diffusion & 72 & 50 & 1.0 & 20 & $695 / 300 / 0.5$ & 108 \\
\hline $1 \mathrm{~T}-\mathrm{MoS}_{2}$ nanotube-N-doped graphene & Melt-diffusion & 80 & 64 & 5.2 & $\mathrm{n} / \mathrm{a}$ & $629 / 100 / 0.2$ & 110 \\
\hline Hollow porous TiN tubes & Melt-diffusion & 74 & 52 & 1.0 & $\mathrm{n} / \mathrm{a}$ & $840 / 450 / 0.5$ & 129 \\
\hline Porous-shell VN nanobubbles & Melt-diffusion + evaporation & 78 & 62 & 5.4 & $\mathrm{n} / \mathrm{a}$ & $799 / 200 / 0.5$ & 131 \\
\hline Co-doped VN yolk-shell & Melt-diffusion & 70 & 49 & 4.1 & $\mathrm{n} / \mathrm{a}$ & $830 / 100 / 0.2$ & 132 \\
\hline $\mathrm{MoSe}_{2} @ \mathrm{FC} @ \mathrm{Mo}_{2} \mathrm{C}^{c}$ & Melt-diffusion + evaporation & 72 & 50 & 5.5 & 5 & $688 / 1000 / 2.0$ & 136 \\
\hline Hollow $\mathrm{Fe}_{3} \mathrm{C}-\mathrm{N}$-doped carbon & Melt-diffusion & 70 & 56 & 1.5 & $\mathrm{n} / \mathrm{a}$ & $586 / 400 / 0.5$ & 137 \\
\hline $\mathrm{Ni}_{2} \mathrm{P}$ yolk-shell & Melt-diffusion + evaporation & 65 & 52 & $\mathrm{n} / \mathrm{a}$ & $\mathrm{n} / \mathrm{a}$ & $394 / 1000 / 5.0$ & 141 \\
\hline $\mathrm{Ni} / \mathrm{Fe} \mathrm{LDH}$ hollow polyhedron & Melt-diffusion & 70 & 49 & $2-3$ & 30 & $501 / 1000 / 1.0$ & 152 \\
\hline$\alpha-\mathrm{Ni}(\mathrm{OH})_{2}$ hollow spheres & Nano-S template & 81 & 57 & 2.2 & $\mathrm{n} / \mathrm{a}$ & $422 / 1000 / 1.0$ & 153 \\
\hline Co-N-doped hollow carbon & Melt-diffusion & 70 & 49 & 2.0 & $35 \mu \mathrm{L}$ per cell & $625 / 500 / 1.0$ & 154 \\
\hline Pd-hollow carbon & $\mathrm{CS}_{2}$ dissolution and melt-diffusion & 76 & 57 & 5.88 & 15 & $742 / 100 / 0.2$ & 158 \\
\hline
\end{tabular}

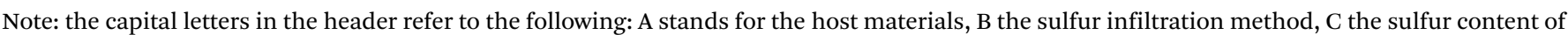

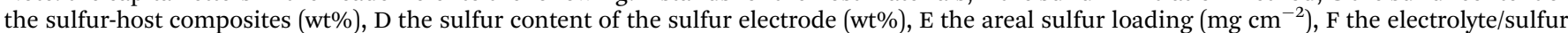

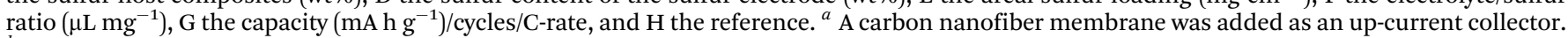

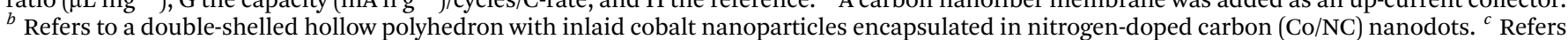
to $\mathrm{MoSe}_{2}$ and $\mathrm{Mo}_{2} \mathrm{C}$ encapsulated into hollow F-doped carbon fibres. 
hollow carbon spheres with a pore size of $2.8 \mathrm{~nm}$ exhibited better sulfur impregnation than those with a pore size of $4.1 \mathrm{~nm}$ and $3.2 \mathrm{~nm} .{ }^{177}$ Nazar et al. demonstrated that an improved cycling stability of LSBs could be achieved via deliberately controlling the shell porosity of the hollow carbon spheres. ${ }^{67}$ Differently, the rational design of polar hollow-structured composites has mainly focused on materials' chemistry, such as chemical interactions between the host and LiPSs and the catalytic effect on the redox reactions, when the physical confinement of the hollow structure is usually taken for granted with a few efforts on further optimization of the geometrical properties. The performance of LSBs is supposed to be further improved via optimizing both the geometrical and chemical properties of the hollow-structured sulfur cathode. ${ }^{70,151}$

Despite the impressive electrochemical performance enabled by using a wide range of advanced hollow structures as sulfur hosts, there is still a long way to go to commercialize LSBs. In terms of hollow-structured material design and preparation, cost-effective, eco-friendly and scalable fabrication methodologies are highly desirable and need more research efforts in the future. As is known, the well-controlled fabrication process in laboratory, which leads to delicate nanoarchitectures, might not work in an industry-scale production. Thus, the reproducibility of the promoted battery performance achieved at the laboratory scale remains a concern, when the materials are scaled up to the industry level. ${ }^{179}$ Besides, the cost of raw materials and the delicate synthesis procedures are generally not a problem in academic research, while these remain another concern for practical applications. Similar to catalysts used in industry, long-term stability of the sulfur host is an important criterion to evaluate their performance, and thus the characterization of the sulfur hosts after long-term electrochemical cycling is essential. Battery is an application-driven technology, and thus, it is essential to keep the criteria for practical application in mind for the design of sulfur hosts and evaluation of battery performance. ${ }^{180}$

From the aspect of performance evaluation, to achieve high performance LSBs with both energy density and cost superior to those of the state-of-the-art LIBs, the sulfur content and mass loading, the electrolyte to sulfur ratio, and the amount of lithium anode have to be strictly controlled. ${ }^{181,182}$ Although there is a growing number of research papers presenting these parameters, the lack of standard LSB systems makes it difficult to achieve a reasonable, comprehensive, and convenient comparison of various home-made systems. Without a standard system, the merits of some specific components may be overstated at the cost of other properties. For example, LSBs with low sulfur content, using a flooded electrolyte and an overdose of lithium at the anode could still achieve high specific capacity. A standard LSB can not only make the real good ones stand out and the shortfalls visible, but also act as a lighthouse to provide a practical direction for the research community. Moreover, most of the studies only demonstrated the champion performance. It is widely known that LSBs are very sensitive to the fabrication and testing conditions, and hence it is hard to make a conclusion that some specific optimization works according to a single impressive battery. In this regard, to make a more reasonable conclusion, the statistic distribution of the performance of a batch cell is required.

Lastly, as mentioned above, the sulfur cathode, lithium anode, electrolyte and the separator all play critical roles in the battery operation. The research efforts have predominantly focused on the cathode parts. Despite the growing research work on the other components, such as solid-state electrolytes and lithium metal anodes, research on the entire LSB systems is still lacking. ${ }^{183-186}$ Furthermore, the interplay of different components has not yet been well understood. LSBs are a complicated system, and a step closer to practical application of LSBs may lie in the incorporation of the advances in different components, and a better understanding of the interplay among them.

\section{Conflicts of interest}

There are no conflicts to declare.

\section{References}

1 M. Li, J. Lu, Z. Chen and K. Amine, 30 years of lithium-ion batteries, Adv. Mater., 2018, 30, 1800561.

2 V. Kolosnitsyn and E. Karaseva, Lithium-sulfur batteries: Problems and solutions, Russ. J. Electrochem., 2008, 44, 506-509.

3 J. Janek and W. G. Zeier, A solid future for battery development, Nat. Energy, 2016, 1, 1-4.

4 Z. P. Cano, D. Banham, S. Ye, A. Hintennach, J. Lu, M. Fowler and Z. Chen, Batteries and fuel cells for emerging electric vehicle markets, Nat. Energy, 2018, 3, 279-289.

5 L. Grande, E. Paillard, J. Hassoun, J. B. Park, Y. J. Lee, Y. K. Sun, S. Passerini and B. Scrosati, The lithium/air battery: still an emerging system or a practical reality?, $A d v$. Mater., 2015, 27, 784-800.

6 S. H. Chung and A. Manthiram, Current status and future prospects of metal-sulfur batteries, Adv. Mater., 2019, 31, 1901125.

7 J. Muldoon, C. B. Bucur and T. Gregory, Quest for nonaqueous multivalent secondary batteries: magnesium and beyond, Chem. Rev., 2014, 114, 11683-11720.

8 P. G. Bruce, S. A. Freunberger, L. J. Hardwick and J.-M. Tarascon, Li-O 2 and $\mathrm{Li}-\mathrm{S}$ batteries with high energy storage, Nat. Mater., 2012, 11, 19-29.

9 H. Danuta, U. Juliusz, D. Herbert and J. Ulam, Electric dry cells and storage batteries, US Pat., 3043896, 1962.

10 H. Yamin, J. Penciner, A. Gorenshtain, M. Elam and E. Peled, The electrochemical behavior of polysulfides in tetrahydrofuran, J. Power Sources, 1985, 14, 129-134.

$11 \mathrm{H}$. Yamin and E. Peled, Electrochemistry of a nonaqueous lithium/sulfur cell, J. Power Sources, 1983, 9, 281-287.

12 Z. W. Seh, Y. Sun, Q. Zhang and Y. Cui, Designing highenergy lithium-sulfur batteries, Chem. Soc. Rev., 2016, 45, 5605-5634. 
13 A. Manthiram, Y. Fu, S.-H. Chung, C. Zu and Y.-S. Su, Rechargeable lithium-sulfur batteries, Chem. Rev., 2014, 114, 11751-11787.

14 X. Ji, K. T. Lee and L. F. Nazar, A highly ordered nanostructured carbon-sulphur cathode for lithium-sulphur batteries, Nat. Mater., 2009, 8, 500-506.

15 Z. Li, Y. Huang, L. Yuan, Z. Hao and Y. Huang, Status and prospects in sulfur-carbon composites as cathode materials for rechargeable lithium-sulfur batteries, Carbon, 2015, 92, 41-63.

16 Q. Pang, X. Liang, C. Y. Kwok and L. F. Nazar, Advances in lithium-sulfur batteries based on multifunctional cathodes and electrolytes, Nat. Energy, 2016, 1, 1-11.

17 Z. Zeng and X. Liu, Sulfur immobilization by "chemical anchor" to suppress the diffusion of polysulfides in lithiumsulfur batteries, Adv. Mater. Interfaces, 2018, 5, 1701274.

18 J. Xu, T. Lawson, H. Fan, D. Su and G. Wang, Updated Metal Compounds (MOFs, S, OH, N, C) Used as Cathode Materials for Lithium-Sulfur Batteries, Adv. Energy Mater., 2018, 8, 1702607.

19 Y. Wang, X. Huang, S. Zhang and Y. Hou, Sulfur hosts against the shuttle effect, Small Methods, 2018, 2, 1700345.

20 W. Ren, W. Ma, S. Zhang and B. Tang, Recent advances in shuttle effect inhibition for lithium sulfur batteries, Energy Storage Mater., 2019, 23, 707-732.

21 T. Tang and Y. Hou, Chemical Confinement and Utility of Lithium Polysulfides in Lithium Sulfur Batteries, Small Methods, 2019, 1900001.

22 D. Liu, C. Zhang, G. Zhou, W. Lv, G. Ling, L. Zhi and Q. H. Yang, Catalytic effects in lithium-sulfur batteries: promoted sulfur transformation and reduced shuttle effect, $A d v$. Sci., 2018, 5, 1700270.

23 H. Al Salem, G. Babu, C. V. Rao and L. M. R. Arava, Electrocatalytic polysulfide traps for controlling redox shuttle process of Li-S batteries, J. Am. Chem. Soc., 2015, 137, 11542-11545.

24 W. G. Lim, S. Kim, C. Jo and J. Lee, A comprehensive review of materials with catalytic effects in Li-S batteries: enhanced redox kinetics, Angew. Chem., Int. Ed., 2019, 58, 18746-18757.

25 J. Park, S.-H. Yu and Y.-E. Sung, Design of structural and functional nanomaterials for lithium-sulfur batteries, Nano Today, 2018, 18, 35-64.

26 J. Zhang, H. Huang, J. Bae, S. H. Chung, W. Zhang, A. Manthiram and G. Yu, Nanostructured host materials for trapping sulfur in rechargeable Li-S batteries: structure design and interfacial chemistry, Small Methods, 2018, 2, 1700279.

27 M. Jana, R. Xu, X.-B. Cheng, J. S. Yeon, J. M. Park, J.-Q. Huang, Q. Zhang and H. S. Park, Rational design of two-dimensional nanomaterials for lithium-sulfur batteries, Energy Environ. Sci., 2020, 13, 1049-1075.

28 Z. Li, H. B. Wu and X. W. D. Lou, Rational designs and engineering of hollow micro-/nanostructures as sulfur hosts for advanced lithium-sulfur batteries, Energy Environ. Sci., 2016, 9, 3061-3070.
29 J. Wang, Y. Cui and D. Wang, Design of hollow nanostructures for energy storage, conversion and production, Adv. Mater., 2019, 31, 1801993.

30 J. Zhao, M. Yang, N. Yang, J. Wang and D. Wang, Hollow Micro-/Nanostructure Reviving Lithium-sulfur Batteries, Chem. Res. Chin. Univ., 2020, 36, 313-319.

31 Q. Sun, B. He, X.-Q. Zhang and A.-H. Lu, Engineering of Hollow Core-Shell Interlinked Carbon Spheres for Highly Stable Lithium-Sulfur Batteries, ACS Nano, 2015, 9, 8504-8513.

32 Z. Yu, M. Liu, D. Guo, J. Wang, X. Chen, J. Li, H. Jin and Z. Yang, X. a. Chen and S. Wang, Radially Inwardly Aligned Hierarchical Porous Carbon for Ultra-Long-Life LithiumSulfur Batteries, Angew. Chem., Int. Ed., 2020, 59, 6406-6411.

33 J. Zang, T. An, Y. Dong, X. Fang, M. Zheng, Q. Dong and N. Zheng, Hollow-in-hollow carbon spheres with hollow foam-like cores for lithium-sulfur batteries, Nano Res., 2015, 8, 2663-2675.

34 Y. Zhong, Q. Lu, Y. Zhu, Y. Zhu, W. Zhou, S. Wang and Z. Shao, Fructose-Derived Hollow Carbon Nanospheres with Ultrathin and Ordered Mesoporous Shells as Cathodes in Lithium-Sulfur Batteries for Fast Energy Storage, $A d v$. Sustainable Syst., 2017, 1, 1700081.

35 C. Zhang, H. B. Wu, C. Yuan, Z. Guo and X. W. Lou, Confining Sulfur in Double-Shelled Hollow Carbon Spheres for Lithium-Sulfur Batteries, Angew. Chem., Int. Ed., 2012, 51, 9592-9595.

36 N. Jayaprakash, J. Shen and S. S. Moganty, A. Corona and L. A. Archer, Porous Hollow Carbon@Sulfur Composites for High-Power Lithium-Sulfur Batteries, Angew. Chem., Int. Ed., 2011, 50, 5904-5908.

37 W. Zhou, C. Wang, Q. Zhang, H. D. Abruña, Y. He, J. Wang, S. X. Mao and X. Xiao, Tailoring pore size of nitrogendoped hollow carbon nanospheres for confining sulfur in lithium-sulfur batteries, Adv. Energy Mater., 2015, 5, 1401752.

38 M. Zhang, C. Yu, C. Zhao, X. Song, X. Han, S. Liu, C. Hao and J. Qiu, Cobalt-embedded nitrogen-doped hollow carbon nanorods for synergistically immobilizing the discharge products in lithium-sulfur battery, Energy Storage Mater., 2016, 5, 223-229.

39 A. Fu, C. Wang, F. Pei, J. Cui, X. Fang and N. Zheng, Recent advances in hollow porous carbon materials for lithiumsulfur batteries, Small, 2019, 15, 1804786.

40 M. Barghamadi, A. S. Best, A. I. Bhatt, A. F. Hollenkamp, M. Musameh, R. J. Rees and T. Rüther, Lithium-sulfur batteries-the solution is in the electrolyte, but is the electrolyte a solution?, Energy Environ. Sci., 2014, 7, 3902-3920.

41 Y.-S. Su, Y. Fu, T. Cochell and A. Manthiram, A strategic approach to recharging lithium-sulphur batteries for long cycle life, Nat. Commun., 2013, 4, 1-8.

42 L. Kong, H.-J. Peng, J.-Q. Huang, W. Zhu, G. Zhang, Z.-W. Zhang, P.-Y. Zhai, P. Sun, J. Xie and Q. Zhang, Beaver-damlike membrane: a robust and sulphifilic $\mathrm{MgBO} 2(\mathrm{OH}) / \mathrm{CNT} /$ PP nest separator in Li-S batteries, Energy Storage Mater., 2017, 8, 153-160.

43 H. Pan, J. Chen, R. Cao, V. Murugesan, N. N. Rajput, K. S. Han, K. Persson, L. Estevez, M. H. Engelhard and 
J.-G. Zhang, Non-encapsulation approach for high-performance Li-S batteries through controlled nucleation and growth, Nat. Energy, 2017, 2, 813-820.

44 D. Lin, Y. Liu and Y. Cui, Reviving the lithium metal anode for high-energy batteries, Nat. Nanotechnol., 2017, 12, 194-206.

45 X. Zhang, A. Wang, X. Liu and J. Luo, Dendrites in lithium metal anodes: suppression, regulation, and elimination, Acc. Chem. Res., 2019, 52, 3223-3232.

46 S. Zhang, K. Ueno, K. Dokko and M. Watanabe, Recent advances in electrolytes for lithium-sulfur batteries, $A d v$. Energy Mater., 2015, 5, 1500117.

47 S. Chen, X. Han, J. Luo, J. Liao, J. Wang, Q. Deng, Z. Zeng and S. Deng, In situ transformation of LDH into hollow cobalt-embedded and N-doped carbonaceous microflowers as polysulfide mediator for lithium-sulfur batteries, Chem. Eng. J., 2020, 385, 123457.

48 B. Meyer, Elemental sulfur, Chem. Rev., 1976, 76, 367-388. 49 W. Zhou, Y. Yu, H. Chen, F. J. DiSalvo and H. C. D. Abruña, Yolk-shell structure of polyaniline-coated sulfur for lithiumsulfur batteries, J. Am. Chem. Soc., 2013, 135, 16736-16743.

50 R. G. Chaudhuri and S. Paria, Synthesis of sulfur nanoparticles in aqueous surfactant solutions, J. Colloid Interface Sci., 2010, 343, 439-446.

51 Y. Guo, J. Zhao, S. Yang, K. Yu, Z. Wang and H. Zhang, Preparation and characterization of monoclinic sulfur nanoparticles by water-in-oil microemulsions technique, Powder Technol., 2006, 162, 83-86.

52 G. Zhou, H. Tian, Y. Jin, X. Tao, B. Liu, R. Zhang, Z. W. Seh, D. Zhuo, Y. Liu and J. Sun, Catalytic oxidation of Li2S on the surface of metal sulfides for Li-S batteries, Proc. Natl. Acad. Sci. U. S. A., 2017, 114, 840-845.

53 X. Liang, C. Hart, Q. Pang, A. Garsuch, T. Weiss and L. F. Nazar, A highly efficient polysulfide mediator for lithium-sulfur batteries, Nat. Commun., 2015, 6, 1-8.

54 A. N. Arias, A. Y. Tesio and V. Flexer, Non-Carbonaceous Materials as Cathodes for Lithium-Sulfur Batteries, J. Electrochem. Soc., 2018, 165, A6119.

55 X. Liang and L. F. Nazar, In Situ Reactive Assembly of Scalable Core-Shell Sulfur- $\mathrm{MnO}_{2}$ Composite Cathodes, ACS Nano, 2016, 10, 4192-4198.

56 K. Kim, P. J. Kim, J. P. Youngblood and V. G. Pol, Surface Functionalization of Carbon Architecture with Nano-MnO2 for Effective Polysulfide Confinement in Lithium-Sulfur Batteries, ChemSusChem, 2018, 11, 2375-2381.

57 X. Zhao, H. Wang, G. Zhai and G. Wang, Facile Assembly of 3D Porous Reduced Graphene Oxide/Ultrathin MnO2 Nanosheets-S Aerogels as Efficient Polysulfide Adsorption Sites for High-Performance Lithium-Sulfur Batteries, Chem. - Eur. J., 2017, 23, 7037-7045.

58 J. Liu, C. Wang, B. Liu, X. Ke, L. Liu, Z. Shi, H. Zhang and Z. Guo, Rational synthesis of $\mathrm{MnO}$ @ $\mathrm{CMK} / \mathrm{S}$ composite as cathode materials for lithium-sulfur batteries, Mater. Lett., 2017, 195, 236-239.

59 L. Ni, Z. Wu, G. Zhao, C. Sun, C. Zhou, X. Gong and G. Diao, Core-Shell Structure and Interaction Mechanism of $\gamma-\mathrm{MnO}_{2}$ Coated Sulfur for Improved Lithium-Sulfur Batteries, Small, 2017, 13, 1603466.

60 S. Tu, X. Zhao, M. Cheng, P. Sun, Y. He and Y. Xu, Uniform Mesoporous MnO2 Nanospheres as a Surface Chemical Adsorption and Physical Confinement Polysulfide Mediator for Lithium-Sulfur Batteries, ACS Appl. Mater. Interfaces, 2019, 11, 10624-10630.

61 Z. Li, J. Zhang and X. W. Lou, Hollow carbon nanofibers filled with $\mathrm{MnO} 2$ nanosheets as efficient sulfur hosts for lithiumsulfur batteries, Angew. Chem., Int. Ed., 2015, 54, 12886-12890.

62 S. Rehman, T. Tang, Z. Ali, X. Huang and Y. Hou, Integrated design of MnO2@ carbon hollow nanoboxes to synergistically encapsulate polysulfides for empowering lithium sulfur batteries, Small, 2017, 13, 1700087.

63 L. Ni, G. Zhao, Y. Wang, Z. Wu, W. Wang, Y. Liao, G. Yang and G. Diao, Coaxial Carbon/MnO2 Hollow Nanofibers as Sulfur Hosts for High-Performance Lithium-Sulfur Batteries, Chem. - Asian J., 2017, 12, 3128-3134.

64 L. Ni, G. Zhao, G. Yang, G. Niu, M. Chen and G. Diao, Dual core-shell-structured S@ C@ MnO2 nanocomposite for highly stable lithium-sulfur batteries, ACS Appl. Mater. Interfaces, 2017, 9, 34793-34803.

65 M. Yan, Y. Zhang, Y. Li, Y. Huo, Y. Yu, C. Wang, J. Jin, L. Chen, T. Hasan, B. Wang and B.-L. Su, Manganese dioxide nanosheet functionalized sulfur@PEDOT coreshell nanospheres for advanced lithium-sulfur batteries, J. Mater. Chem. A, 2016, 4, 9403-9412.

$66 \mathrm{~J} . \mathrm{Wu}, \mathrm{Q}$. Ma, C. Lian, Y. Yuan and D. Long, Promoting polythionate intermediates formation by oxygen-deficient manganese oxide hollow nanospheres for high performance lithium-sulfur batteries, Chem. Eng. J., 2019, 370, 556-564.

67 S. Evers, T. Yim and L. F. Nazar, Understanding the nature of absorption/adsorption in nanoporous polysulfide sorbents for the Li-S battery, J. Phys. Chem. C, 2012, 116, 19653-19658.

68 C. Yuan, S. Zhu, H. Cao, L. Hou and J. Lin, Hierarchical sulfur-impregnated hydrogenated $\mathrm{TiO} 2$ mesoporous spheres comprising anatase nanosheets with highly exposed (001) facets for advanced Li-S batteries, Nanotechnology, 2015, 27, 045403.

69 Z. Wei Seh, W. Li, J. J. Cha, G. Zheng, Y. Yang, M. T. McDowell, P.-C. Hsu and Y. Cui, Sulphur-TiO2 yolk-shell nanoarchitecture with internal void space for long-cycle lithium-sulphur batteries, Nat. Commun., 2013, 4, 1331.

70 E. H. M. Salhabi, J. Zhao, J. Wang, M. Yang, B. Wang and D. Wang, Hollow Multi-Shelled Structural TiO2- x with Multiple Spatial Confinement for Long-Life Lithium-Sulfur Batteries, Angew. Chem., Int. Ed., 2019, 131, 9176-9180.

71 J. Ni, L. Jin, M. Xue, J. Zheng, J. P. Zheng and C. Zhang, $\mathrm{TiO}_{2}$ microboxes as effective polysufide reservoirs for lithium sulfur batteries, Electrochim. Acta, 2019, 296, 39-48.

72 X. Gao, G. Li, Y. Xu, Z. Hong, C. Liang and Z. Lin, $\mathrm{TiO}_{2}$ Microboxes with Controlled Internal Porosity for HighPerformance Lithium Storage, Angew. Chem., Int. Ed., 2015, 54, 14331-14335.

73 W. Yang, L. Zhang, Y. Hu, Y. Zhong, H. B. Wu and X. W. Lou, Microwave-Assisted Synthesis of Porous Ag2S-Ag 
Hybrid Nanotubes with High Visible-Light Photocatalytic Activity, Angew. Chem., Int. Ed., 2012, 51, 11501-11504.

74 X. Tao, J. Wang, Z. Ying, Q. Cai, G. Zheng, Y. Gan, H. Huang, Y. Xia, C. Liang, W. Zhang and Y. Cui, Strong Sulfur Binding with Conducting Magnéli-Phase $\mathrm{TinO}_{2 n-1}$ Nanomaterials for Improving Lithium-Sulfur Batteries, Nano Lett., 2014, 14, 5288-5294.

75 Q. Pang, D. Kundu, M. Cuisinier and L. F. Nazar, Surfaceenhanced redox chemistry of polysulphides on a metallic and polar host for lithium-sulphur batteries, Nat. Commun., 2014, 5, 4759.

76 J. Wang, J. Wan, N. Yang, Q. Li and D. Wang, Hollow multishell structures exercise temporal-spatial ordering and dynamic smart behaviour, Nat. Rev. Chem., 2020, 4, 159-168.

77 J. Wang, H. Tang, H. Wang, R. Yu and D. Wang, Multishelled hollow micro-/nanostructures: promising platforms for lithium-ion batteries, Mater. Chem. Front., 2017, 1, 414-430.

78 D.-S. Bin, Z.-X. Chi, Y. Li, K. Zhang, X. Yang, Y.-G. Sun, J.-Y. Piao, A.-M. Cao and L.-J. Wan, Controlling the Compositional Chemistry in Single Nanoparticles for Functional Hollow Carbon Nanospheres, J. Am. Chem. Soc., 2017, 139, 13492-13498.

79 Z. Li, J. Zhang, B. Guan, D. Wang, L.-M. Liu and X. W. D. Lou, A sulfur host based on titanium monoxide@ carbon hollow spheres for advanced lithium-sulfur batteries, Nat. Commun., 2016, 7, 1-11.

80 Z. Li, B. Y. Guan, J. Zhang and X. W. D. Lou, A compact nanoconfined sulfur cathode for high-performance lithiumsulfur batteries, Joule, 2017, 1, 576-587.

81 X. Wu, Y. Du, P. Wang, L. Fan, J. Cheng, M. Wang, Y. Qiu, B. Guan, H. Wu and N. Zhang, Kinetics enhancement of lithium-sulfur batteries by interlinked hollow $\mathrm{MoO}_{2}$ sphere/ nitrogen-doped graphene composite, J. Mater. Chem. A, 2017, 5, 25187-25192.

82 W. Qi, W. Jiang, F. Xu, J. Jia, C. Yang and B. Cao, Improving confinement and redox kinetics of polysufides through hollow NC@ $\mathrm{CeO}_{2}$ nanospheres for high-performance lithium-sulfur batteries, Chem. Eng. J., 2020, 382, 122852.

83 L. Fan, H. Wu, X. Wu, M. Wang, J. Cheng, N. Zhang, Y. Feng and K. Sun, Fe-MOF derived jujube pit like $\mathrm{Fe}_{3} \mathrm{O}_{4} /$ C composite as sulfur host for lithium-sulfur battery, Electrochim. Acta, 2019, 295, 444-451.

84 M. Zhu, S. Li, J. Liu and B. Li, Promoting polysulfide conversion by $\mathrm{V}_{2} \mathrm{O}_{3}$ hollow sphere for enhanced lithiumsulfur battery, Appl. Surf. Sci., 2019, 473, 1002-1008.

85 B. Cao, D. Li, B. Hou, Y. Mo, L. Yin and Y. Chen, Synthesis of double-shell SnO2@ C hollow nanospheres as sulfur/ sulfide cages for lithium-sulfur batteries, ACS Appl. Mater. Interfaces, 2016, 8, 27795-27802.

86 J. Wang, W. Wang, Y. Zhang, Z. Bakenov, Y. Zhao and $\mathrm{X}$. Wang, Synthesis of highly defective hollow doubleshelled Co3O4- x microspheres as sulfur host for highperformance lithium-sulfur batteries, Mater. Lett., 2019, 255, 126581.
87 L. Hu, C. Dai, H. Liu, Y. Li, B. Shen, Y. Chen, S. J. Bao and M. Xu, Double-Shelled NiO-NiCo2O4 Heterostructure@ Carbon Hollow Nanocages as an Efficient Sulfur Host for Advanced Lithium-Sulfur Batteries, Adv. Energy Mater., 2018, 8, 1800709.

88 W. Wang, Y. Zhao, Y. Zhang, J. Wang, G. Cui, M. Li, Z. Bakenov and X. Wang, Defect-Rich Multishelled Fe-Doped Co3O4 Hollow Microspheres with Multiple Spatial Confinements to Facilitate Catalytic Conversion of Polysulfides for High-Performance Li-S Batteries, ACS Appl. Mater. Interfaces, 2020, 12, 12763-12773.

89 J.-X. Lin, Y.-X. Mo, P.-F. Zhang, Y.-Y. Li, Y.-J. Wu, S.-J. Zhang, Z.-G. Gao, J.-D. Chen, W.-F. Ren, J.-T. Li, Y. Zhou, L. Huang and S.-G. Sun, Ultrahigh sulfur content up to $93 \mathrm{wt} \%$ encapsulated in multilayer nanoshell of $\mathrm{V} / \mathrm{V}_{2} \mathrm{O}_{5}$ composite to suppress shuttle effect of lithium-sulfur battery with high-performance, Mater. Today Energy, 2019, 13, 267-276.

90 X. Liu, J. Q. Huang, Q. Zhang and L. Mai, Nanostructured metal oxides and sulfides for lithium-sulfur batteries, $A d v$. Mater., 2017, 29, 1601759.

91 J. S. Jirkovsky, A. Björling and E. Ahlberg, Reduction of oxygen on dispersed nanocrystalline CoS2, J. Phys. Chem. C, 2012, 116, 24436-24444.

92 M. S. Faber, R. Dziedzic, M. A. Lukowski, N. S. Kaiser, Q. Ding and S. Jin, High-performance electrocatalysis using metallic cobalt pyrite $\left(\mathrm{CoS}_{2}\right)$ micro-and nanostructures, J. Am. Chem. Soc., 2014, 136, 10053-10061.

93 Z. Yuan, H.-J. Peng, T.-Z. Hou, J.-Q. Huang, C.-M. Chen, D.-W. Wang, X.-B. Cheng, F. Wei and Q. Zhang, Powering Lithium-Sulfur Battery Performance by Propelling Polysulfide Redox at Sulfiphilic Hosts, Nano Lett., 2016, 16, 519-527.

94 S. D. Seo, D. Park, S. Park and D. W. Kim, Brain-Coral-Like Mesoporous Hollow CoS2@ N-Doped Graphitic Carbon Nanoshells as Efficient Sulfur Reservoirs for LithiumSulfur Batteries, Adv. Funct. Mater., 2019, 29, 1903712.

95 R. Bouchard, P. Russo and A. Wold, Preparation and electrical properties of some thiospinels, Inorg. Chem., 1965, 4, 685-688.

96 Z.-F. Huang, J. Song, K. Li, M. Tahir, Y.-T. Wang, L. Pan, L. Wang, X. Zhang and J.-J. Zou, Hollow Cobalt-Based Bimetallic Sulfide Polyhedra for Efficient All-pH-Value Electrochemical and Photocatalytic Hydrogen Evolution, J. Am. Chem. Soc., 2016, 138, 1359-1365.

$97 \mathrm{H}$. Xu and A. Manthiram, Hollow cobalt sulfide polyhedraenabled long-life, high areal-capacity lithium-sulfur batteries, Nano Energy, 2017, 33, 124-129.

98 J. Pu, Z. Shen, J. Zheng, W. Wu, C. Zhu, Q. Zhou, H. Zhang and F. Pan, Multifunctional Co3S4@sulfur nanotubes for enhanced lithium-sulfur battery performance, Nano Energy, 2017, 37, 7-14.

99 H. Behret, H. Binder and G. Sandstede, Electrocatalytic oxygen reduction with thiospinels and other sulphides of transition metals, Electrochim. Acta, 1975, 20, 111-117.

100 T. Chen, Z. Zhang, B. Cheng, R. Chen, Y. Hu, L. Ma, G. Zhu, J. Liu and Z. Jin, Self-Templated Formation of Interlaced Carbon Nanotubes Threaded Hollow $\mathrm{Co}_{3} \mathrm{~S}_{4}$ Nanoboxes for 
High-Rate and Heat-Resistant Lithium-Sulfur Batteries, J. Am. Chem. Soc., 2017, 139, 12710-12715.

101 H. Zhang, M. Zou, W. Zhao, Y. Wang, Y. Chen, Y. Wu, L. Dai and A. Cao, Highly Dispersed Catalytic Co3S4 among a Hierarchical Carbon Nanostructure for HighRate and Long-Life Lithium-Sulfur Batteries, ACS Nano, 2019, 13, 3982-3991.

102 N. Kumar, N. Raman and A. Sundaresan, Synthesis and properties of cobalt sulfide phases: CoS2 and Co9S8, Z. anorg. allg. Chem., 2014, 640, 1069-1074.

103 Q. Pang, D. Kundu and L. F. Nazar, A graphene-like metallic cathode host for long-life and high-loading lithium-sulfur batteries, Mater. Horiz., 2016, 3, 130-136.

104 X. Tao, J. Wang, C. Liu, H. Wang, H. Yao, G. Zheng, Z. W. Seh, Q. Cai, W. Li and G. Zhou, Balancing surface adsorption and diffusion of lithium-polysulfides on nonconductive oxides for lithium-sulfur battery design, Nat. Commun., 2016, 7, 11203.

105 C. Dai, J. M. Lim, M. Wang, L. Hu, Y. Chen, Z. Chen, H. Chen, S. J. Bao, B. Shen and Y. Li, Honeycomb-Like Spherical Cathode Host Constructed from Hollow Metallic and Polar Co9S8 Tubules for Advanced Lithium-Sulfur Batteries, Adv. Funct. Mater., 2018, 28, 1704443.

106 T. Chen, L. Ma, B. Cheng, R. Chen, Y. Hu, G. Zhu, Y. Wang, J. Liang, Z. Tie and J. Liu, Metallic and polar Co9S8 inlaid carbon hollow nanopolyhedra as efficient polysulfide mediator for lithium-ulfur batteries, Nano Energy, 2017, 38, 239-248.

107 Z. Li, Z. Xiao, P. Li, X. Meng and R. Wang, Enhanced Chemisorption and Catalytic Effects toward Polysulfides by Modulating Hollow Nanoarchitectures for Long-Life Lithium-Sulfur Batteries, Small, 2020, 16, 1906114.

108 C. Ye, L. Zhang, C. Guo, D. Li, A. Vasileff, H. Wang and S. Z. Qiao, A 3D hybrid of chemically coupled nickel sulfide and hollow carbon spheres for high performance lithiumsulfur batteries, Adv. Funct. Mater., 2017, 27, 1702524.

109 H.-E. Wang, X. Li, N. Qin, X. Zhao, H. Cheng, G. Cao and W. Zhang, Sulfur-deficient MoS 2 grown inside hollow mesoporous carbon as a functional polysulfide mediator, J. Mater. Chem. A, 2019, 7, 12068-12074.

110 B. Yu, Y. Chen, Z. Wang, D. Chen, X. Wang, W. Zhang, J. He and W. He, 1T-MoS2 nanotubes wrapped with $\mathrm{N}$-doped graphene as highly-efficient absorbent and electrocatalyst for Li-S batteries, J. Power Sources, 2020, 447, 227364.

111 Q. Liu, J. Jin and J. Zhang, NiCo2S4@ graphene as a bifunctional electrocatalyst for oxygen reduction and evolution reactions, ACS Appl. Mater. Interfaces, 2013, 5, 5002-5008.

112 A. Sivanantham, P. Ganesan and S. Shanmugam, Hierarchical NiCo2S4 nanowire arrays supported on Ni foam: an efficient and durable bifunctional electrocatalyst for oxygen and hydrogen evolution reactions, Adv. Funct. Mater., 2016, 26, 4661-4672.

113 L. Shen, J. Wang, G. Xu, H. Li, H. Dou and X. Zhang, $\mathrm{NiCo}_{2} \mathrm{~S}_{4}$ nanosheets grown on nitrogen-doped carbon foams as an advanced electrode for supercapacitors, $A d v$. Energy Mater., 2015, 5, 1400977.
114 J. Xiao, L. Wan, S. Yang, F. Xiao and S. Wang, Design hierarchical electrodes with highly conductive NiCo2S4 nanotube arrays grown on carbon fiber paper for highperformance pseudocapacitors, Nano Lett., 2014, 14, 831-838.

115 X. Tan, X. Wang, X. Wang, Y. Wang, C. Li and D. Xia, $\mathrm{NiCo}_{2} \mathrm{~S}_{4}$ yolk-shell hollow spheres with physical and chemical interaction toward polysulfides for advanced lithium-sulfur batteries, Ionics, 2019, 25, 4047-4056.

116 X. Y. Yu, L. Yu and X. W. Lou, Metal sulfide hollow nanostructures for electrochemical energy storage, Adv. Energy Mater., 2016, 6, 1501333.

117 L. Zhou, Z. Zhuang, H. Zhao, M. Lin, D. Zhao and L. Mai, Intricate hollow structures: controlled synthesis and applications in energy storage and conversion, Adv. Mater., 2017, 29, 1602914.

118 N. Mosavati, S. O. Salley and K. S. Ng, Characterization and electrochemical activities of nanostructured transition metal nitrides as cathode materials for lithium sulfur batteries, J. Power Sources, 2017, 340, 210-216.

119 X. Lu, G. Wang, T. Zhai, M. Yu, S. Xie, Y. Ling, C. Liang, Y. Tong and Y. Li, Stabilized TiN nanowire arrays for highperformance and flexible supercapacitors, Nano Lett., 2012, 12, 5376-5381.

120 B. Avasarala and P. Haldar, Electrochemical oxidation behavior of titanium nitride based electrocatalysts under PEM fuel cell conditions, Electrochim. Acta, 2010, 55, 9024-9034.

121 Z. Cui, C. Zu, W. Zhou, A. Manthiram and J. B. Goodenough, Mesoporous Titanium Nitride-Enabled Highly Stable LithiumSulfur Batteries, Adv. Mater., 2016, 28, 6926-6931.

122 T.-G. Jeong, D. S. Choi, H. Song, J. Choi, S.-A. Park, S. H. Oh, H. Kim, Y. Jung and Y.-T. Kim, Heterogeneous catalysis for lithium-sulfur batteries: enhanced rate performance by promoting polysulfide fragmentations, ACS Energy Lett., 2017, 2, 327-333.

123 X. Xiao, H. Wang, W. Bao, P. Urbankowski, L. Yang, Y. Yang, K. Maleski, L. Cui, S. J. Billinge and G. Wang, Two-Dimensional Arrays of Transition Metal Nitride Nanocrystals, Adv. Mater., 2019, 31, 1902393.

124 W. G. Lim, C. Jo, A. Cho, J. Hwang, S. Kim, J. W. Han and J. Lee, Approaching ultrastable high-rate Li-S batteries through hierarchically porous titanium nitride synthesized by multiscale phase separation, Adv. Mater., 2019, 31, 1806547.

125 X. Liu, Y. Zhang, T. Wu and J. Huang, Hierarchical nanotubular titanium nitride derived from natural cellulose substance and its electrochemical properties, Chem. Commun., 2012, 48, 9992-9994.

126 C. Li, J. Shi, L. Zhu, Y. Zhao, J. Lu and L. Xu, Titanium nitride hollow nanospheres with strong lithium polysulfide chemisorption as sulfur hosts for advanced lithiumsulfur batteries, Nano Res., 2018, 11, 4302-4312.

127 J. Luo, J. Zheng and B. Dang, Hollow TiN Nanospheres as Advanced Host Materials for High Performance LithiumSulfur Batteries, ChemistrySelect, 2019, 4, 14027-14030.

128 L. Chen, W. Yang, H. Zhang, J. Liu and Y. Zhou, Self-templated preparation of hollow mesoporous TiN microspheres as sulfur 
host materials for advanced lithium-sulfur batteries, J. Mater. Sci., 2018, 53, 10363-10371.

129 D.-R. Deng, T.-H. An, Y.-J. Li, Q.-H. Wu, M.-S. Zheng and Q.-F. Dong, Hollow porous titanium nitride tubes as a cathode electrode for extremely stable $\mathrm{Li}-\mathrm{S}$ batteries, J. Mater. Chem. A, 2016, 4, 16184-16190.

130 Z. Sun, J. Zhang, L. Yin, G. Hu, R. Fang, H.-M. Cheng and F. Li, Conductive porous vanadium nitride/graphene composite as chemical anchor of polysulfides for lithium-sulfur batteries, Nat. Commun., 2017, 8, 1-8.

131 L. Ma, H. Yuan, W. Zhang, G. Zhu, Y. Wang, Y. Hu, P. Zhao, R. Chen, T. Chen and J. Liu, Porous-shell vanadium nitride nanobubbles with ultrahigh areal sulfur loading for highcapacity and long-life lithium-sulfur batteries, Nano Lett., 2017, 17, 7839-7846.

132 W. Ren, L. Xu, L. Zhu, X. Wang, X. Ma and D. Wang, Cobalt-doped vanadium nitride yolk-shell nanospheres@ carbon with physical and chemical synergistic effects for advanced Li-S batteries, ACS Appl. Mater. Interfaces, 2018, 10, 11642-11651.

133 X. Liang, A. Garsuch and L. F. Nazar, Sulfur Cathodes Based on Conductive MXene Nanosheets for High-Performance Lithium-Sulfur Batteries, Angew. Chem., Int. Ed., 2015, 54, 3907-3911.

134 X. Liang, Y. Rangom, C. Y. Kwok, Q. Pang and L. F. Nazar, Interwoven MXene Nanosheet/Carbon-Nanotube Composites as Li-S Cathode Hosts, Adv. Mater., 2017, 29, 1603040.

135 Z. Wang, X. Xu, Z. Liu, S. Ji, S. O. A. Idris and J. Liu, Hollow spheres of Mo2C@ C as synergistically confining sulfur host for superior Li-S battery cathode, Electrochim. Acta, 2020, 332, 135482.

136 Y. Xiao, Y. Liu, G. Qin, P. Han, X. Guo, S. Cao and F. Liu, Building MoSe2-Mo2C incorporated hollow fluorinated carbon fibers for Li-S batteries, Composites, Part B, 2020, 108004.

137 H. Zhang, H. Cui, J. Li, Y. Liu, Y. Yang and M. Wang, Frogspawn inspired hollow $\mathrm{Fe}_{3} \mathrm{C} @ \mathrm{~N}-\mathrm{C}$ as an efficient sulfur host for high-rate lithium-sulfur batteries, Nanoscale, 2019, 11, 21532-21541.

138 Y. Mi, W. Liu, X. Li, J. Zhuang, H. Zhou and H. Wang, High-performance Li-S battery cathode with catalyst-like carbon nanotube-MoP promoting polysulfide redox, Nano Res., 2017, 10, 3698-3705.

139 Y. Zhong, L. Yin, P. He, W. Liu, Z. Wu and H. Wang, Surface Chemistry in Cobalt Phosphide-Stabilized Lithium-Sulfur Batteries, J. Am. Chem. Soc., 2018, 140, 1455-1459.

140 Y. Yang, Y. Zhong, Q. Shi, Z. Wang, K. Sun and H. Wang, Electrocatalysis in lithium sulfur batteries under lean electrolyte conditions, Angew. Chem., Int. Ed., 2018, 130, 15775-15778.

141 J. Cheng, D. Zhao, L. Fan, X. Wu, M. Wang, N. Zhang and K. Sun, Ultra-high rate Li-S batteries based on a novel conductive Ni2P yolk-shell material as the host for the $\mathrm{S}$ cathode, J. Mater. Chem. A, 2017, 5, 14519-14524.

142 Z. Ye, Y. Jiang, J. Qian, W. Li, T. Feng, L. Li, F. Wu and R. Chen, Exceptional adsorption and catalysis effects of hollow polyhedra/carbon nanotube confined CoP nanoparticles superstructures for enhanced lithium-sulfur batteries, Nano Energy, 2019, 64, 103965.

143 F. Ma, X. Wang, J. Wang, Y. Tian, J. Liang, Y. Fan, L. Wang, T. Wang, R. Cao and S. Jiao, Phase-transformed Mo4P3 nanoparticles as efficient catalysts towards lithium polysulfide conversion for lithium-sulfur battery, Electrochim. Acta, 2020, 330, 135310.

144 M. Sharon and G. Tamizhmani, Transition metal phosphide semiconductors for their possible use in photoelectrochemical cells and solar chargeable battery (Saur Viddyut Kosh V), J. Mater. Sci., 1986, 21, 2193-2201.

145 S. T. Oyama, Novel catalysts for advanced hydroprocessing: transition metal phosphides, J. Catal., 2003, 216, 343-352.

146 X.-Q. Niu, X.-L. Wang, D.-H. Wang, Y. Li, Y.-J. Zhang, T. Yang, T. Yu and J.-P. Tu, Metal hydroxide-a new stabilizer for the construction of sulfur/carbon composites as high-performance cathode materials for lithium-sulfur batteries, J. Mater. Chem. A, 2015, 3, 17106-17112.

147 J. Jiang, J. Zhu, W. Ai, X. Wang, Y. Wang, C. Zou, W. Huang and T. Yu, Encapsulation of sulfur with thin-layered nickelbased hydroxides for long-cyclic lithium-sulfur cells, Nat. Commun., 2015, 6, 8622.

148 F. Song and X. Hu, Exfoliation of layered double hydroxides for enhanced oxygen evolution catalysis, Nat. Commun., 2014, 5, 1-9.

149 G. Fan, F. Li, D. G. Evans and X. Duan, Catalytic applications of layered double hydroxides: recent advances and perspectives, Chem. Soc. Rev., 2014, 43, 7040-7066.

150 K.-H. Goh, T.-T. Lim and Z. Dong, Application of layered double hydroxides for removal of oxyanions: a review, Water Res., 2008, 42, 1343-1368.

151 J. Zhang, H. Hu, Z. Li and X. W. Lou, Double-shelled nanocages with cobalt hydroxide inner shell and layered double hydroxides outer shell as high-efficiency polysulfide mediator for lithium-sulfur batteries, Angew. Chem., Int. $E d .$, 2016, 55, 3982-3986.

152 J. Zhang, Z. Li, Y. Chen, S. Gao and X. W. Lou, Nickel-iron layered double hydroxide hollow polyhedrons as a superior sulfur host for lithium-sulfur batteries, Angew. Chem., Int. Ed., 2018, 57, 10944-10948.

153 C. Dai, L. Hu, M.-Q. Wang, Y. Chen, J. Han, J. Jiang, Y. Zhang, B. Shen, Y. Niu and S.-J. Bao, Uniform $\alpha$-Ni $(\mathrm{OH})$ 2 hollow spheres constructed from ultrathin nanosheets as efficient polysulfide mediator for long-term lithium-sulfur batteries, Energy Storage Mater., 2017, 8, 202-208.

154 Y.-J. Li, J.-M. Fan, M.-S. Zheng and Q.-F. Dong, A novel synergistic composite with multi-functional effects for high-performance Li-S batteries, Energy Environ. Sci., 2016, 9, 1998-2004.

155 E.-i. Negishi and L. Anastasia, Palladium-Catalyzed Alkynylation, Chem. Rev., 2003, 103, 1979-2018.

156 A. F. Littke and G. C. Fu, Palladium-Catalyzed Coupling Reactions of Aryl Chlorides, Angew. Chem., Int. Ed., 2002, 41, 4176-4211. 
157 E. Antolini, Palladium in fuel cell catalysis, Energy Environ. Sci., 2009, 2, 915-931.

158 S. Ma, L. Wang, Y. Wang, P. Zuo, M. He, H. Zhang, L. Ma, T. Wu and G. Yin, Palladium nanocrystals-imbedded mesoporous hollow carbon spheres with enhanced electrochemical kinetics for high performance lithium sulfur batteries, Carbon, 2019, 143, 878-889.

159 X.-F. Yang, A. Wang, B. Qiao, J. Li, J. Liu and T. Zhang, Single-atom catalysts: a new frontier in heterogeneous catalysis, Acc. Chem. Res., 2013, 46, 1740-1748.

160 C. Wang, H. Song, C. Yu, Z. Ullah, Z. Guan, R. Chu, Y. Zhang, L. Zhao, Q. Li and L. Liu, Iron single-atom catalyst anchored on nitrogen-rich MOF-derived carbon nanocage to accelerate polysulfide redox conversion for lithium sulfur batteries, J. Mater. Chem. A, 2020, 8, 3421-3430.

161 B. Wang, F. Jin, Y. Xie, H. Luo, F. Wang, T. Ruan, D. Wang, Y. Zhou and S. Dou, Holey graphene modified LiFePO4 hollow microsphere as an efficient binary sulfur host for high-performance lithium-sulfur batteries, Energy Storage Mater., 2020, 26, 433-442.

162 D. Su, M. Cortie, H. Fan and G. Wang, Prussian Blue Nanocubes with an Open Framework Structure Coated with PEDOT as High-Capacity Cathodes for Lithium-Sulfur Batteries, Adv. Mater., 2017, 29, 1700587.

163 M. Ashuri, H. Dunya, Z. Yue, D. Alramahi, X. Mei, K. Kucuk, S. Aryal, C. U. Segre and B. K. Mandal, Enhancement in Electrochemical Performance of Lithium-Sulfur Cells through Sulfur Encapsulation in Hollow Carbon Nanospheres Coated with Ultra-Thin Aluminum Fluoride Layer, ChemistrySelect, 2019, 4, 12622-12629.

164 Y. Fu and A. Manthiram, Core-shell structured sulfurpolypyrrole composite cathodes for lithium-sulfur batteries, RSC Adv., 2012, 2, 5927-5929.

165 Y. Xie, H. Zhao, H. Cheng, C. Hu, W. Fang, J. Fang, J. Xu and Z. Chen, Facile large-scale synthesis of core-shell structured sulfur@ polypyrrole composite and its application in lithium-sulfur batteries with high energy density, Appl. Energy, 2016, 175, 522-528.

166 Y. Liu, W. Yan, X. An, X. Du, Z. Wang, H. Fan, S. Liu, X. Hao and G. Guan, A polypyrrole hollow nanosphere with ultra-thin wrinkled shell: Synergistic trapping of sulfur in Lithium-Sulfur batteries with excellent elasticity and buffer capability, Electrochim. Acta, 2018, 271, 67-76.

167 T. Ben, C. Pei, D. Zhang, J. Xu, F. Deng, X. Jing and S. Qiu, Gas storage in porous aromatic frameworks (PAFs), Energy Environ. Sci., 2011, 4, 3991-3999.

168 L. J. Murray, M. Dincă and J. R. Long, Hydrogen storage in metal-organic frameworks, Chem. Soc. Rev., 2009, 38, 1294-1314.

169 B. Guo, T. Ben, Z. Bi, G. M. Veith, X.-G. Sun, S. Qiu and S. Dai, Highly dispersed sulfur in a porous aromatic framework as a cathode for lithium-sulfur batteries, Chem. Commun., 2013, 49, 4905-4907.

170 J. Zheng, J. Tian, D. Wu, M. Gu, W. Xu, C. Wang, F. Gao, M. H. Engelhard, J.-G. Zhang, J. Liu and J. Xiao, Lewis
Acid-Base Interactions between Polysulfides and Metal Organic Framework in Lithium Sulfur Batteries, Nano Lett., 2014, 14, 2345-2352.

171 M. Du, Q. Li, Y. Zhao, C.-S. Liu and H. Pang, A review of electrochemical energy storage behaviors based on pristine metal-organic frameworks and their composites, Coord. Chem. Rev., 2020, 416, 213341.

172 P. Geng, S. Cao, X. Guo, J. Ding, S. Zhang, M. Zheng and H. Pang, Polypyrrole coated hollow metal-organic framework composites for lithium-sulfur batteries, J. Mater. Chem. A, 2019, 7, 19465-19470.

173 B. Q. Li, S. Y. Zhang, L. Kong, H. J. Peng and Q. Zhang, Porphyrin organic framework hollow spheres and their applications in lithium-sulfur batteries, Adv. Mater., 2018, 30, 1707483.

174 B. Zhang, X. Qin, G. Li and X. Gao, Enhancement of long stability of sulfur cathode by encapsulating sulfur into micropores of carbon spheres, Energy Environ. Sci., 2010, 3, 1531-1537.

175 Z. Li, L. Yuan, Z. Yi, Y. Sun, Y. Liu, Y. Jiang, Y. Shen, Y. Xin, Z. Zhang and Y. Huang, Insight into the electrode mechanism in lithium-sulfur batteries with ordered microporous carbon confined sulfur as the cathode, Adv. Energy Mater., 2014, 4, 1301473.

176 Y. Dong and T. Ben, Impregnated Sulfur in Carbonized Nitrogen-containing Porous Organic Frameworks as Cathode with High Rate Performance and Long Cycle Life for Lithium-sulfur Batteries, Chem. Res. Chin. Univ., 2019, 35, 654-661.

177 G. He, S. Evers, X. Liang, M. Cuisinier, A. Garsuch and L. F. Nazar, Tailoring Porosity in Carbon Nanospheres for Lithium-Sulfur Battery Cathodes, ACS Nano, 2013, 7, 10920-10930.

178 T. Chen, L. Ma, B. Cheng, R. Chen, Y. Hu, G. Zhu, Y. Wang, J. Liang, Z. Tie, J. Liu and Z. Jin, Metallic and polar Co9S8 inlaid carbon hollow nanopolyhedra as efficient polysulfide mediator for lithium-sulfur batteries, Nano Energy, 2017, 38, 239-248.

179 Y. Ye, F. Wu, S. Xu, W. Qu, L. Li and R. Chen, Designing realizable and scalable techniques for practical lithium sulfur batteries: a perspective, J. Phys. Chem. Lett., 2018, 9, 1398-1414.

180 A. Eftekhari and D.-W. Kim, Cathode materials for lithium-sulfur batteries: a practical perspective, J. Mater. Chem. A, 2017, 5, 17734-17776.

181 J. Lochala, D. Liu, B. Wu, C. Robinson and J. Xiao, Research progress toward the practical applications of lithium-sulfur batteries, ACS Appl. Mater. Interfaces, 2017, 9, 24407-24421.

182 A. Bhargav, J. He, A. Gupta and A. Manthiram, Lithiumsulfur batteries: attaining the critical metrics, Joule, 2020, 4, 285-291.

183 H. Yuan, J. Liu, Y. Lu, C. Zhao, X. Cheng, X. Nan, Q. Liu, J. Huang and Q. Zhang, Toward Practical All-solid-state Batteries with Sulfide Electrolyte: A Review, Chem. Res. Chin. Univ., 2020, 36, 377-385. 
184 M. Rana, B. Luo, M. Kaiser, I. Gentle and R. Knibbe, The role of functional materials to produce high areal capacity lithium sulfur battery, J. Energy Chem., 2020, 46, 195-209.

185 M. Rana, S. Ahad, M. Li, B. Luo, L. Wang, I. Gentle and R. Knibbe, Review on areal capacities and long-term cycling performances of lithium sulfur battery at high sulfur loading, Energy Stor. Mater., 2019, 18, 289-310.

186 H. Wang and Y. Tang, Artificial Solid Electrolyte Interphase Acting as "Armor" to Protect the Anode Materials for High-performance Lithium-ion Battery, Chem. Res. Chin. Univ., 2020, 36, 402-409. 